Cómo citar este artículo / How to cite this article: Almagro-Gorbea, M., Lorrio Alvarado, A. J. y Torres Ortiz, M. (2021). Los focenses y la crisis de c. 500 A. C. en el Sureste: de La Fonteta y Peña Negra a La Alcudia de Elche. Lucentum, XL, 63-110. https://doi.org/10.14198/LVCENTVM.18058

\title{
LOS FOCENSES Y LA CRISIS DE C. 500 A. C. EN EL SURESTE: DE LA FONTETA Y PEÑA NEGRA A LA ALCUDIA DE ELCHE
}

\author{
PHOCAEANS AND THE C. 500 BC CRISIS IN SOUTHEASTERN IBERIA: FROM LA FONTETA AND \\ PEÑA NEGRA TO LA ALCUDIA DE ELCHE
}

Recepción: 23/10/2020

Aceptación: 04/02/2021
MARTÍN ALMAGRO-GORBEA

Real Academia de la Historia, Madrid, España

anticuario@rah.es

https://orcid.org/0000-0003-0065-5878

ALBERTO J. LORRIO ALVARADO

INAPH-Universidad de Alicante, España

alberto.1orrio@ua.es

https://orcid.org/0000-0003-1879-4681

MARIANO TORRES ORTIZ

Universidad Complutense de Madrid, España

mtorreso@ghis.ucm.es

https://orcid.org/0000-0003-2564-7794

\section{Resumen}

Las cuencas del Bajo Vinalopó y del Bajo Segura fueron una de las áreas más estratégicas de la península ibérica en la Antigüedad. Hacia el 500 a. C. este territorio sufre profundos cambios: hacia el 525 a. C. desaparecen la colonia fenicia de La Fonteta y la población orientalizante de Peña Negra, identificada con la ciudad de Herna (OM 456-460) y surge como nuevo centro territorial la ciudad ibérica de Ilici, en la actual Alcudia de Elche. Precisamente, hacia el 500 a. C. aparece un nuevo horizonte de importaciones griegas en el Sureste de Iberia asociado a un nuevo estilo jonio-ibérico en pilares-estela y esculturas y a la introducción de la escritura "greco-ibérica». Estos elementos reflejan una política expansiva focense, contemporánea a las Guerras Médicas y a los conflictos coloniales entre griegos y púnicos en el Mediterráneo Occidental. Como consecuencia, la «crisis del 500 a. C.» supuso un profundo cambio, al sustituirse la estructura territorial y urbana orientalizante, de raíces fenicias, y surgir la ciudad-estado «ibérica», más próxima al mundo helénico.

Palabras clave. La Fonteta; Peña Negra; La Alcudia; Ilici; colonización fenicia; colonización focense; cultura ibérica; enfrentamientos greco-púnicos.

\begin{abstract}
The Bajo Vinalopó and Bajo Segura basins were one of the most strategic areas of the Iberian Peninsula in Antiquity. Around $500 \mathrm{BC}$ this territory underwent profound changes. The Phoenician colony of La Fonteta and the orientalizing population of Peña Negra, identified with the city of Herna (OM 456-460), disappear c. 525 BC, and the Iberian city of Ilici (La Alcudia, Elche) emerges as a new territorial center. Precisely around $500 \mathrm{BC}$ we document in the southeastern area of Iberia a horizon of Greek imports, associated with a new Ionian-Iberian style in pillars-stelae and sculptures, as well as the introduction of the «Greek-Iberian» writing. All these elements reflect an expansive Phocaean policy, contemporary to the Greco-Persian Wars and to the colonial conflicts between Greeks and Punics in the Western Mediterranean. As a consequence, the «crisis of $500 \mathrm{BC}$ » represented a profound change, with the substitution of the orientalizing territorial and urban structure, of Phoenician origin, and the appearance of the «Iberian» city-state, closer to the Hellenic world.
\end{abstract}

Key words. La Fonteta; Peña Negra; La Alcudia; Ilici; Phoenician colonization; Phocaean colonization; Iberian culture; Greco-Punic wars.

Financiación: Este trabajo se ha realizado en el marco del proyecto del Ministerio de Ciencia, Innovación y Universidades HAR201787495-P, «Fenicios e indígenas en el Sureste de la Península Ibérica: Bronce final y Hierro Antiguo entre el Vinalopó y el Segura». 


\section{INTRODUCCIÓN}

Desde los tiempos de A. Schulten, el tema de los focenses ha sido uno de los polos de atracción en los estudios de la colonización de la península ibérica, que durante un siglo se habían centrado inicialmente en Ampurias, gracias a la información que ofrecían las fuentes escritas y las excavaciones, y después en Huelva, al descubrirse el emporion focense en Tartessos, que confirmaba las escuetas noticias de Herodoto.

A estos dos polos de atracción, se debe añadir en la actualidad la cuenca del Bajo Segura - Bajo Vinalopó, que era otra de las áreas más estratégicas de la península ibérica en la Antigüedad, ya que unía el control de las importantes vías de comunicación terrestres y marítimas, una rica tradición metalúrgica, una gran potencialidad agrícola de regadío y un clima muy favorable, por lo que era particularmente atractiva.

Hacia el 500 a. C. se advierte un profundo cambio en este territorio que refleja una política expansiva focense que coincide con los años álgidos de las Guerras Médicas y de los conflictos coloniales entre griegos y púnicos en el Mediterráneo Occidental, lo que no parece ser casual y no deja de llamar la atención. Los hallazgos y estudios realizados en estos últimos años evidencian que a partir de $c .525$ a. C. se produjo una profunda modificación en la orientación política y cultural de ese pequeño territorio, al desaparecer la colonia fenicia de La Fonteta y el asentamiento orientalizante de Peña Negra, desaparición que se asocia a una nueva estructuración de este estratégico territorio, centrado a partir de esos años en la ciudad ibérica de Ilici, en la actual Alcudia de Elche.

Este profundo cambio en el Sureste de Iberia queda documentado por un rico horizonte de importaciones griegas datadas $c .500$ a. C., a las que se debe añadir la presencia de escultores jonios que contribuyeron a crear y difundir un nuevo estilo jonio-ibérico que dio lugar a las mejores creaciones de la plástica ibérica, como la Dama de Elche o las esculturas del heroon de Porcuna. Paralela puede considerarse la introducción de una escritura «jonio-ibérica» arcaica, que arraigó en el Sureste hasta avanzado el siglo III a. C., así como la aparición de otros elementos culturales, como los signa equitum, que denotan cambios contemporáneos en la estructura política e ideológica, transformaciones que reflejan una fuerte y repentina helenización de estos territorios. Por ello, la «crisis del 500 a. C.», tuvo una profunda repercusión en estas tierras en las que supuso un profundo cambio cuyos ecos perduran hasta la expansión bárquida del siglo III a. C., pues la estructura territorial y urbana orientalizante de raíces fenicias fue sustituida por la ciudad-estado «ibérica», que surge en estas circunstancias y que ya resulta más próxima al mundo helénico en sus formas culturales y, sin duda también, en sus estructuras políticas e ideológicas.

Esta agresiva política comercial focense, probablemente dirigida desde Massalia a través de Ampurias, se centró en el Sureste por ser la zona de mayor interés estratégico en las costas mediterráneas de Iberia, pues desde ella se controlaban las vías de comunicación y los mercados de Andalucía y también era el acceso más fácil a la Celtiberia, de gran importancia para obtener mercenarios. Desde este punto de vista, este «horizonte del 500 a. C.», debe enmarcarse en los enfrentamientos producidos en el Mediterráneo al final del arcaísmo, en la generación de c.500-475 a. C., que constituye el marco histórico general para comprender el desarrollo de estos cambios constatados en el Sureste de Iberia.

\section{EL MARCO GEOGRÁFICO: EL BAJO VINA- LOPÓ Y EL BAJO SEGURA EN EL I MILENIO A. C.}

La desembocadura del río Segura en la Antigüedad era un territorio de evidente atracción para los pueblos coloniales, interesados en controlarlo dada su importancia estratégica, como evidencian los yacimientos emplazados en la zona a partir del siglo VIII a. C. (Aranegui et al., 1993; Gutiérrez Lloret et al., 1998-99: 51 s.; Rouillard et al., 2007; Uroz Rodríguez y Uroz Sáez, 2010; González Prats (Coord.), 2011; García Menárguez y Prados, 2014; 2017; Abad et al., 2017; Mas et al., 2017; Prados et al., 2018) y la elocuente referencia de Avieno en la Ora Maritima ${ }^{1}$, que los hallazgos arqueológicos permiten comprender hoy mejor, ya que el único momento en el que se puede hablar de presencia de poblaciones fenicias en este entorno se sitúa precisamente en los siglos VIII-VI a. C., lo que atestigua el uso por parte de Avieno de fuentes muy antiguas que deben fecharse en el siglo VI a. C. (cf. Antonelli, 1998).

Los límites físicos de este territorio quedan perfectamente delimitados entre la línea de costa que de noreste a suroeste se extiende desde el cabo Cervera en

\footnotetext{
1. Dehinc in huius insulae confiniis (455) immensa tergum latera diffundit palus. Theodorus illic (nec stupori sit ibi quod in feroci barbaroque sat loco cognomen huius Graeciae accipis sono) prorepit amnis. Ista Phoenices prius (460) loca incolebant. Rursus hinc se litoris fundunt harenae et litus hoc tres insulae cinxere late. Hic terminus quondam stetit Tartessiorum, hic Herna civitas fuit. Gymnetes istos gens locos insederant. (465) Sicani ad usque praefluentis alveum, nunc destitutus et diu incolis carens sibi sonorus Alebus amnis effluit (Schulten, 1955: 81) («Desde aquí, en los confines de esta isla, (455) extiende sus riberas una enorme laguna. Allí desemboca lentamente el río Teodoro [Segura] -y no te sorprenda oír en un paraje feroz y bárbaro un nombre en lengua de Grecia-. Los fenicios fueron los primeros en habitar estos lugares. (460) A partir de aquí [la desembocadura del Segura], de nuevo se extienden las arenas del litoral y tres islas ciñen la costa en toda su amplitud. Aquí estuvo en otros tiempos la frontera de los Tartesios y aquí estuvo la ciudad de Herna. El pueblo de los Gimnetes ocupó estos lugares (465) hasta el lecho del río Sicano [Júcar] que los baña. Ahora fluye y suena sólo para sí el río Alebo [Vinalopó], abandonado y despoblado desde hace tiempo»).
} 
Torrevieja hasta el cabo de Santa Pola (MTNE, hojas 892 a 894 y 913-914) y las últimas estribaciones de las Cordilleras Béticas Orientales que cierran por el norte esta cubeta natural. En efecto, la Sierra de Crevillente (835 m s.n.m.) constituye un claro límite por su parte septentrional, que prosigue al este del Vinalopó y al norte de Elche en las sierras del Tabayá (404 m s.n.m.), de la Losa (287 m s.n.m.) y de la Sierra Grossa (235 m s.n.m.), mientras que su límite oriental es la zona llana de Las Lomas, que se prolonga por el sureste hasta los domos miopliocenos de la Sierra de Santa Pola (144 m s.n.m.), situados ya junto al mar. Su límite occidental lo configuran las sierras de Callosa (561 m s.n.m.) y de Orihuela (633 m s.n.m.). El río Segura queda enmarcado al norte por estas sierras y hacia el sur por una serie de cerros y cabezos menos destacados que separan su cuenca de las zonas endorreicas de las salinas de La Mata y Torrevieja. Es una cadena de pequeñas elevaciones, continuación de las sierras prelitorales murcianas, como la Sierra de Hurchillo (271 m s.n.m.), al sur de Orihuela, el Cabezo Redondo en Benejúzar (214 m s.n.m.), el Cerro Atalaya de Rojales (127 m s.n.m.) y. ya situados junto a la costa, el Cerro del Castillo (68 m s.n.m.) y El Moncayo (104 m s.n.m.), en Guardamar del Segura. Frente a estas elevaciones, en la margen izquierda del río Segura quedaba casi aislada entre las zonas palustres y el cordón litoral la Sierra del Molar (63 m s.n.m.), formada por domos miopliocenos.

El clima es mediterráneo subdesértico/subtropical seco, dada su muy escasa pluviosidad, pues sólo alcanza $291 \mathrm{~mm}$ en Orihuela y $250 \mathrm{~mm}$ en Guardamar del Segura (AA. VV., 1976: 103). Sin embargo, lo más característico de este territorio es su estructura hidrográfica. El río Segura cruza la parte occidental del territorio de oeste a este hasta desembocar en Guardamar atravesando lo que debía ser una zona palustre, que de forma periódica sufre las grandes crecidas del río (años 1328, 1452, 1545, 1651, 1879, 1946, 1973, 1987, 2016 y 2019). Estas avenidas inundan todo el valle, pues la de 1879 llegó a alcanzar en Orihuela $2500 \mathrm{~m}^{3} / \mathrm{s}$, a pesar de que su caudal es de sólo $26 \mathrm{~m}^{3} / \mathrm{s}$. En la Antigüedad sería una extensa zona de esteros, marjales y albuferas, al sur de los cuales discurría el río Segura (Ferrer García, 2010), posiblemente navegable en determinadas zonas y momentos durante la Protohistoria, hecho de evidente interés dadas las estrechas relaciones durante el Hierro Antiguo entre los dos principales núcleos urbanos de la zona: La Fonteta y Peña Negra.

La parte oriental de este territorio lo cruza de norte a sur el río Vinalopó, que no alcanza $1 \mathrm{~m}^{3} / \mathrm{s}$, aunque con avenidas ordinarias que oscilan entre los 150 y 200 $\mathrm{m}^{3} / \mathrm{s}$, por lo que sus arrastres han contribuido a rellenar la parte oriental de esta cubeta natural, en la cual se pierden sus aguas en una amplia zona de marjales y albuferas que durante la Prehistoria y la Protohistoria estarían mucho más desarrolladas e, incluso, abiertas al mar, pues constituían la antigua Albufera de Elche (Ferrer y Blázquez, 1999), prácticamente desecada en el siglo XVIII. En consecuencia, salvo las sierras y elevaciones calizas, es una zona de áreas pantanosas, semejantes a otras similares del litoral mediterráneo, separadas del mar por el cordón de dunas litorales, que actualmente está en gran parte desecada o convertida en salinas, como las de Santa Pola, y en lagunas salobres, como la Laguna del Hondo, aunque los arrastres del Vinalopó hicieron que al menos ya desde época ibérica existiera una lengua de paso que separó la Albufera de Elche de la Laguna de El Hondo, lengua que uniría la casi insular Sierra del Molar, situada al norte de la desembocadura del Segura, con La Alcudia de Elche, permitiendo el paso de una antigua vía ibérica de la que se han conservado profundas huellas de ruedas de carro (Senent, 1930: 5; Gutiérrez Lloret et al., 1998-1999: 58; Grau y Moratalla, 2001: 174 s. y 185 s.).

La principal característica de este territorio del Sureste de la península ibérica es su importancia estratégica, pues controla rutas esenciales marítimas y terrestres de la antigua Hispania. Desde esta zona litoral se controla la llamada «ruta de las islas», atestiguada por topónimos en -oussa (García Alonso, 1996) probablemente relacionados con las navegaciones eubeas de época precolonial acaecidas en paralelo a la presencia fenicia (Antonelli, 2006: 7 s.), y que en la península ibérica quedarían demostradas por las cerámicas eubeas halladas en Huelva (González de Canales et al., 2004: 86-94, lám. 19 y 47-49), a las que según Domínguez Monedero (2013: 16) habría que añadir algunas piezas más, de La Rebanadilla (Sánchez Sánchez-Moreno et al., 2012: 75, fig. 12) y El Carambolo (Fernández Flores y Rodríguez Azogue, 2007: 204, fig. 84, lám. 9), que Domínguez Monedero (2014: 250) considera también de origen probablemente eubeo, y por la tradición que relaciona desde época geométrica griega a Briareo, un personaje con un gran peso en el imaginario euboico, con el estrecho de Gibraltar (López Pardo, 2005: 5-6; Antonelli, 2006: 9-12). Esta ruta procedía del Mediterráneo Oriental y, a través de Sicilia (Syrakoussa, Aigoussai), el norte de África (Pithekousai, cf. Boardman 2006: 195 y 197; vid. también Kourou, 2002) y Cerdeña (Ichnoussa), llegaba a las Islas Baleares (Meloussa, Kromiussa, Pytiussa, Ophioussa) y al Levante de Hispania (Onus(s)a o Oinoussa, Avieno O.M. 491; cf. Pérez Vilatela, 1994).

Esta ruta la documenta el comercio de armas e instrumentos del Bronce Final que desde la península ibérica alcanzan Cerdeña, Sicilia e Italia continental (Ruiz-Gálvez, 1986; Lo Schiavo, 1991; Fundoni y Bella, 2015). El uso de esta ruta prosigue en la colonización fenicio-púnica, pues permitía desde el Oriente del Mediterráneo enlazar con las colonias y factorías fenicias de la Costa del Sol hasta alcanzar Gadir y los mercados de Tartessos ${ }^{2}$ (Ruiz de Arbulo, 1990; Díes Cusí, 1994). Esta ruta explica la importancia de la

\footnotetext{
2. En este trabajo se utiliza el término Tartessos ya que posee un largo recorrido en la historiografía desde hace más de un siglo y es el más reconocido internacionalmente.
} 


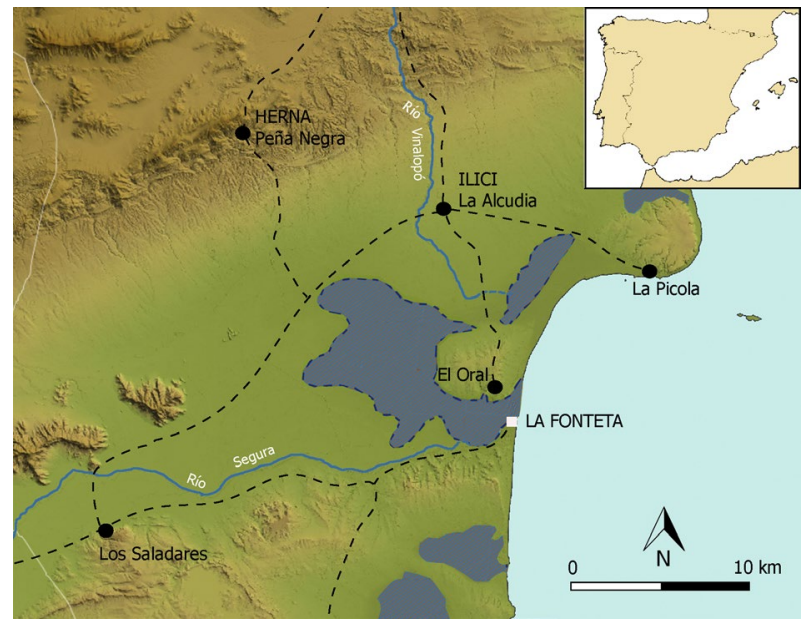

Figura 1: Ejes de comunicación del Sureste en época prerromana, con los principales yacimientos citados en el texto. (Propuesta de reconstrucción de la línea de costa a inicios de la Edad del Hierro, según C. Ferrer. Cartografía: S. Pernas)

colonia fenicia de La Fonteta, establecida en este territorio, la más septentrional de las localizadas en Hispania, situada a mitad de camino entre Baria (Villaricos) y la isla de Ebusus (Ibiza), como escala estratégica en las vías de comunicación marítimas desde y hacia la antigua Hispania en el I milenio a. C. La importancia de esta zona queda además reforzada porque de ella arrancaban tres importantes vías terrestres de comunicación hacia el interior, además de controlar la que corría paralela a la costa (Fig. 1).

Destaca, sin duda, el río Segura, cuyo tramo final posiblemente sería navegable y se podría remontar desde su desembocadura para después cruzar o rodear la Sierra de Segura, en la que nace, hasta enlazar con la Vía Heraclea entre Alcaraz y Castulo (Linares, Jaén). Otra ruta similar remontaba el Segura y el Guadalentín, con núcleos tan destacados en la zona murciana como Santa Catalina del Monte, El Castellar de Librilla y Lorca (Ros, 1986-87; 1989; López Mondejar, 2016: 135 s., fig. 4; vid. para época ibérica Ramos Martínez, 2018), hasta alcanzar las hoyas granadinas de la Penibética donde se localizan los oppida ibéricos de Tutugi (Galera), Basti (Baza), Acci (Guadix), Iliberis (Granada) e Ilurco (Pinos Puente) (Adroher et al., 2002), cuyo origen se remonta al Bronce Final, lo que evidencia la importancia de esta ruta a partir de esa fecha. Desde cualquiera de estas dos rutas terrestres se podía alcanzar Tartessos en la Andalucía Occidental y las rutas interiores de Andalucía Oriental que permitían competir con los asentamientos fenicios andaluces de la Costa del Sol.

Sin embargo, la ruta principal debió ser la «Vía Salaria Ibérica». Damos esta denominación para indicar que tuvo un papel equivalente al de la Via Salaria en la Italia central desde la Edad del Bronce, cuyo control por parte de Roma explica su predomino en el Lacio. Toda la zona del Bajo Segura y Vinalopó eran áreas pantanosas con salinas, que constituyen una de las claves del territorio, dada su alta capacidad de producción de sal, mantenida hasta la actualidad. Esta producción salina es fundamental para comprender la importancia de la vía que, en dirección norte por el valle del Vinalopó, constituye el más fácil acceso desde la costa mediterránea del Sureste a la Meseta, por lo que siempre ha sido un camino natural de penetración que prosigue hasta el valle del Tajo a la altura de Complutum (Alcalá de Henares, Madrid). Es una vía esencial de trashumancia de gran antigüedad, usada hasta fines del siglo XX, aunque su uso en el Bronce Tardío ya lo indican hallazgos como el «Tesoro de Villena» (Ruiz Gálvez, 1993; Mederos, 1999; Hernández Pérez, 2017) y el monumento de Pozo Moro a inicios de la cultura ibérica, a fines del siglo VI a. C. (Almagro-Gorbea, 1983a). Su importancia estratégica en época romana pasó a la vía de Carthago Nova a Complutum (Sillières, 1982; Fernández Montoro et al., 2011), aunque la ruta por el Vinalopó coincide con un ramal septentrional que partiría de Ilici. Esta vía ha perdurado hasta la actualidad como vía de trashumancia en la Vereda Real de Cartagena a Cuenca, que corre paralela y muy próxima al Camino Viejo de Chinchilla a Murcia, actualmente en trance de desaparecer (Morote, 1979; Sillières, 1982) sustituido en un primer momento por la carretera nacional N-301 y posteriormente por la actual autovía A-30 de Madrid a Murcia y Alicante.

La Vía Salaria Ibérica partía de la zona de marismas de las desembocaduras de los ríos Segura y Vinalopó, que estaría controlada inicialmente por el asentamiento fenicio de La Fonteta y por la población orientalizante de Herna/Peña Negra y posteriormente por la Ilici ibérica. Durante el Hierro Antiguo la principal comunicación desde la zona del Bajo Segura - Bajo Vinalopó sería a través de la Sierra de Crevillente y la ciudad de Herna/Peña Negra (Lorrio et al., 2017: 87 s.; Lorrio et al., 2020b: 532), hasta alcanzar el Medio Vinalopó y desde allí la Meseta. En época ibérica, el centro geopolítico de la comarca se trasladaría a Ilici (Domínguez Monedero, 1984: 146 s., mapa 4; Santos, 1992; Abad, 2004), desde donde la vía remontaba el valle del Vinalopó hasta llegar a Villena, aunque la dificultad que plantean las sierras prelitorales que separan la plana litorial y el valle de Monforte - Novelda ha llevado a plantear diferentes trazados (Arasa, 2009: 83), $\mathrm{y}$, desde allí, cruzaba la zona meseteña de Albacete y Cuenca de sur a norte y, tras pasar por Pozo Moro, proseguía por Saltigi (Chinchilla, Albacete) y Segobriga (Saelices, Cuenca) hasta Complutum, donde enlazaba con una gran vía transversal protohistórica que en época romana pasó a ser la vía de Caesaraugusta a Castulo y a Emerita. Confirma la importancia de esta vía el estratégico emplazamiento de Pozo Moro en un cruce con otro de los grandes ejes viarios de la Hispania prerromana, la Vía Heraclea, que de este a oeste comunicaba el valle del Guadalquivir con la costa mediterránea del Levante (Sillières, 1982; Almagro-Gorbea, 1983a: 181 s.; Blánquez, 1990a; 1990b: 51-56; Alcalá-Zamora, 2003: 228 s.), ya que, desde Pozo Moro hacia el oeste, 
por Balazote y Peñas de San Pedro (Albacete) (Lorrio et al., 2014: fig. 5:A), comunicaba fácilmente, a través del río Jardín y del Guadalmena, con la rica zona minera del alto Guadalquivir bordeando por el norte la Sierra de Alcaraz, mientras que hacia el este, por el corredor de Montesa, alcanzaba la población ibérica de Saiti (Játiva, Valencia) y la llanura litoral valenciana.

Las vías citadas, en especial la Vía Salaria Ibérica, explican la importancia estratégica de la desembocadura del río Segura en la Antigüedad, ya que esta vía de penetración era más importante en las costas mediterráneas de Iberia que la del río Palancia desde Saguntum (Valencia) o la del Ebro desde Amposta (Tarragona). En efecto, esa Vía Salaria debe de considerarse la principal vía de comercio de la sal hacia el interior de la Meseta desde la Edad del Bronce (Ruiz-Gálvez, 1989: 54 s.; 1992: 234; 1993: 49, 64; 1995: 143 s.; Hernández Pérez, 1997: 111; Delibes et al., 1991: 212; Mederos, 1999: 126 s.; Mederos y Ruiz Cabrero, 2001), cuyo control explica posiblemente el origen del oro del «Tesoro de Villena». Asociado a esta vía y posiblemente también al comercio de la sal estaría el ganado trashumante que desde los pastos de las serranías de la Meseta bajan a invernar al Sureste, para los cuales la sal era un elemento esencial, como lo sería también para curar jamones y cecinas que permitían conservar carne y constituían la principal reserva de proteína animal. El control económico y político de esta importante vía se ejercería desde el asentamiento fenicio de La Fonteta y el orientalizante de Herna/Peña Negra, pero en el paso del siglo VI al V a. C. dicho control debió de pasar, como veremos, a La Alcudia de Elche, la antigua Ilici, lo que explica el florecimiento de esta población, hecho que supuso un profundo cambio económico, político y cultural en toda la zona.

A partir del inicio de los asentamientos coloniales, quizás ya desde los primeros contactos precoloniales, el comercio de la sal y de productos ganaderos potenciaría los intercambios comerciales de las factorías coloniales de la costa con las tierras interiores de la Meseta, tanto con las áreas serranas ganaderas de la Celtiberia, las cerealistas y ganaderas de la Oretania y las mineras de Castulo, además de alcanzar las ciudades-estado tartésicas a través de las vías terrestres señaladas, por lo que la Vía Salaria Ibérica se convirtió en la principal salida de las poblaciones de la Meseta al Mediterráneo. En consecuencia, también sería utilizada por los mercenarios hispanos, especialmente celtíberos, que a partir del siglo V a. C. participaban en los conflictos del Mediterráneo Central (Graells, 2014).

\section{EL DESARROLLO CULTURAL DEL BRON- CE FINAL AL PERIODO ORIENTALIZANTE (SIGLOS IX-VI A. C.)}

A partir de un momento avanzado del Bronce Final, hacia los siglos X-IX a. C., surgen nuevos asentamientos que reflejan contactos con el Mediodía peninsular y con las poblaciones coloniales fenicias desde finales del siglo IX y a lo largo del siglo VIII a. C. y, posteriormente, con los griegos focenses desde el siglo VI a. C. Esta etapa ofrece un proceso de nuclearización poblacional cuyo máximo exponente en la región es la fundación del gran asentamiento indígena de Peña Negra (Crevillent, Alicante), una de las principales poblaciones protohistóricas del Sureste y del Levante de la península ibérica (Figs. 2 y 4). Sin antecedentes inmediatos, presenta una ocupación desde el Bronce Final Pleno (Peña Negra I), c. 925/900 a 725/700 cal BC., al Hierro Antiguo (Peña Negra II), cuyo final se sitúa hacia el 540-520 a. C. (González Prats, 1993; Lorrio et al., 2017; 2020b: 532). Asociada a Peña Negra estaba la necrópolis de Les Moreres, el más destacado cementerio de los siglos IX a VII a. C. de todo el Sureste peninsular (González Prats, 2002; Lorrio, 2017). Las más de 150 sepulturas documentadas confirman la importancia del poblado al que se vincula y permiten correlacionar la información funeraria y la del hábitat, algo excepcional en el Sureste y el Levante en esa etapa.

En el Bronce Final (PN I), Peña Negra se configura como un extenso poblado de gran dinamismo, abierto a los contactos marítimos, pero también a otros territorios peninsulares. Importaciones de diversa procedencia evidencian contactos comerciales con la Europa Atlántica y con el Mediterráneo en el marco de la denominada 'precolonización', que dan idea de la entidad de este asentamiento ya desde el siglo IX a. C. Se han identificado brazaletes de marfil, cuentas de vidrio, cerámicas a torno, cerámica con decoración de retícula bruñida, fíbulas de codo o los primeros objetos de hierro (González Prats, 1990: 90-92; 1992: 245, 253 s.; Carrasco et al., 2013: 40, fig. 3:1-2; Álvarez-Sanchís et al., 2016: 152). Un vertedero metalúrgico evidencia una producción a gran escala destinada parcialmente a la exportación. Del mismo vertedero proceden algunos fragmentos de marfil en bruto, lo que sugiere que existiría un taller de eboraria en la zona. En el mismo sector, aunque ya en la fase final de Peña Negra I, se localizaron varios telares que indican la importancia de la actividad textil en el asentamiento y que Ruiz-Gálvez (1993: 56; 2005: 263) relacionó con la introducción del telar vertical y de telas con motivos geométricos - e incluso de la púrpura-, como indican los característicos diseños geométricos de las cerámicas decoradas y la presencia de fíbulas (Cáceres, 1997).

Estos hallazgos indican la entidad del asentamiento desde su etapa inicial, lo que confirma igualmente la existencia de una extensa necrópolis de incineración en Les Moreres, cuyas dataciones radiocarbónicas más antiguas se remontan a pleno siglo $\mathrm{X}$ a. $\mathrm{C}^{3}$, que

3. Dirk Brandherm y Alberto Lorrio, «The application of scientific dating techniques to the Late Bronze Age/Early Iron Age funerary record of south-east Spain: a pilot study», British Academy/Leverhulme Trust SRG $\ 171556$. 


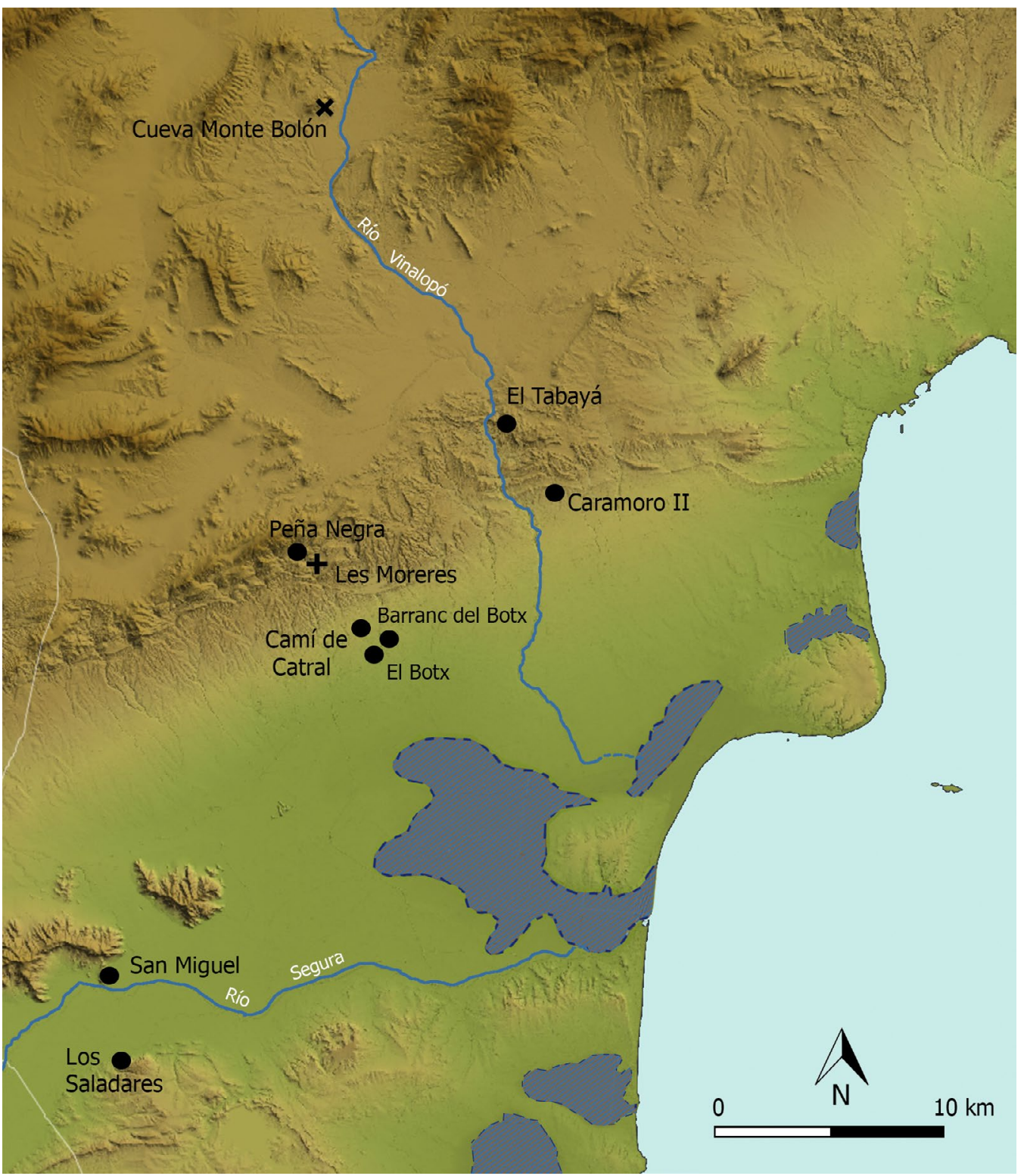

Figura 2: El poblamiento del Bajo Segura en el Bronce Final Pleno y Reciente: Poblados $(\bullet)$. Necrópolis $(+)$. Cuevas de enterramiento (X). (Cartografía: S. Pernas)

refleja el crecimiento demográfico de la comunidad de Peña Negra. Por su parte, en el hinterland crevillentino inmediato de Peña Negra se documentan pequeños asentamientos secundarios dispersos relacionados con el aprovechamiento de los suelos agrícolas, como el de Barranc del Botx (García Borja et al., 2007), aunque el hallazgo de moldes de fundición en la zona evidencia igualmente actividades metalúrgicas complejas (Trelis, 1996), lo que indica el papel jerarquizador de Peña Negra ya desde su etapa inicial.

El panorama regional (Fig. 2) evidencia igualmente la importancia del poblamiento en el entorno de la Sierra de Orihuela desde el siglo IX a. C., con la aparición de pequeños asentamientos en cerro, como Los Saladares (Arteaga y Serna, 1975; 1979-1980) o Ladera de San Miguel (Soriano, 1985: 110, fig. 2:16; Diz y Yus, 2014: 108-110), en Orihuela. A unos $2 \mathrm{~km}$ de la ciudad de
Elche se localiza Caramoro II (González Prats y Ruiz Segura, 1992; García Borja et al., 2010), un poblado fortificado, algo excepcional durante el Bronce Final regional, localizado sobre una loma amesetada sobre la margen izquierda del río Vinalopó, para el que se ha planteado una cronología de los siglos XI-IX cal BC (García Borja et al., 2010: 44 s.). Este asentamiento confirma la importancia de la ruta del Vinalopó desde estas etapas del Bronce Final (González Prats y Ruiz Segura, 1992: 25), con ejemplos como El Tabayá, en Aspe (Hernández y López, 1992).

Hacia el siglo VIII a. C., según corrobora la Ora Maritima de Avieno (vv. 451-455: ista Phoenices prius loca incolebant), se produce una novedad tan importante como la temprana presencia fenicia en el Bajo Segura, confirmada por la fundación de los asentamientos fenicios de La Fonteta y el Cabezo Pequeño del Estaño. El 
Cabezo del Estaño es un pequeño asentamiento amurallado con una superficie en torno a 1 ha, situado en La Rinconada, a escasos $2 \mathrm{~km}$ al oeste de Guardamar, en la margen derecha del río Segura, aunque originariamente se localizaría en el borde interior del antiguo estuario, posteriormente colmatado, lo que, junto a la sismicidad de la zona, debió provocar que el lugar se abandonara en favor de La Fonteta. Se ha interpretado como una posible factoría prístina según se desprende de las dataciones radiocarbónicas que remiten a principios del siglo VIII a. C. para su inicio, aunque el material recuperado resulte algo posterior, situándose su abandono hacia mediados del siglo VII a. C. (García Menárguez y Prados, 2014; 2017; Prados et al., 2018). Por su parte, La Fonteta (Fig. 3,A) puede considerarse como un núcleo de carácter urbano, con una superficie en su fase reciente de algo más de 1,5 ha, localizado en el paraje conocido como «Las Dunas de Guardamar», en la margen derecha del río Segura y próximo a su actual desembocadura, aunque en época protohistórica este emplazamiento sería un pequeño promontorio costero ubicado junto al paleocauce de la desembocadura del río Segura, con un entorno de humedales (Barrier y Montenat, 2007: 7 s.), que albergaría un importante puerto, a través del cual se canalizaría todo el comercio con las poblaciones indígenas. Efectivamente, estos asentamientos suponían el puerto de entrada y salida de productos desconocidos hasta entonces en estas tierras y de nuevas actividades artesanales: la siderurgia asociada al instrumental de hierro, la metalurgia del plomo y la plata, una variada vajilla a torno, entre la que destacan numerosas ánforas, de forma y volumen normalizados, abundantes productos de lujo, etc. (Rouillard et al., 2007; González Prats (Coord.), 2011; 2014a; 2014b; Prados et al., 2018). La Fonteta ofrece una buena muestra de estas novedades, registrando una intensa fabricación de objetos metálicos, un variado repertorio de cerámicas fenicias, la presencia de cerámicas griegas arcaicas y de otras procedencias, así como de objetos suntuarios como huevos de avestruz, marfil y escarabeos, algunos de lo cuales se habrían realizado en la propia colonia, evidencia del dinamismo comercial de la población (Fig. 3,C) (Rouillard et al., 2007; González Prats (Coord.), 2011; 2014a: 2014b).

Las intervenciones arqueológicas en La Fonteta (1996-2002 y 2018-2019) confirman la compleja evolución del enclave, con diferentes fases de ocupación que abarcan un largo periodo entre su fundación hacia finales del siglo VIII a. C. y su abandono hacia el tercer cuarto del siglo VI a. C., aunque González Prats (1998: 202 s.; González Prats y Ruiz Segura, 2000; González Prats, 2010b; 2011a: 14 s.) remonta su origen a mediados o la segunda mitad del siglo VIII a. C. y su final lo sitúe en torno a mediados del VI a. C., mientras que el equipo hispano-francés dirigido por Rouillard sitúa la cronología del asentamiento entre el último cuarto del siglo VIII a. C. y el 500 a. C. (Gailledrat, 2007a), lo que ha podido concretarse en nuestra campaña en 2018-2019 (Lorrio et al., 2019).
La datación del inicio de la ocupación a mediados del siglo VIII a. C. propuesta por González Prats se basa en el hallazgo de dos fragmentos de cerámica geométrica griega, en concreto un fragmento de borde de un skyphos de la clase Thapsos hallado en la fase IB-II (García Martín, 2000: 210, figs. 2, 2 y 7; 2011: 531, fig. 1: F-20964) y otro de la misma clase del que se conserva parte del cuerpo y el asa horizontal de la fase II (García Martín, 2011: 531, lám. I: F-33666). Además, han aparecido numerosas kotylai del Protocorintio Medio, cuyos fondos conocidos muestran la típica decoración de rayos de este periodo, igualmente halladas en contextos de la fase II tanto en las excavaciones dirigidas por González Prats (García Martín, 2000: 211, fig. 9; 2011: 532 s., lám. I) como en las efectuadas por nosotros en 2018-2019 y actualmente en estudio.

La cronología de la cerámica de la clase Thapsos ha sido fijada entre el 750 y mediados del siglo VII a. C. (Neeft, 1981: 20 s.; Kourou, 1994: 42; Gadolou, 2017: 323 s.), mientras que el Protocorintio Medio se fecha entre el 690 y el 650 a. C. Por ello, la asociación de los skyphoi de la clase Thapsos y las kotylai del Protocorintio Medio en la fase II de La Fonteta sugiere una fecha para ésta entre el primer cuarto avanzado y mediados del siglo VII a. C., por lo que la cronología de la fase I y, por tanto, del inicio del asentamiento, habría que situarla en el tránsito entre los siglos VIII-VII a. C. Esta cronología para el inicio del asentamiento de La Fonteta ya había sido sugerida por otros investigadores (Ramon, 2010: 224) y vendría avalada por la aparición ya desde la fase I del yacimiento de cerámica gris, pithoi, urnas tipo Cruz del Negro y jarros de boca de seta de cuerpo piriforme, tipos todos ellos cuya aparición está bien atestiguada en el Castillo de Doña Blanca a finales del siglo VIII a. C. (Ruiz Mata y Pérez, 1995: 63 s.).

Para definir la fecha final del asentamiento en La Fonteta es un elemento clave la cerámica local con decoración pintada, que se podría definir ya como ibérica. Ésta se generaliza en la fase VII de González Prats, aunque ya existe alguna pieza en la fase VI, y en las fases IVb, Va y Vb definidas por el equipo hispanofrancés, sobre todo en las dos últimas.

De esta manera, se documentan en dichos contextos vasos y urnas de orejetas perforados con sus respectivas tapaderas (Rouillard et al., 2007: fig. 238:16-19; González Prats, 2014b: 665-669, fig. 80-82), las urnas de cuello corto y borde exvasado con labio moldurado (Rouillard et al., 2007: fig. 208:5, 222, 239; González Prats, 2014b: fig. 77:3754), platos con decoración pintada tanto interior como exterior (Rouillard et al., 2007: fig. 208:1-3, 221:1-3,7) o motivos decorativos como las aguas verticales o los círculos y semicírculos concéntricos (Rouillard et al., 2007: fig. 221:9-10, 222:9-10; 238:13; González Prats, 2014b: fig. 78, 80-81, 83). Desde el punto de vista cronológico, es significativo que esta cerámica sólo se generaliza en un momento posterior a las importaciones cerámicas griegas halladas en la fase VI de La Fonteta, cuyo final no parece posterior a mediados del siglo VI a. C. Por ello, el final 


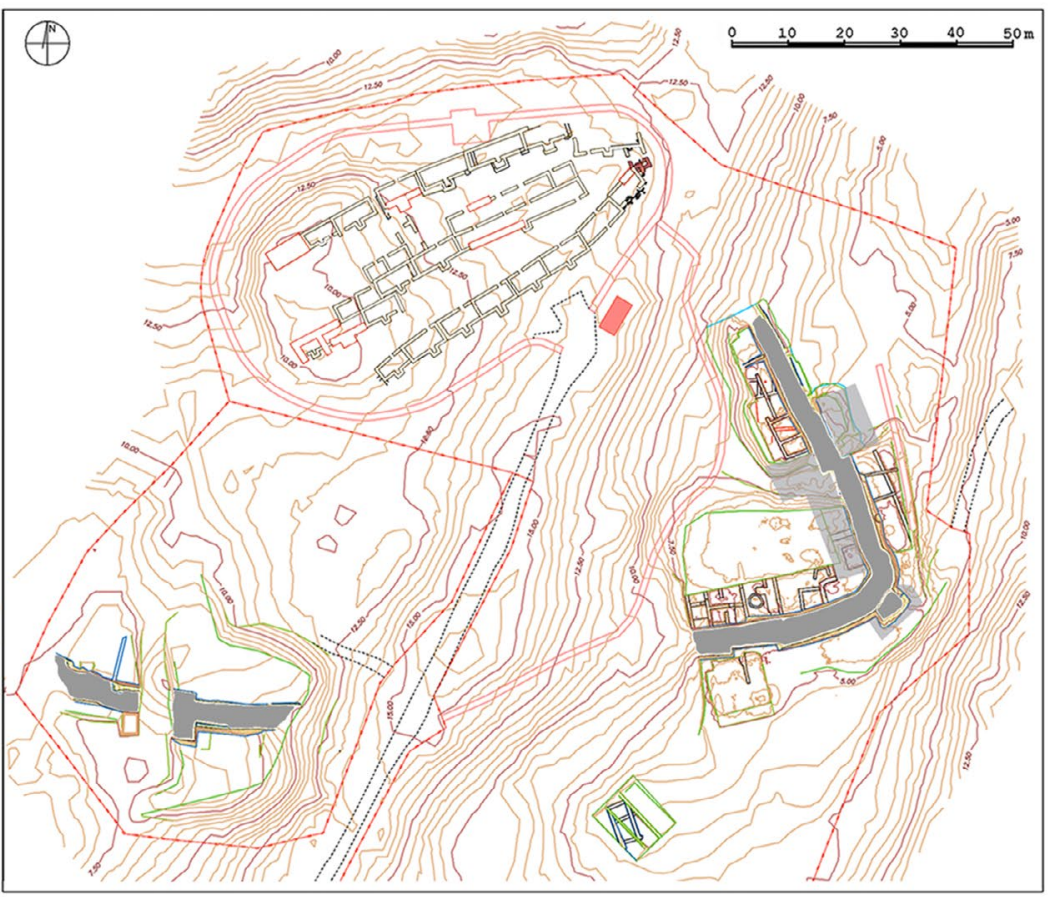

A
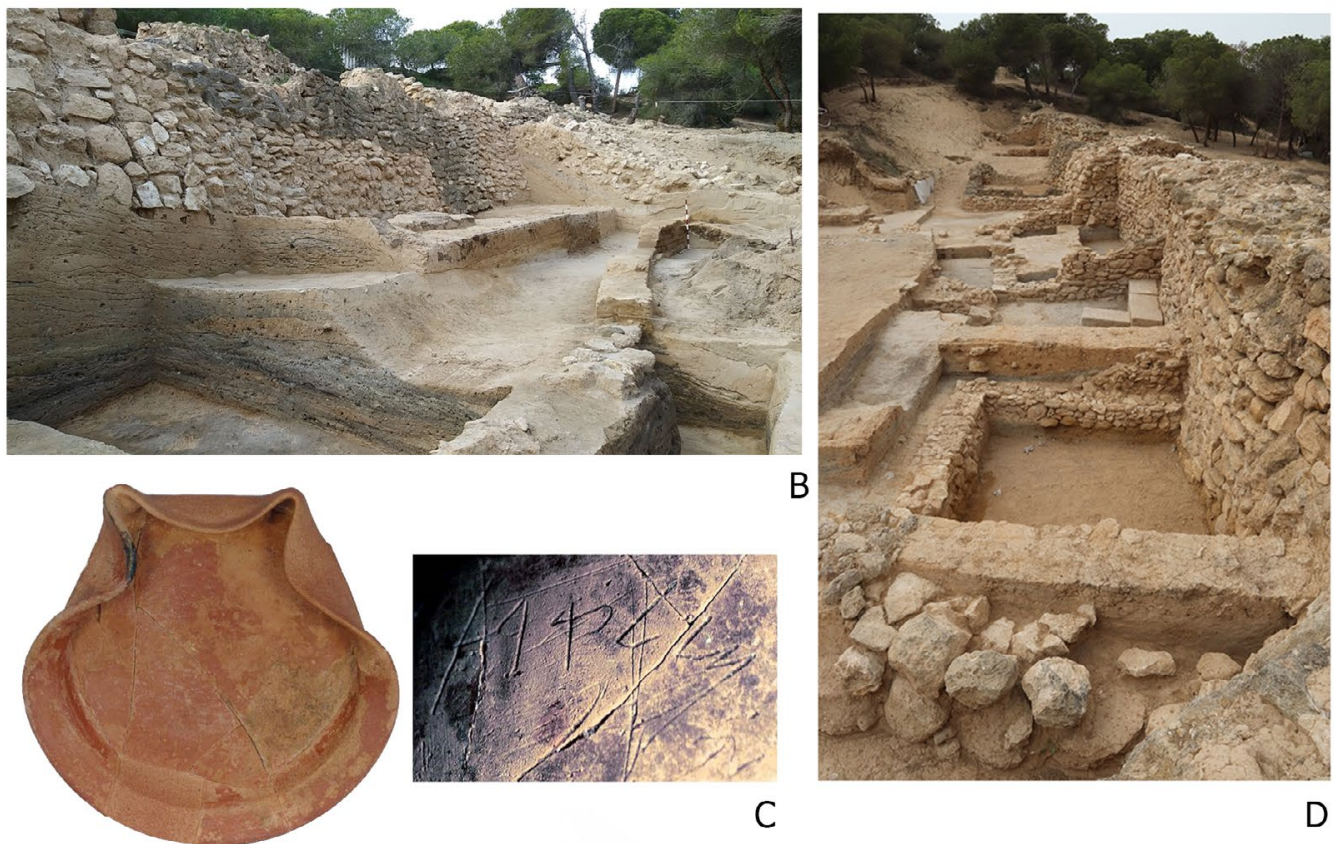

Figura 3: La Fonteta. A, Conjunto arqueológico de Las Dunas de Guardamar, con las zonas de la ciudad protohistórica de La Fonteta objeto de excavación entre 1996 y 2002 y zona de intervención en 2018-2019 (en gris claro). B, Vista de la zona a extramuros (Corte 55), con la muralla, el glacis y el antemural de la fase 'Fonteta Reciente'. En primer término, los basureros recortados de 'Fonteta Arcaica'. Campaña de 2018-2019. C, Lucerna de Fonteta III con la inscripción MLQRT. D, Vista de la muralla de 'Fonteta Reciente', con las construcciones adosadas por su cara interna, en 2019. (A, topografía I. Segura; B-D, fotos E. López -B-, A. González Prats -C-y P. Camacho -D-).

del asentamiento puede situarse en el tercer cuarto del siglo VI a. C. y no más tarde del 525/520 a. C. ${ }^{4}$, en consonancia con lo que ocurre en Peña Negra (vid. infra).

4. Resultaba problemática la identificación, en la fase $\mathrm{Vb}$ de las excavaciones hispano-francesas, de un fragmento de una copa de barniz negro que P. Rouillard relacionó con una copa ática del tipo C de Bloesch, que fechó c. 500 a. C. (Rouillard et al., 2007: 190, fig. 252), y que, como mucho, podría situarse c. 510 a. C. (Sparkes y Talcott, 1970: 88, 91 s.), fecha para el final de La Fonteta en contradicción con los hallazgos de este yacimiento y de su entorno. Es de pasta de color ocre anaranjado Munsell 2.5YR 7/10. Presenta barniz negro brillante al interior del cuerpo. El asa tiene un barniz pardo-rojizo por mala cocción, su parte interna está reservada y se inserta en una zona en reserva, cuya parte superior conserva restos de 
González Prats (1998; 2011a: 7-86) engloba las fases más antiguas del yacimiento en la denominada 'Fonteta Arcaica' (=Fonteta I-III), que registra una intensa actividad artesanal y metalúrgica, con potentes basureros (Fig. 3,B), y en alguna de sus fases un urbanismo de casas ortogonales pluricelulares de tapial (Corte 25, FII) o con zócalos de mampostería (FIII). A la fase 'Fonteta Reciente' corresponde una muralla perimetral con torres adosadas, foso y antemural (Fig. 3, B y D), cuyo excavador fecha en el último cuarto del siglo VII a. C. (Fonteta IV). La evolución urbanística de esta fase evidencia una remodelación del espacio intramuros con viviendas adosadas al paramento interno de la muralla (Fonteta V) (Fig. 3,D). En las inmediaciones de la muralla se desmantelan algunos espacios de hábitat, que se transforman en zonas de circulación abierta y vertedero (Fonteta VI) y luego en zonas de actividades artesanales (Fonteta VII). La última fase de la ocupación protohistórica es una vivienda con robusto zócalo de piedra (Fonteta VIII) tras la que se abandonaría de forma paulatina el lugar y se desmoronarían las edificaciones y la muralla (Fonteta IX). Por su parte, el equipo dirigido por Rouillard (Azuar et al., 1998; Azuar et al., 2000; Rouillard et al., 2007; Rouillard, 2010) identificó 5 fases de ocupación en su sector, localizado inmediatamente al norte del excavado por González Prats. La fase I, de finales del siglo VIII a. C., proporcionó escasas y endebles evidencias de ocupación, identificadas por niveles de suelo arcillosos y estructuras o improntas de fosas, hogares de placa de arcilla y estructuras relacionadas con actividades artesanales como hornos. La fase II es un hábitat estable con casas de planta pluricelular con un urbanismo regular, denso y con fases de remodelación internas. La fase III supuso una reorganización general, al desaparecer el espacio de hábitat anterior sustituido por un área de uso artesanal y de circulación. Las últimas fases, IV y V, se relacionan

barniz, como las copas de bandas o de Siana, aunque también pudiera ser la línea a torno que ofrecen las copas de labio o de comastas para resaltar el borde. El color del barniz unido a la forma del asa relativamente redondeada, gruesa en relación con su tamaño poco saliente y dispuesta en horizontal es propio de copas áticas anteriores a mediados del siglo VI, por lo que parece pertenecer a una copa de comastas, fechable c. 580-560 a. C.

A esta pieza se añaden dos fragmentos que fueron considerados áticos (García Martín, 2011: 536) procedentes a la Fase VI. En realidad, el fragmento de kýlix (F-10026) es el fondo de una copa jonia con una línea decorativa en reserva, cuyo tipo no se puede precisar por su reducido tamaño, pero cuya cronología no pasa del último cuarto del siglo VI. El otro fragmento, interpretado como un kántharos (F-10072), tiene la misma pasta y "barnizado" que el fragmento de kýlix y el resto de las copas jonias halladas en La Fonteta, por lo que podría tratarse de un oinochóe jonio de unos 15-20 cm de altura con asas de sección circular. Ambas piezas corresponden a la primera mitad del siglo VI a. C., aunque su pequeño tamaño no permita precisar su cronología exacta (agradecemos a R. Esteve la valoración de estas piezas). con la construcción de una muralla, fechada $c .600 / 575$ a. C. en su fase inicial, con sucesivas remodelaciones que se extenderían hasta el 550-525 a. C., pues su abandono a finales del siglo VI a. C. lo evidencian potentes derrumbes de la construcción defensiva posteriormente cubiertos por el sedimento dunar reciente (Gailledrat, 2007a: 27-29). El hallazgo de algunos elementos arquitectónicos y votivos reutilizados en la construcción de la muralla como golas egipcias, sillares, cipos y estelas betílicas (Dridi y Debœuf, 2007; González Prats, 2011b) sugieren la existencia de un templo o santuario o de un espacio funerario en uso desde la fase arcaica de la ciudad, cuya ubicación es desconocida.

La Fonteta explica la importancia del poblamiento orientalizante en el área del Bajo Vinalopó y el Bajo Segura, caracterizado por un dinamismo documentado por la investigación arqueológica desde hace décadas (González Prats, 1986; 1991; 2001; 2005; 2010a), pero la elección del lugar debió de tener en cuenta las fuertes relaciones existentes desde el Bronce Final con los asentamientos indígenas, principalmente con Peña Negra, desde la que se controlaba visualmente la gran hondonada que formaba en la Antigüedad el Sinus Ilicitanus (Plin. Nat. Hist., III,19) y la desembocadura del río Segura (Fig. 4,C). A partir del Hierro Antiguo, Peña Negra (PN II) registra una profunda remodelación al originarse un núcleo urbano que probablemente es la ciudad de Herna citada por Rufo Festo Avieno en la Ora Maritima (vv. 456-460) ${ }^{5}$, como indican la entidad de sus construcciones, su extensión de más de 40 ha distribuidas por diversas colinas ${ }^{6}$ y su ubicación

5. Aunque se trata de una fuente controvertida y resulte aventurado atribuir sin discusión determinados pasajes a un supuesto periplo de gran antigüedad, las noticias aportadas en la Ora Maritima sobre el curso bajo del río Segura o Theodorus apuntan a que Avieno debio de haber utilizado información quizás del siglo VI a. C. o anterior, al señalar explícitamente a los fenicios como los primeros pobladores de la zona («Ista Phoenices prius loca incolebant»), lo que coincide con la información arqueológica de ese momento, pero no posterior, o situar aquí el límite de los tartesios ( quondam stetit Tartessiorum»), con independencia de si el carácter orientalizante de las poblaciones de este territorio pudiera o no justificar tal consideración. También las noticias sobre el Bajo Vinalopó podrían estar haciendo referencia a este mismo momento, si nos atenemos a la escasa entidad de los asentamientos de la zona, muy diferente al panorama posterior como veremos. En este contexto, la referencia a la ciudad de Herna («Hic Herna civitas fuit»), aparentemente desvinculada de los fenicios y relacionada en cambio con las poblaciónes indígenas de la zona, podría referirse a Peña Negra, como ya señalara hace años González Prats (1983: 277; 1993: 181), al ser el único de los yacimientos autóctonos de este territorio de carácter indudablemente urbano.

6. El asentamiento aparece estructurado a partir de dos moles rocosas y las vaguadas inmediatas. González Prats (1983: fig. 2) individualizó diferentes sectores (I-IX) directamente relacionados con el asentamiento del Bronce Final y el Hierro Antiguo (I-IX), todos ellos objeto de trabajos de excavación y/o prospección, lo que ha permitido calcular su superficie en 

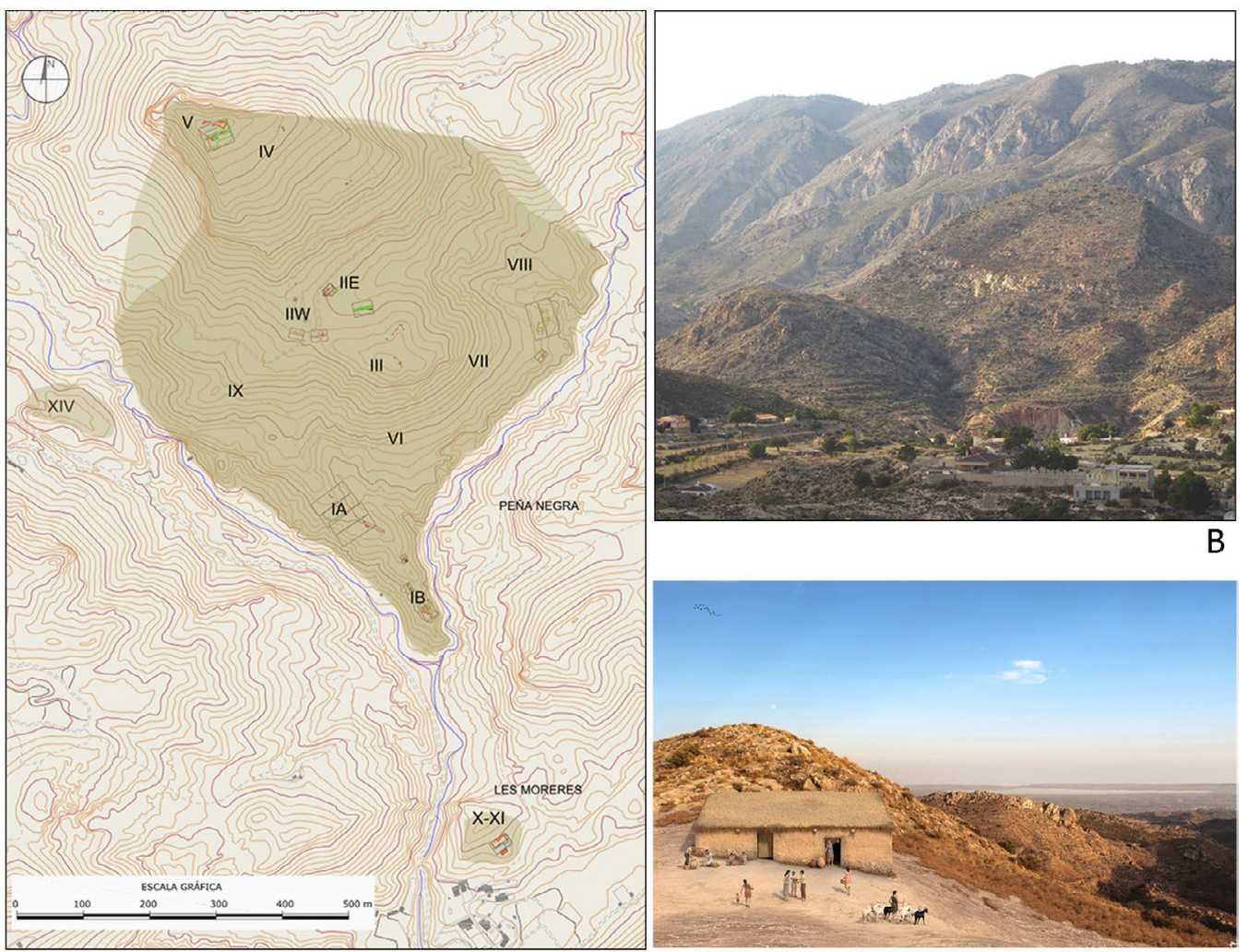

A

C
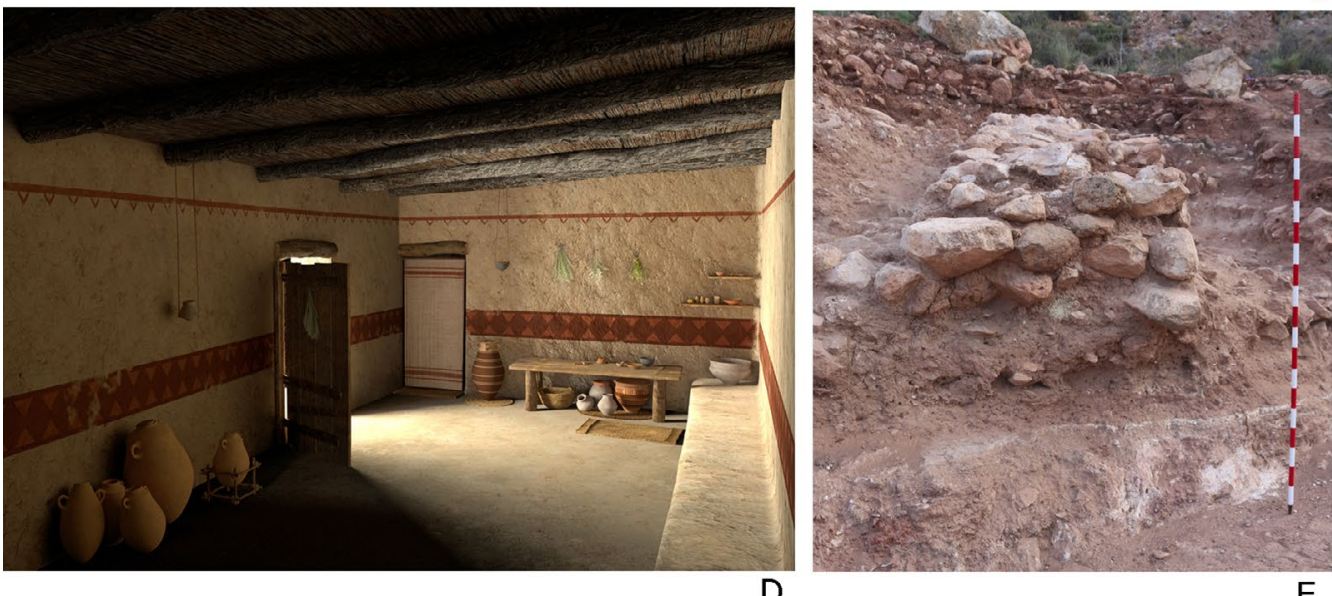

$\mathrm{E}$

Figura 4: A, Plano de Peña Negra con sus diferentes sectores. B, Peña Negra desde el sureste. C, Reconstrucción virtual de una vivienda excavada en Sector II. Al fondo, la laguna del Hondo y la línea de costa, donde se localiza La Fonteta. D, Reconstrucción virtual del interior de una vivienda del Hierro Antiguo. E, Vista de un tramo de muralla del Hierro Antiguo (A, según A. Lorrio, topografía I. Segura; B-C-D, foto e infografías J. Quesada; E, foto P. Camacho)

en uno de los principales pasos intermontanos de la Sierra de Crevillente, a través del cual se conecta el área del Bajo Vinalopó - Bajo Segura con el Medio y Alto Vinalopó (González Prats, 1993; Lorrio et al.,

más de 40 ha, superior incluso a las 34 ha propuestas inicialmente por González Prats (1993: 181). El urbanismo disperso de las fases más antiguos daría paso durante el Hierro Antiguo a una densa ocupación caracterizada por un urbanismo adaptado a la topografía del terreno (Lorrio et al., 2020b). Un modelo similar se ha señalado recientemente para otro destacado núcleo indígena del Sureste, El Castellar de Librilla
2017; 2020b: 532). El contacto directo con las poblaciones fenicias asentadas en la desembocadura del río Segura explicaría su espectacular desarrollo y la aparición de nuevas formas de vida y de pensamiento, que

(Murcia), para el que se ha planteado para su momento de máxima expansión, durante el siglo VII y la primera mitad del VI a. C., una superficie de unas 45 ha, que dotó a este asentamiento, caracterizado por un urbanismo polinuclear, «de una imagen de núcleo de poder para la región muy similar a la presentada en Peña Negra» (Cutillas y Rosa Sala, 2020: 90). 
dieron lugar a un periodo orientalizante. Se introducen en este momento la escritura, el torno de alfarero, la metalurgia del hierro, nuevos modelos de bronces, joyas, fíbulas y broches de cinturón asociados a nuevas formas de vestir, collares de pasta vítrea y amuletos y otros objetos de lujo, entre ellos perfumes, vajilla fina a torno y raras piezas de engobe rojo y objetos exóticos, como vasos de alabastro o huevos de avestruz, así como el consumo de vino, aceite y salazones. Todos estos cambios están presentes en Peña Negra y afectarían a ámbitos tan diversos como la religión, con la llegada de nuevos dioses y la aparición de nuevos rituales, de los que tenemos diversas evidencias (Lorrio et al., e.p.), o el artesanado, con productos importados y también fabricados en talleres locales, como evidencia la producción alfarera, la metalurgia y la orfebrería (González Prats, 1991: 113; 1993: 184 s.; Lorrio et al., 2020a; 2020b).

El urbanismo de Herna/Peña Negra refleja estas innovaciones, con la construcción de una muralla (Fig. 4, E) y la reorganización del asentamiento, con una «ciudadela» que ocupa una posición central y dominante y que habría albergado unos pocos edificios singulares, entre los que destaca el situado en la zona más alta, de tipo pluridepartamental y con áreas de almacenaje. Junto a este sector las recientes excavaciones han descubierto edificios rituales de carácter público, mientras que el resto del asentamiento lo forman barrios diferenciados, con áreas residenciales y otras artesanales, localizadas preferentemente en las zonas bajas. Las viviendas son de planta cuadrangular, con patrones estandarizados importados del ámbito colonial, con zócalos de mampostería, alzados de adobe, paredes decoradas con pintura roja formando bandas y motivos geométricos y cubierta vegetal revestida de barro $\mathrm{y}$, a veces, con orientación topoastronómica (Fig. 4,CD). Ofrecen tabiques para compartimentar y, en algún caso, dos pisos. También se han identificado estructuras hidráulicas a modo de cisternas con plantas trapezoidales y muros de mampostería impermeabilizados con arcilla. La extensión del asentamiento, de unas 40 ha como se ha señalado, ocupadas densamente a pesar de la difícil topografía del terreno (Fig. 4,A-B), su urbanismo y el conocimiento de la escritura indican una creciente evolución hacia formas de vida urbana comparable a la de los núcleos tartésicos del siglo VI a. C. de Andalucía Occidental.
Las murallas y el sistema de fortines, con Les Barricaes y El Cantal de la Campana (Trelis y Molina, 2017) controlando las vías de comunicación y el territorio inmediato, evidencian el papel jerarquizador de Peña Negra en la zona. La fase Peña Negra II (González Prats, 1983: 140-262; 1993: 184-187) se data $c$. 725/700 a 540/520 a. C., aunque la mayoría de los contextos estudiados sean del siglo VI a. C. En la etapa final se observan episodios de inseguridad que explicarían la rápida construcción de fortificaciones entre finales del siglo VII e inicios del siglo VI a. C., fenómeno igualmente observado en La Fonteta. Esta inestabilidad la confirma la frecuencia en ambos yacimientos de puntas de flecha, algunas con marcas de impacto o uso, con importantes concentraciones en los sectores de la periferia de Peña Negra (Lorrio et al., 2016: 37 s.), lo que se ha relacionado con episodios de asedio o asalto (cf. Kreimerman, 2016) que explicarían las ocultaciones registradas en el yacimiento, como el conocido «tesori1lo» (González Prats, 1976; 1978) o el lujoso cinturón de bronce que apareció enrollado en el interior de un hoyo (González Prats, 1982: 370-373, fig. 31, lám. X; Graells y Lorrio, 2017: 167: fig. 94, láms. 2 y 3) y el abandono de ambos yacimientos.

El abandono de Herna/Peña Negra se produciría, como ya se ha mencionado, en el tercer cuarto del siglo VI a. C., circa 540-520 a. C., pero es interesante señalar la correlación entre el final de Peña Negra y los niveles más recientes de La Fonteta (Fig. 5). En el abandono final de La Fonteta, en el tercer cuarto del siglo VI a. C., en cualquier caso, como hemos señalado, no más tarde del 525/520 a. C., debieron de incidir diversos factores históricos y sociales, episodios de inestabilidad y problemas medioambientales y sísmicos que se han reconocido como especialmente activos en este entorno y que serían determinantes, como ocurre en el abandono del Cabezo Pequeño del Estaño, pues modificarían sustancialmente las condiciones para una ocupación estable de este estratégico puerto.

Como veremos, la ruptura que supone el final de Peña Negra y La Fonteta respecto a la fase siguiente que documentan los yacimientos ibéricos de la zona resulta evidente, como señalan aspectos como el nuevo patrón de poblamiento o el urbanismo, sin que falten otros, como la cerámica protoibérica de dichos asentamientos, con formas como urnas de orejetas y urnas con borde moldurado derivadas de los pithoi

\begin{tabular}{|c|c|c|c|}
\hline & LA FONTETA & PEÑA NEGRA & LES MORERES \\
\hline Bronce Final & & $\begin{array}{c}\text { PN I } \\
925 / 900 \text { a } 725 \text { a. C. }\end{array}$ & $\begin{array}{c}\text { LM I } \\
925 / 900 \text { a } 725 \text { a. C. }\end{array}$ \\
\hline \multirow{2}{*}{ Hierro Antiguo } & $\begin{array}{c}\text { FONTETA ARCAICA } \\
\text { F-I/F-III } \\
\text { 725-625/600 a. C. }\end{array}$ & $\begin{array}{c}\text { PN IIA } \\
725-600 \text { a. C. }\end{array}$ & $\begin{array}{c}\text { LM II } \\
725-650 / 625 \text { a. C. }\end{array}$ \\
\hline & $\begin{array}{c}\text { FONTETA RECIENTE } \\
\text { F-IV/V - F-IV/VIII } \\
625 / 600-540 / 520 \text { a. C. }\end{array}$ & $\begin{array}{c}\text { PN IIB } \\
600-/ 540 / 520 \text { a. C. }\end{array}$ & \\
\hline
\end{tabular}

Figura 5: Correlación entre los yacimientos de La Fonteta y Peña Negra-Les Moreres 


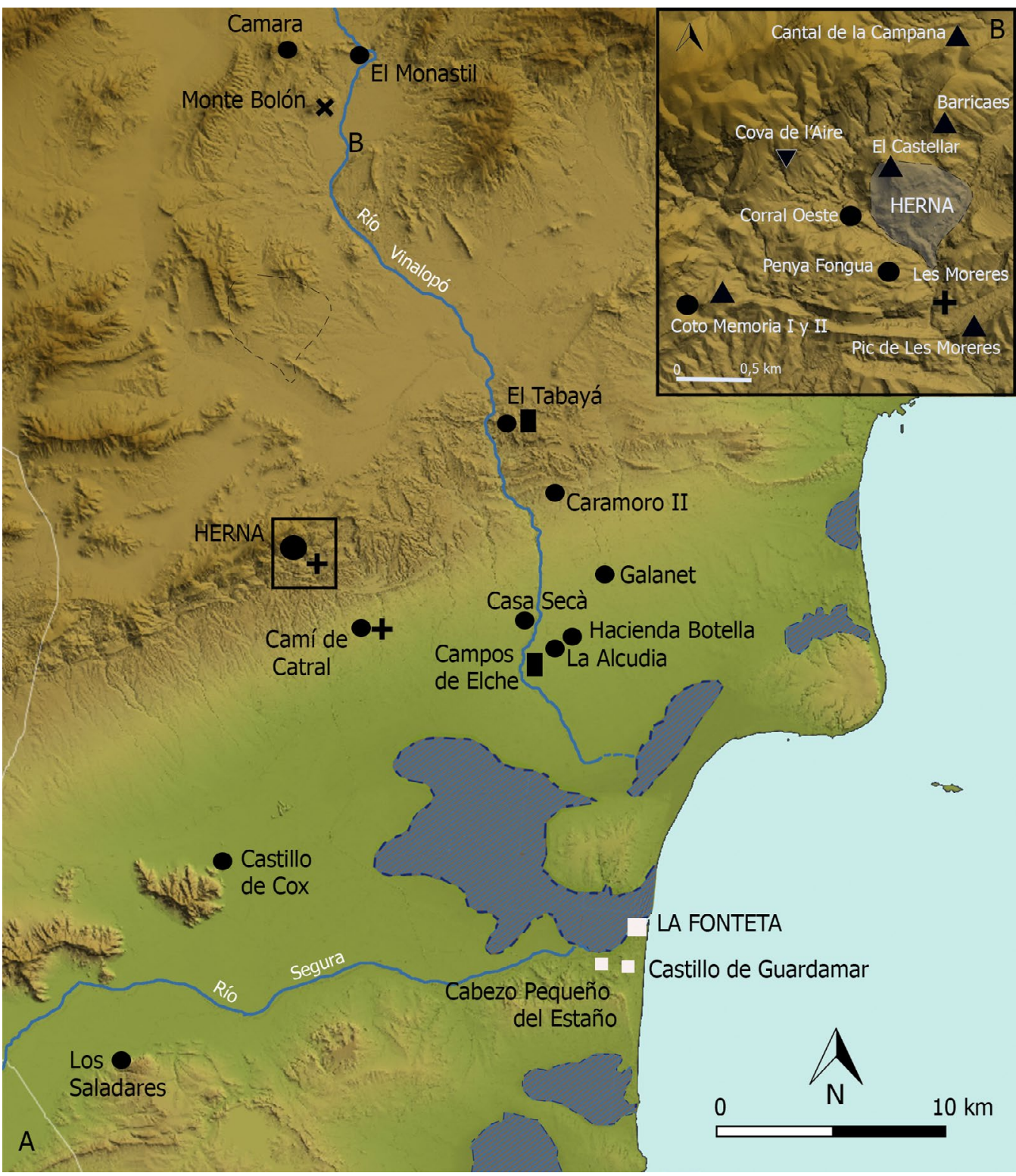

Figura 6: El poblamiento del Bajo Segura en el Hierro Antiguo: Yacimientos indígenas: Poblados $(\bullet)$, fortines/puntos de control territorial $(\boldsymbol{\Delta})$, depósitos (\), necrópolis $(+)$, cuevas de enterramiento $(\mathrm{X})$, otras cuevas $(\boldsymbol{\nabla})$. Yacimientos fenicios ( $\square)$. (Cartografía: S. Pernas).

fenicio-occidentales y orientalizantes, ya documentados en los asentamientos mencionados pero que se generalizan en el horizonte del Ibérico Antiguo, mientras que resulta significativa la ausencia de fíbulas anulares hispánicas en Peña Negra y en La Fonteta, que ya son frecuentes en el poblado de El Oral (Abad y Sala, 1993: 229, fig. 170:12-14; Sala, 2001: 150, fig. 32:12) y en la necrópolis de El Molar (Peña, 2003: $85-87$, fig. 25), por lo que proporcionan un término ante quem para su abandono.

Posiblemente, el control territorial fenicio durante esta etapa se reduciría al entorno más inmediato a la desembocadura del Segura (Fig. 6), con el asentamiento de La Fonteta y su poblado satélite del Cabezo Pequeño del Estaño, al menos en la etapa en la que ambos coexistieron, aunque sea aceptable la propuesta de González Prats (1993: 184) de situar en Peña Negra un barrio artesanal vinculado a población fenicia cuya influencia entre las elites indígenas debió ser notable. Por su parte, el control de las vías de comunicación hacia el interior parecen haber estado en manos indígenas, tanto la que sigue el curso del río Segura, en la que destaca el asentamiento de Los Saladares, como la que se dirige hacia la Meseta, a través de la Sierra de Crevillente, con Hernal Peña Negra como centro redistribuidor de los productos coloniales hacia el valle medio del Vinalopó, pues así lo evidencian la red de fortines y atalayas destinados a controlar el territorio inmediato que rodea Herna/Peña Negra y el acceso a dicha vía (Trelis y Molina, 2017; Lorrio et al., 2020b), pero también la presencia de materiales de origen colonial, en ocasiones claramente relacionados con Herna/Peña Negra, en poblados como Camara y El Monastil en Elda (Poveda, 1994; 19941995; 2000), y El Castellar en Villena (Esquembre y 
Ortega, 2017), que cabe interpretar posiblemente como territorios-satélite regidos por elites sociales vinculadas a su centro político, que no sería otro que Hernal Peña Negra, lo que permitiría extender el control territorial efectivo fuera de la chora o área territorial de la ciudad (Lorrio et al., 2020b: 532 s.). Peña Negra, aunque vinculada al ámbito orientalizante del Mediodía peninsular, debería su espectacular desarrollo al contacto directo con las poblaciones fenicias asentadas en la desembocadura del río Segura, principalmente con el enclave fenicio de La Fonteta, como contrapunto y socio comercial preferente durante el Hierro Antiguo. De acuerdo con esta interpretación, su posición geoestratégica resulta fundamental al controlar las vías de contacto del Sureste - Levante y, sobre todo, la que desde la desembocadura del Segura se dirigía hacia la Meseta, teniendo en cuenta que la llanura aluvial sería navegable hasta muy cerca de lo que hoy es el núcleo urbano de Crevillent (Lorrio et al., 2020b: 522 y 532).

El territorio de influencia de Herna/Peña Negra debió de extenderse igualmente al área del Bajo Segura - Bajo Vinalopó, en la que se conocen asentamientos de mucha menor entidad durante esta etapa (Fig. 6) (Pernas, 2008: 139-144). La ocupación a partir del siglo VII a. C. de las zonas llanas del Camp d'Elx debe de considerarse una iniciativa del núcleo rector de Hernal Peña Negra, sobre todo si tenemos en cuenta la ausencia durante el Hierro Antiguo de asentamientos relacionados con el aprovechamiento de los suelos agrícolas en el glacis crevillentino, sí documentados en cambio durante el Bronce Final. Los datos aportados por Casa de Secà, Hacienda Botella, Galanet o Finca del Tío Bou evidencian la intensificación productiva de las tierras de mayor capacidad agrícola de la zona (Soriano et al., 2012: 88 y 94), al tiempo que contradicen que el tramo final del Vinalopó estuviera deshabitado, según la Ora Maritima de Avieno (vid. supra), aunque es probable que esta ausencia de noticias se debiera a la escasa entidad de los asentamientos de la zona, sin parangón con el núcleo urbano de Herna. En Casa de Secá se identificó una gran fosa rellena de desechos domésticos que incluyen, junto a cerámicas a mano, producciones fenicias como ánforas y platos de engobe rojo, que se han relacionado con un asentamiento agropecuario localizado en sus proximidades, mientras que en Hacienda Botella aparecieron fosas elípticas, posiblemente vertederos, con cerámicas a mano (Soriano et al., 2012: 88). Más difícil es valorar La Alcudia de Elche, en la que se ha apuntado una posible ocupación del Hierro Antiguo a partir de la presencia en su estrato ' $\mathrm{H}$ ' de cerámicas a mano y a torno (Moratalla, 2004-2005: $101 \mathrm{~s}$.), aunque los datos son poco determinantes y en cualquier caso no han podido ser contrastados, aunque sí sea segura la presencia de un ánfora fenicia (n. ${ }^{\circ}$ inv. LA-556; Ramos Fernández, 1975: 81, lám. 26: 2; Aranegui, 1981: 54), cuyo borde es muy similar al de las ánforas del tipo T-10.1.1.1 de Ramon (1995: 229-230, fig. 108 y 195), que se fechan entre mediados del siglo VIII y mediados del VII a. C., aunque la inclinación de los

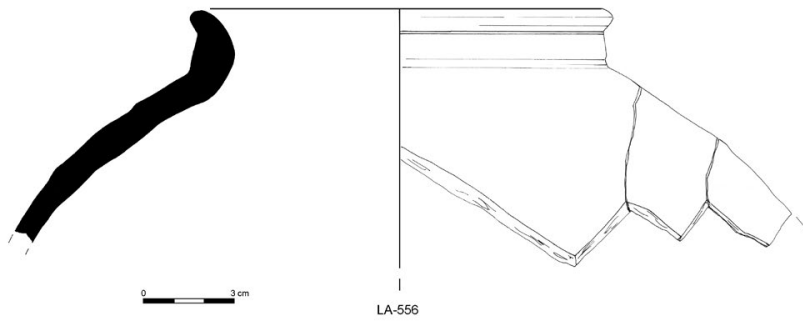

Figura 7: Ánfora fenicia de La Alcudia de Elche (Fundación La Alcudia). (Dibujo M. ${ }^{a}$ D. Sánchez de Prado)

hombros sugiere una fecha más reciente, y que, por las características de su pasta, sería muy probablemente de fabricación local (Fig. 7), aunque no haya sido posible identificar el contexto del hallazgo ${ }^{7}$ ni por tanto determinar las características y entidad de la ocupación, posiblemente no muy diferente a la del resto de yacimientos conocidos en la zona. También en Elche, como hemos comentado, se localiza Caramoro II, que pudiera haber estado ocupado durante el Hierro Antiguo, como confirmaría el hallazgo en superficie de ánforas fenicias (González Prats y Ruiz Segura, 1992: 17), aunque no se haya constado material asimilable a esta etapa en las intervenciones más recientes (García Borja et al., 2010: 44 s.).

De gran interés es el depósito formado por un conjunto de hachas-lingote con o sin apéndices laterales recuperado a finales del siglo XIX en un lugar indeterminado de los «campos de Elche». El conjunto suele vincularse a La Alcudia (González Prats, 1985; Vives-Ferrándiz, 2005: 121; etc.), aunque tal atribución se realizó en una fecha muy posterior a su descubrimiento (Ibarra, 1926: $63 \mathrm{~s}$.) sin aportar dato alguno que así lo justificase (vid. Lorrio et al., e.p., con la discusión). Este tipo de hachas-lingote aparece casi exclusivamente en yacimientos del Bajo Segura - Bajo Vinalopó, como La Fonteta y Peña Negra, y en zonas próximas, como la Sierra del Tabayá, pues a estos ejemplares sólo se añaden los recuperados en un depósito de la isla de Formentera y un fragmento hallado en el poblado de El Tossal del Mortòrum, en Castellón (González Prats, 1985; Le Meaux y Sánchez de Prado, 2007: fig. 258; Renzi, 2010; González Prats, 2014a: 281, figs. 35-38; Montero, 2017: 100, figs. 8, 1 y 8, 2; vid., con la bibliografía anterior, Lorrio et al., 2020a). Los más antiguos corresponden a una fase avanzada del Bronce Final, pero en su gran mayoría se fechan ya en el Hierro Antiguo, entre los siglos VII y VI a. C. (Lorrio et al., 2020a: 856). Aunque puede tratarse de un depósito ritual, no puede descartarse su interpretación comercial, pues se halló alejado de los centros productores localizados en Peña Negra y La Fonteta, donde se han encontrado moldes de fabricación (Renzi,

7. Agradecemos la información a la Dra. A. Ronda, responsable del Área de Catalogación de la Fundación Universitaria La Alcudia de Investigación Arqueológica. 
2010; González Prats, 2014: 279 s., fig. 35; Lorrio et al., 2020a: 855), y próximo a la desembocadura del Vinalopó, en relación quizás con redes de distribución y de circulación de productos hacia las zonas interiores (Soriano et al., 2012: 94), como indican los hallazgos de la Sierra del Tabayá, lo que evidencia el funcionamiento y la importancia del ramal originario de la ruta del Bajo Vinalopó durante esta época del Bronce Final.

Hacia el Sur, en la zona de la Vega del Segura, los yacimientos se concentran en torno a las sierras de Callosa y Orihuela (Fig. 6), con asentamientos como el Castillo de Santa Bárbara, en Cox (Torres Salinas, 1995a; 1995b; Moratalla, 2004: 136 s.), o Los Saladares (Arteaga y Serna, 1975; 1979-1980), en Orihuela, aunque igualmente se haya supuesto la ocupación de la Ladera de San Miguel (Moratalla, 2004: 82 s.), dado su emplazamiento privilegiado y su amplia secuencia desde el Bronce Final hasta época romana, aunque ni las colecciones de superficie ni los sondeos realizados han podido documentar materiales del Hierro Antiguo (Diz y Yus, 2014: 108 s.). Es interesante analizar el poblado de Los Saladares (Arteaga, 1979-1980), tanto por sus dimensiones, unas 0,3 ha en su configuración actual, como por su larga ocupación entre un momento avanzado del Bronce Final ( $c a$. siglo VIII a. C.) y el desarrollo de la cultura ibérica ( $c a$. siglo III a. C.), pues, junto a Peña Negra, refleja las transformaciones de un asentamiento cuasi urbano. Los Saladares se sitúa en un pequeño cabezo próximo a la Sierra de Hurchillo, al sur del río Segura, a unos $3 \mathrm{~km}$ al suroeste de la actual Orihuela, con un emplazamiento topoastronómico que parece constituir el centro umbilical de esa zona del Segura, marcado al norte por el pico de La Cruz de la Muela, de 465 m s.n.m., en la Sierra de Orihuela, el Pico Hurchillo al este, de 271 m s.n.m, y el pico Bermejo al sur, de $311 \mathrm{~m}$ s.n.m. En su configuración actual, el poblado se circunscribe a la ladera noroeste de un pequeño montículo, pues en los años 70 del siglo XX se realizaron labores de explanación de la ladera baja del cabezo para abancalar el terreno y ampliar la zona de cultivo, trabajos que destruyeron buena parte de sus restos y redujeron notablemente su extensión (Arteaga y Serna, 1975: 19). Los Saladares refleja primeros contactos indígenas con los establecimientos fenicios de La Fonteta y el Cabezo Pequeño del Estaño, pues evidencia muy pronto la llegada de influjos del ámbito colonial que transformaron el asentamiento, que debió jugar un papel relevante en el control y redistribución de los productos coloniales a través del río Segura, cuya vida prosiguió hasta convertirse en el poblado ibérico que controlaba este tramo del río, una zona de salinas y el fértil terreno de su entorno (Arteaga, 1979-1980).

Más difíciles de valorar son otros hallazgos, como el fragmento de asa de tipo 'rodio' de la primera mitad del siglo VI a. C. recuperada, al parecer, en la necrópolis de El Molar (San Fulgencio), fechada entre finales del siglo VI y finales del V a. C. (vid. infra), aunque la pieza no aparezca recogida en las publicaciones donde se dio a conocer esta interesante necrópolis, lo que plantea ciertas dudas sobre su lugar de hallazgo (Graells y Bottini, 2017). El influjo orientalizante se mantendría en la zona hasta finales del siglo VI y entrado el siglo V a. C., como evidencian algunos elementos del poblado de El Oral (vid. infra), como su arquitectura doméstica o parte de su cultura material (Abad y Sala, 2009; Abad et al., 2017: 236-238). De influjo orientalizante es igualmente el monumento turriforme con escultura del Parque Infantil de Elche (Ramos Fernández y Ramos Molina, 1992), fechado por sus excavadores en la segunda mitad del siglo VI a. C., y también las esculturas de toros de estilo tartesio-ibérico de El Molar, el Parque Infantil de Elche, Monforte del Cid y Sax (Chapa, 2005: fig. 2; Almagro-Gorbea y Torres, 2010: 382 s., fig. 303:D-G), que jalonaban hacia el interior la importante Vía Salaria Ibérica y que evidencian la continuidad de su importancia en este periodo.

\section{EL COMERCIO FOCENSE Y EL HORIZONTE DE IMPORTACIONES GRIEGAS DEL 500 A. C.}

A finales del siglo VI a. C. se produce el abandono de La Fonteta y de Peña Negra asociado a una importante reordenación de sus territorios al aparecer nuevos asentamientos en la zona, que ya cabe considerar como ibéricos.

Este interesante proceso requiere ser interpretado con una amplia visión de conjunto. A partir del siglo VI a. C. se produjo la expansión colonial focense en las costas de Iberia (Cabrera, 1988-89; 2000; Domínguez Monedero, 2000). En este proceso colonial los hallazgos arqueológicos permiten diferenciar tres fases. Un primer horizonte focense lo definen importaciones de copas jonias B2 y aríbalos corintios por las zonas costeras de Iberia, incluidos yacimientos hispano-fenicios y orientalizantes, en el marco de un comercio empórico jonio, básicamente focense, en la ruta hacia Tartessos. En el Sureste, este horizonte sólo se documenta en La Fonteta y en un fragmento del santuario de La Luz (Cabrera, 2000: 171 s.; Santos, 2009c: 301 s.). Estos aryballoi debieron llegar a Iberia a través del mundo comercial focense de Occidente desde la Magna Grecia, donde son relativamente frecuentes (Shefton, 1982: 353; Jiménez y Ortega, 2004: fig. 24). Así lo indica su mayor presencia y antigüedad en Ampurias (Trías, 1967: 31 s.; Shefton, 1982: 354; Aquilué et al., 2000: 308 , figs. 20 y 21: 4), aunque las cerámicas corintias no sean frecuentes en la península ibérica, como se observa en Huelva (Cabrera, 1988-1989: 56), ni tampoco en el mundo focense de Occidente. Este «horizonte de aryballoi corintios» se fecha en el segundo y tercer cuarto del siglo VI a. C., c. 575-530 a. C. ${ }^{8}$

8. A este «horizonte de aryballoi corintios», entre otros, pertenecerían 9 aryballoi de Huelva (Cabrera 1988-89: 56; Jiménez y Ortega, 2004: 86), 1 de Coria del Río (Belén, 1993: 47, fig. 7, 
La caída de Focea en manos de Ciro (Antonelli, 1997: 81 s.) hacia el 545 a. C. y el abandono del emporion focense de Huelva supusieron el final del citado «horizonte colonial focense» (Almagro-Gorbea et al., 2018). Probablemente como consecuencia de esos episodios y de la consiguiente batalla de Alalia hacia el 540 a. C. (Hdt. I,166,2; Jehasse, 1962; Tsirkin, 1983; Domínguez Monedero, 1991; Antonelli, 1997: 117119; 2008: 225 s.; Krings, 1998: 139 s.; Bernardini et al., 2000; Bernardini, 2001), a partir de la segunda mitad del siglo VI a. C. disminuyen las importaciones griegas en el Sureste y el Levante ibéricos, antes de volver a aumentar a mediados del siglo $\mathrm{V}$ a. C. Esta segunda fase, que finaliza antes de fines de dicha centuria, supuso una progresiva occidentalización del comercio empórico focense, al descender las importaciones cerámicas de la Grecia del Este y aumentar las de las colonias griegas de Sicilia y Magna Grecia y las de Massalia, que se generalizan a fines de esa centuria (Cabrera, 2000: 171; Santos, 2009c: 303 s.). Entre las importaciones que aparecen en el Levante peninsular destacan las copas B2, muchas de las cuales Cabrera (2000: 171) fechó en este momento, pues están bien representadas en las fases IIIb y IIIc de la Palaiapolis ampuritana (Aquilué et al., 2000: 294 y 296). Estas copas proceden tanto de la Grecia del Este (Aquilué et

2; Escacena e Izquierdo, 1996), 1 fragmentado de Los Villares de Jerez de la Frontera (López Rosendo, 2007: 13-14, fig. 4), 2 ó 3 fragmentos de Malaca (Gran-Aymerich, 1988: fig. 10; 1991: 128 s.; Jiménez y Ortega, 2004: 86), 1 fragmento de alabastrón o de aryballos de Toscanos (Shefton, 1982: 353, lám. 23f), 1 aryballos del Corintio Medio de Villaricos (Trías, 1967: 463: lám. 192, n. ${ }^{\circ}$ 4), 1 aryballos fragmentado de los alrededores de Cartagena (Almagro-Gorbea, observación personal en el mercado anticuario en 2002) y 1 aryballos de Villajoyosa, Alicante (Shefton, 1982: 354, n. 49); ya en Tarragona hay 1 de Mianes, Santa Bárbara, 1 en Mas de Mussols, La Palma (Maluquer de Motes, 1987: 64, fig. 11, lám. 5, 1) y 1 en Milmanda, Vimbodí (Graells, 2006). En el Ampurdán, hay 1 aryballos de Mas Gusó (Casas y Soler, 2000: fig. 7, 5), 1 de la necrópolis de Vilanera, en La Escala, 9 o 10 aryballoi y un alabastrón de Ampurias (Trías, 1967: 31 s., lám. I; Rouillard, 1991: 169; Castanyer et al., 1999: 164, fig. 182183; Graells, 2006) y 1 en la Palaiapolis ampuritana. Tambien hay 1 muy fragmentado de la necrópolis ibicenca de Puig des Molins (Gómez Bellard, 1990: 77, fig. 72, lám. 12). En este mismo horizonte se sitúan los aryballoi de Náucratis, de los que se conocen 5 en Ampurias (Trías, 1967), 1 en Mailhac, en el Sur de Francia, 2 de Ibiza, 1 en El Molar, fechado c. 550 a. C. (Padró, 1975: 138-139, fig. 2), 1 en la necrópolis ibérica de Hoya de Santa Ana, Albacete (Blánquez, 1990b: 328, fig. 97), 2 en Los Villares (Blánquez, 1990b: 179-180, fig. 36), 1 en la necrópolis de Melegriz, Albacete (Castillo, 2020: 147, fig. 25), 1 en la necrópolis de La Bobadilla, Jaén (Maluquer de Motes et al., 1973: 16 s., lám. 4) y 1 fechado a partir del 570 a. C., de Cancho Roano (Jiménez Ávila y Ortega, 2004: fig. 2, 3), aunque se ha señalado la ausencia de estos aryballoi naucráticos en Huelva (Domínguez Monedero y Sánchez, 2001: 86), lo que pudiera indicar una fecha posterior al 545 a. C. (Almagro-Gorbea et al., 2018). al., 2000: 301-304, fig. 15 y 17) como de talleres del Mediterráneo central (Aquilué et al., 2000: 306 s., fig. 19) y también aparecen en el pecio griego de Cala Sant Vicenç (Santos, 2009a: 99, fig. 94 s.; van Conpernolle, 2009), cuyo hundimiento se ha datado entre 520510/500 a. C. (Nieto y Santos, 2009: 318 y 328). Por ello, habría que situar en esta fase las copas B2 halladas en la fase II-B de Los Saladares (Arteaga, 1976-1978: 59) y la atribuida al Tossal de Manises (Rouillard 1976: 7-8, fig. 1; 1978: 277, fig. 2:1).

Junto a estas copas se incluyen las ánforas de tipo A-MGR 1, «Corintias B arcaicas», utilizadas para comercializar vino de la Magna Grecia (Santos, 2009c: 304), una de las cuales ha aparecido en 2018-2019 en La Fonteta ${ }^{9}$. Fragmentos de estas ánforas aparecen en la fase IIIa de Ampurias y dos bordes y una base en la fase IIIb (560/550-540 a. C.) (Aquilué et al., 2000: 333, fig. 40:5-7), a las que se deben añadir otras piezas (Sourisseau, 2011: 217, nota 255) inicialmente clasificadas como ánforas «jonias» (Aquilué et al., 2000: 333, fig. 40:8-10) y también se hallaron varios ejemplares en el pecio griego de Cala Sant Vicenç (Santos, 2009b: 126 s., 129-132, fig. 117 y 119-120). Este tipo de ánfora se ha documentado también en las excavaciones efectuadas bajo el palacio de Buenavista en Málaga, en un contexto del 560-540/530 a. C. (Cisneros et al., 2000: 198, fig. 9: P.B. MA. 98:21/23/2 y P.B. MA. 98. $21 / 23 / 1$ ), en Guadalmar, en un contexto que remite a los últimos años del siglo VI a. C. (Florido et al., 2012: 162-164, fig. 25:e) ${ }^{10}$, en la c/ Berdigón 13 de Huelva

Estos aryballoi son piezas de escasa calidad que documentan la llegada de perfumes corintios. Su difusión se relaciona con el «horizonte colonial focense», que también documentan las copas jonias B2 (Domínguez Monedero, 2000: 35-37; 2002: 192, fig. 2) y algunos escasos bronces de calidad, como el casco de la Ría de Huelva (Almagro-Gorbea et al., 2004: 174 s.), datado c. 560 a. C., o el Centauro de Rollos, de $c$. 550 a. C. (García Bellido, 1948: 87 s., lám. 24; Riis, 1959: 47; Olmos, 1983; 2000a; Croissant y Rouillard, 1996: 57, n. ${ }^{\circ}$ 4, fig. 5; Bardelli y Graells, 2012: 37), además de vajilla de bronce para el simposion (Graells, 2009; Bardelli y Graells, 2012: 35 s.) y escarabeos (Almagro-Gorbea y Graells, 2011). Algunos aryballoi y alabastrones de Ampurias se fechan ya en el Corintio Antiguo (Trías, 1967: 31, lám. I,1), lo que parece confirmar, por su mayor antigüedad y número, la vinculación al comercio focense de estos materiales, pero la mayoría son ya del Corintio Reciente I, por lo que se fechan en el segundo cuarto del siglo VI a. C. En consecuencia, estas importaciones griegas representan la fase de mayor actividad del comercio focense en Iberia, especialmente con Tartessos, antes de su desaparición en la segunda mitad del siglo VI a. C., tras la conquista de Focea por Ciro el 546 a. C. (Hdt. I,163 y 165) y la casi contemporánea desaparición del comercio focense en Huelva/Tartessos (Almagro-Gorbea et al., 2018).

9. Trabajo en fase de elaboración.

10. No obstante, el perfil del borde de esta pieza se acerca más al de las denominadas ánforas «jonio-masaliotas» (forma 2 de Sourisseau) o a una forma de transición entre las formas 1 y 2 de Sourisseau, ya que, junto al baquetón en el cuello, presenta la incisión en la parte baja del borde. 
(López Domínguez et al., 2006: 2097, fig. 9: 143) y en la c/ Méndez Núñez 5 de la misma ciudad, donde se han fechado entre 560-540/530 a. C. (Fernández Jurado et al., 1994: 82, fig. 10:8) ${ }^{11}$.

La tercera fase, ya posterior a la desaparición de $\mathrm{La}$ Fonteta y Peña Negra, la representa un horizonte fechado en torno al 500 a. C. que parece ir dirigido a controlar la Vía Salaria Ibérica tras la crisis de Tartessos. Este nuevo horizonte lo caracterizan básicamente importaciones de vasos áticos traídos probablemente por el comercio focense de Ampurias (Shefton, 1995: 129 y 142), acompañados de ánforas masaliotas, corintias y de la Grecia del Este (Sala, 1994; Cabrera, 2000: 171), y a él pueden atribuirse también algunos vasos metálicos etruscos, probablemente llegados igualmente con el comercio ampuritano, aunque este tema sea discutido (Graells, 2008). A este «horizonte del 500 a. C.» pertenece el ajuar de la tumba de Pozo Moro, formado por un kylix probablemente del círculo de Epeleios, datado c. 505500 a. C. (Almagro-Gorbea, 2009a), un Schnabelkanne de bronce 'vulcente' (Almagro-Gorbea, 1983a: lám. 15, a-b; Graells, 2008: 207) y un gran lekythos de la Clase Atenas 581 (Almagro-Gorbea, 1983a: 184, lám. 15 , c-d), fechado c. 510-500 a. C. relacionado con el Grupo de Leagros, como la pelike de figuras negras del Pintor de Eucharides de la necrópolis Cabezo Lucero, atribuible a la tumba que pudo iniciar la necrópolis (Almagro-Gorbea, 2009b). Esta pelike, datada c. 500490 a. C., parece anterior a los restantes vasos áticos del yacimiento, tanto de figuras negras (Rouillard, 1993: 87) como de figuras rojas, entre éstos la copa C del Pintor del Louvre G 265 (Rouillard, 1991: 556 s.; 1993: 89; Aranegui et al.,1993: lám. 69; Domínguez Monedero y Sánchez, 2001: 43), ya ligeramente posterior, c. 470-460 a. C. A estos vasos se puede añadir el ánfora de figuras negras, también atribuida al Grupo de Leagros, hallada en Valencia (Mata y Burriel, 2000: fig. 4:2-4), una crátera de columnas de figuras negras aparecida en La Albufereta de Alicante del último tercio del siglo VI a. C. (García Martín y Llopis, 1995), los fragmentos de copas Droop del Círculo de Rodas 12264 hallados en Cabezo del Tío Pío, en Archena, Murcia, de fines del siglo VI a. C. (García Cano, 1991: 373, fig. 2, 3 y 4; Domínguez Monedero y Sánchez, 2001: 38) y el lekythos de Liria (Trías, 1968: lám. 157, 1-5; Shefton, 1995: 140; Domínguez Monedero y Sánchez, 2001: 51, fig. 44), ya algo posterior y de menor calidad. Tras el 500 a. C. prosiguen las importaciones en el Sureste de vasos áticos de calidad, como el kylix del Pithos Painter aparecido en Mengíbar, Jaén, datado en el 490-480 a. C. (Almagro-Gorbea, 2015), muy probablemente llegado desde el Sureste, la citada copa del Pintor del Louvre G 265 de Cabezo Lucero que representa una importante

11. Esta pieza fue clasificada por sus editores como un ánfora jonio-masaliota, cuyo contexto, junto al kantharos que publican en la fig. 5: 1, sería ya del Tartésico Final III (560540/530 a. C.). importación del círculo del Pintor de Brygos, el kylix de rojo coral de inicios del siglo $\mathrm{V}$ a. C. de la Loma del Escorial, Los Nietos, Murcia (Trías, 1967: 384, n. ${ }^{\circ}$ 1, lám. 176, 1) y el ánfora ática de la Cova dels Pilars de Agres, Alicante (Olmos y Grau, 2005), ya datada c. 470-460 a. C., quizás como otra ánfora ática de Segóbriga de mediados del V a. C. que, junto al olpe de bronce de Haza del Arca, confirmaría el uso de la Via Salaria Ibérica hasta la Meseta en fechas tempranas del siglo V a. C. (Almagro-Gorbea, 1992). A estas importaciones se suman los kylikes de forma C, como el de Pozo Moro (Sparkes y Talcott, 1970: 91 s., lám. 19), forma creada a fines del siglo VI a. C. o poco después (Shefton, 1995: 128, fig. 1), documentada en Cataluña (Padró y Sanmartí, 1992: 187), Puig de la Nau, Castellón (Sanmartí, 1976; Oliver, 2006) y el Sureste, pues sólo en Cabezo Lucero han aparecido más de 10 ejemplares (Rouillard, 1993; Shefton, 1995: 128). También en el poblado de El Oral han aparecido más de 20 fragmentos de vasos áticos fechados hacia el 500 a. C., entre los que destacan 10 o 12 copas de tipo C, 1 Vicup, 1 copa de figuras negras, 1 lekanis, 1 lekythos y 1 hydria o ánfora (Domínguez Monedero, 2001-2002: 196) y en la cercana necrópolis de El Molar, donde además de una copa de Siana, claramente anterior, se cita una copa de figuras negras (Domínguez Monedero y Sánchez, 2001: 45 s.) y un lekythos de figuras negras tardías de la primera mitad del siglo V a. C. (Trías, 1967: 378, lám. 376: 7; García Martín, 2000: 208).

A este horizonte de vasos áticos importados en la desembocadura del Segura se añade la vajilla metálica, llegada básicamente desde Italia. Destacan los Schnabelkanne de bronce, dos de taller vulcente, uno hallado en la tumba citada de Pozo Moro (AlmagroGorbea, 1983a: lám. 15, a-b; Weber, 1983; Graells, 2008: 207; Bardelli y Graells, 2012: 34), comparable a otro de Málaga, fechado entre el 525 y el 475 a. C., probablemente de inicios del siglo V a. C. (Graells, 2008: 206 s.). A éstos hay que añadir un tercer ejemplar también etrusco de la Provincia de Cuenca (Graells, 2008; Bardelli y Graells, 2012: 34), de c. 500 a. C., pieza que confirma la importancia de la Vía Salaria Ibérica que comunicaba el Sureste con la Meseta (Graells, 2008: 208) y explica esta concentración de bronces etruscos en esa zona de Iberia (Bardelli y Graells, 2012: 31 s., fig. 13).

También son particularmente frecuentes en el Sureste los pequeños jarros de bronce fundido a la cera perdida, en ocasiones denominados olpes (Abad, 1988; Pozo, 2003), que parecen fecharse entre fines del siglo VI y el V a. C. (Jiménez Ávila, 2002: 381 s.), aunque su datación sea más imprecisa. En el Sureste ha aparecido uno de origen etrusco en El Oral, San Fulgencio, Alicante (Abad, 1988: 331, fig. 1), otro de la Magna Grecia en el Cabecico del Tesoro, Verdolay, Murcia (Abad, 1988: 333, fig. 2; García Cano, 1991: 375, fig. $3: 2)$ y hay otro posible en la Colección Saavedra de Lorca, Murcia (Thouvenot, 1927: 96, n. ${ }^{\circ} 481$ ), a los que cabe añadir un Schnabelkanne de fines del siglo V de El 
Cigarralejo, Mula, Murcia (Cuadrado, 1987: 172-175, fig. 62:10; Jiménez Ávila, 2002: 381, fig. 254:1; Botto y Vives-Ferrándiz, 2006: 142, fig. 50). A éstos se suma el de Haza del Arca, en Cuenca (Lorrio y Sánchez de Prado, 2002: 169 s.; Lorrio, 2007), sin duda llegado por la Vía Salaria Ibérica, y los hallados en Andalucía Central, en el Mirador de Rolando, Granada (Arribas, 1967: 79-80 n. ${ }^{\circ}$ 43, 95, fig. 12:43; Marzoli, 1991: 216), y en Pedro Abad, Córdoba (Marcos Pous, 1983-1984: 35 n. $^{\circ}$ 2), y en Andalucía Oriental, en Sexi, Almuñécar, Granada (Pozo, 2003: 19, lám. 18, fig.7 y 26), además de un fragmento de palmeta de la base del asa en las Baleares (Bardelli, 2017; R. Graells, comunicación personal). La variedad tipológica de estos jarritos podría indicar en algún caso producciones locales, pero Abad (1988: 329-345) los consideró itálicos y los relacionó por su asa sencilla con una cabeza de ánade en su parte superior con el grupo A griego de Weber (1983) y Marzoli (1991: 216) los asocia con el tipo 5a de Beazley y el tipo 5a de Weber. Este horizonte también incluiría un aplique de asa en forma de palmeta de Covalta, Valencia (García Bellido, 1948: 109, lám. 43, 25; Bardelli y Graells, 2012: 34 s., fig. 17), y quizás el infundibulum etrusco de la segunda mitad del siglo VI a. C. recuperado en el mar en Jávea (Vives-Ferrándiz, 2007; Botto y Vives-Ferrándiz, 2006: 144, figs. 55-56; Bardelli y Graells, 2012: 32 s.), además del sátiro itifálico del Llano de la Consolación (García Bellido, 1948: 91 s., lám. 26; Olmos, 1977; 2000b; Shefton, 1982: 362, n. 69; Herfort-Koch, 1986: 121, K153; Rouillard, 1997: 186, n 296; Bardelli y Graells, 2012: 37, fig. 18B), que por su estilo parece un bronce laconio tardoarcaico, no alejado del 500 a. C., y también se debe incluir la estátera de Lesbos hallada en Bolbax, Murcia, de $c$. 500-480 a. C. (Lillo, 1981).

Estas importaciones de bronces, que Bardelli y Graells (2012: 33, fig. 13) denominaron «serie griega del Sureste», se integran en el horizonte de vasos áticos de $c .500 \pm 10$ a. C. Bronces y cerámicas reflejan el comercio focense-masaliota desde Ampurias, pero en un ambiente comercial muy distinto del focense arcaico desarrollado hasta el tercer cuarto del siglo VI a. C., caracterizado por copas jonias, ánforas de vino y aryballoi corintios (Shefton, 1982: 354; Cabrera, 2000: 170 s.; Almagro-Gorbea, 2008: 590). Las importaciones cerámicas de c. 500 a. C. son productos de calidad de carácter suntuario destinados a las elites que reflejan un impulso renovado del comercio ampuritano en la generación de fines del siglo VI a inicios del V a. C. (Almagro-Gorbea, 1996: 77 s.; 2009b, 16 s.; AlmagroGorbea et al., 2008: 1075 s.; Torres, 2002: 385), probablemente para recuperar la actividad perdida tras la crisis que supuso la caída de Focea en manos de Ciro, la desaparición del emporion focense de Tartessos hacia el 550-540 a. C. y la batalla de Alalia (Almagro-Gorbea et al., 2008: 1010 s.; Almagro-Gorbea et al., 2018). Los vasos áticos, entre los que destacan las copas de tipo C, testimonian este nuevo impulso del comercio focense distribuido desde Ampurias (Shefton, 1995: 129, 142), a pesar de las dudas de Shefton (1995: 148, n. 14bis) sobre la llegada de los vasos de Pozo Moro a través del comercio ampuritano, quizás por el valor y diversidad de los objetos de este ajuar, incluido el Schnabelkanne de Vulci (Graells, 2008), pero el lekythos de Pozo Moro, la pelike de Cabezo Lucero y los restantes vasos áticos citados, como probablemente los bronces itálicos asociados, sugieren su llegada desde la Italia tirrénica vía Ampurias en esos años del paso del siglo VI al V a. C.

Esta nueva red comercial hace suponer circunstancias especiales en las que el Bajo Segura debió jugar un papel esencial. El horizonte de importaciones suntuarias del 500 a. C. suponía una nueva política focense en el Sureste de Iberia que parece bastante «agresiva», tanto en el ámbito comercial como por su trasfondo político, pues iba dirigida a lograr un doble objetivo. Por una parte, buscaba controlar esa estratégica zona del Sureste de Iberia, esencial por formar parte de las rutas por las islas Baleares a Cerdeña e Italia y por Ibiza a Sicilia y Cartago. Pero no menos importante es que esta zona controlaba, como se ha indicado, dos vías terrestres de gran importancia estratégica: la Vía Salaria Ibérica, que desde la desembocadura del río Segura llegaba hasta la Celtiberia Meridional, ruta convertida en época romana en la Vía de Carthago Nova a Complutum, y otra vía que alcanzaba Andalucía Oriental remontando el río Segura o el Guadalentín, objetivo que también podía alcanzarse desde las planicies de Albacete por el río Jardín (vid. supra). En efecto, en esta nueva estructuración del comercio ampuritano destaca la actividad de la Vía Salaria Ibérica que, por el valle del río Vinalopó, llegaba hasta la vía Heraclea en el importante nudo de comunicaciones del Sureste con la Meseta que representaba Pozo Moro, pues controlaba el paso hacia la Andalucía Oriental y hacia el interior de la Meseta (Almagro-Gorbea, 1983a: 182), lo que explica la aparición de las ricas importaciones del ajuar de Pozo Moro, del Schnabelkanne de la Provincia de Cuenca, del jarrito de bronce de Haza del Arca y del ánfora de Segobriga (vid. supra), además de los hallazgos que indicarían que para alcanzar Andalucía Oriental desde el Sureste se prefería el Valle del Vinalopó y la Vía Heraclea a la vía del Segura (Rouillard et al., 2007: 505).

La Vía Salaria Ibérica hacia la Celtiberia era de gran importancia estratégica, ya que controlaría el comercio de la sal, esencial para el ganado y sus productos derivados, como pieles y jamones, cecinas, etc. El interés estratégico de esta vía aumentaría en esos años al ser utilizada por los mercenarios celtíberos, que tan importante papel jugaron en los conflictos del Mediterráneo Central a partir del siglo V a. C. (García Bellido, 1952; García Gelabert y Blázquez, 1987-1988; Quesada, 2009; Graells, 2014; Marín, 2016). A su vez, la vía hacia Andalucía Oriental se asociaba a intereses económicos y relaciones políticas, entre los que se incluiría la obtención de la plata de la zona minera de Castulo (Ramon et al., 2011). Estos intereses se reflejan en los influjos jonios llegados a Andalucía Oriental 
desde el Sureste a partir de inicios del siglo $\mathrm{V}$ a. C. (Almagro-Gorbea y Lorrio, 2007; Almagro-Gorbea et al., 2019), entre los que destaca la plástica jonio-ibérica (Fig. 8), los signa equitum ibéricos (Fig. 13,1 y 2,A) $\mathrm{y}$, ya en fechas más tardías, la llegada de cerámicas áticas, probablemente desde Ampurias en esta nueva fase expansiva el comercio focense, que alcanzará su auge en el siglo IV a. C.

El impacto de este horizonte comercial del 500 a. C. no fue sólo económico, pues bronces y vasos áticos testimonian nuevos elementos culturales e ideológicos. Destaca el creciente consumo ritual de vino entre las elites ibéricas. Los kylikes de forma $\mathrm{C}$ sustituyen las raras copas jonias de tipo B2, al tiempo que se constata la difusión entre la elite de cultos dionisíacos, que suponían nuevas concepciones cosmológicas, de fecundidad, de heroización y de la vida y la muerte. Lo testimonia la danza orgiástica de oklasma del joven desnudo del kylix de Pozo Moro, propia de comastas relacionados con el culto a Dionisos (Schauenburg, 1981: 86; Deonna, 1953: 6 s.; Todisco, 2007), que en Grecia se asocia a cultos heroicos (Schweizer, 1936: 291-292) y en Oriente, de donde procedía, a ceremonias funerarias y a banquete en cortes y templos. La asimilación de estas danzas por los íberos perdura tres siglos después en el saltimbanqui representado en un monumento turriforme funerario de Osuna de fines del siglo II o primera mitad del siglo I a. C. (García Bellido, 1943: 131 s., lám. 35; Rouillard, 1997: 35). El simbolismo de estas danzas se asociaba al culto a Dionisos como divinidad taumatúrgica y ctónica de la felicidad en esta vida y en el Más Allá. También la escena del thiasos de Dionisos del lekythos de Pozo Moro, decorado con sátiros y ménades, alude a estos mitos orgiásticos dionisíacos (Almagro-Gorbea, 1983a: lám. 15), lo mismo que el sátiro del Llano de la Consolación (García Bellido, 1948: lám. 26), mientras que en la pelike de Cabezo Lucero las hileras de hojas de hiedra que adornan el campo y las cabezas de los personajes aluden igualmente a temas dionisíacos.

En consecuencia, estos vasos de calidad del horizonte del 500 a. C. indican que las elites del Sureste de Iberia asimilaron ritos y creencias dionisíacas desde el último cuarto del siglo VI a. C. (Olmos y Sánchez, 1995: 113), como confirman los jarros de bronce (Graells, 2008) y el ajuar de Pozo Moro, en el que la elección de temas fue intencionada, lo que supone que las elites ibéricas adoptaron nuevas concepciones religiosas, seguramente introducidas por los focenses, como indican estos objetos. Esta introducción del culto dionisíaco en Iberia resulta poco posterior a la de Etruria (Werner, 2005: 75) y parece contemporánea a la de Roma (Daremberg y Saglio, 1877: 636 s.), donde el culto oficial a Dionisos como Liber Pater fue introducido el 496 a. C. (Dion. Hal. VI, 17; Tac. ann. II,49; Bruhl, 1953: 13 s.).

Este horizonte dionisíaco del 500 a. C. es el precedente de las numerosas importaciones de cerámicas áticas con temas dionisíacos de fines del siglo $\mathrm{V}$ y del
IV a. C. (Villanueva, 1987; Olmos y Sánchez, 1995: 123 s.; Domínguez Monedero y Sánchez, 2001: passim) y sus ritos orgiásticos pudieron continuar, helenizada, la hierogamia orientalizante representada en Pozo Moro hacia el 500 a. C. (Almagro-Gorbea, 1983a: 204, lám. 26; López Pardo, 2006: 96 s.), sustituida por representaciones del tardo arcaísmo griego en los vasos áticos citados, en el sátiro itifálico del Llano de la Consolación (García Bellido, 1948: 91 s., lám. 26; Olmos, 1977; Shefton, 1982: 362, n. 69; Rouillard, 1997: 186, n. $^{\circ}$ 296) y en la escultura del onanista del heroon de Obulco, Porcuna, Jaén, hacia el 480 a. C. (González Navarrete, 1987: 121 s., n. ${ }^{\circ}$ 19; Negueruela, 1990: 245 s.). Estos elementos orgiásticos, que perduran en algunos exvotos ibéricos (Álvarez Ossorio, 1941: lám. 123, n. ${ }^{\circ} 1662$, etc.), se asociarían a mitos locales, como ya intuyó Negueruela (1990: 245), con simbolismo cosmológico y escatológico, de fecundidad, felicidad y pervivencia en el Más Allá, pues beber vino da fuerza, al tiempo que produce la embriaguez como estado de trance que aproxima al éxtasis y al Otro Mundo.

\section{LOS PILARES-ESTELA Y LA INTRODUC- CIÓN DE LA PLÁSTICA JONIO-IBÉRICA}

La nueva política colonial jonio-focense se refleja también en la aparición y difusión en esas fechas por el Sureste de un estilo jonio-ibérico en esculturas y bronces que sustituye al orientalizante precedente, en especial en la zona de Elche, estilo que se hace patente en los pilares-estela y en los animales que los remataban (Almagro-Gorbea, 1983b; Izquierdo, 2000: 67 s.).

El pilar-estela es un monumento funerario de origen sirio-fenicio (Almagro-Gorbea, 1983b; Almagro-Gorbea y Torres, 2010: 287 s., fig. 242), no documentado en Focea ni en las áreas focenses de Massalia, Elea y Emporion. Su origen oriental lo confirma tanto la sirena de la necrópolis de Villaricos, que estaría dispuesta sobre un pilar-estela fenicio con gola (Almagro-Gorbea y Torres, 2006; 2010: 279 s.), como el monumento representado en la estela de Arados (Perrot y Chipiez, 1885: 73; Moscati Ed., 1988: 300). Estos monumentos, rematados por una esfinge, una sirena, un león o un toro, tuvieron amplia aceptación en el mundo indígena y se generalizan entre las elites del Sureste (Almagro-Gorbea, 1983b; Izquierdo, 2000), pues, ubicados en cruces de camino y en puntos destacados del paisaje, resaltaban el prestigio del dinasta heroizado, en torno al cual surgía la necrópolis gentilicia de sus descendientes, como ocurre en Cabezo Lucero (Aranegui et al., 1993: n. ${ }^{\circ} 40,42,51$ ) o en Pozo Moro (Alcalá-Zamora, 2004).

Los focenses aprovecharon esta tradición funeraria, pues hacia el 500 a. C. artesanos jonios introdujeron elementos estilísticos greco-orientales (AlmagroGorbea, 1983b; Almagro-Gorbea y Torres, 2010: 374 s.). Los toros, leones, esfinges y sirenas orientalizantes 
de origen fenicio que coronaban los monumentos fueron paulatinamente sustituidos por animales con formas jonias introducidas por artesanos focenses y las golas de origen fenicio adoptaron molduras jonias (Almagro-Gorbea, 1983a: 262; Izquierdo, 2000: 75 s.; Almagro-Gorbea et al., 2004: n. ${ }^{\circ}$ 363-365), con contarios, ovas y cimacios lésbicos (Ganzert, 1983; Altekamp, 1991), molduras que pasan a ser características de estos monumentos jonio-ibéricos del Sureste (Almagro-Gorbea et al., 2015-2016: fig. 10), como el pilar-estela de Monforte del Cid, con un magnífico toro de estilo jonio tardo-arcaico (Almagro-Gorbea y Ramos Fernández, 1986; Blech, 2001: 621, lám. 218; contra, Prados, 2007), dispuesto sobre una gola con cimacio lésbico. La misma fecha en coincidencia con el horizonte de importaciones del 500 a. C. ofrecen algunas estelas rematadas en palmetas arcaicas (Izquierdo, 2000: fig. 65 y 70:1).

El estilo del arcaísmo final de las molduras y esculturas de estos pilares-estela se data a fines del siglo VI a. C., lo que coincide con el horizonte de importaciones de c. 500 a. C. (Almagro-Gorbea, 2009b), aunque estos monumentos perduraron a lo largo del siglo $\mathrm{V}$ a. $\mathrm{C}$. hasta desaparecer en las crisis políticas e ideológicas de la sociedad ibérica (Almagro-Gorbea, 2009a). Un ejemplo es la necrópolis de Cabezo Lucero, situada a pocos kilómetros de La Fonteta, en Guardamar del Segura, con fragmentos de toros y de un león, cimacios con ovas y dardos, cornisas de gola y una estela en forma de palmeta que corresponden a un mínimo de 6 pilares-estela rematados con un animal dispuesto sobre una gola (Llobregat, 1993: 76-81). Todos aparecieron muy dañados, probablemente por ritos de damnatio memoriae, frecuentes en muchos monumentos ibéricos. Uno de estos pilares-estela, el $C L 1$, con un ave rapaz, una palmeta jonia arcaica y un bóvido (Aranegui et al., 1993: 80, lám. 54-58) se asocia a la valiosa pelike de Eucharides (Almagro-Gorbea, 2009b), por lo que debió ser una de las tumbas más antiguas, fechada $c .490$ a. C.

En los pilares-estela del Sureste predominan los toros de estilo jonio-ibérico, como los de Monforte del Cid, Cabezo Lucero, la Cala de Benidorm y Agost, que siguen modelos del arcaísmo final, lo que lleva a fecharlos del 500 a. C. en adelante, aunque también hay toros orientalizantes que incorporan el nuevo estilo jonioibérico (Almagro-Gorbea y Torres, 2010: 382-384, Tipo C), como los de El Molar y Redován. Las esfinges y sirenas igualmente sustituyen las formas fenicias que ofrece la esfinge del Parque Infantil de Elche (Chapa, 1980: 188 s., fig. 4.16, lám. 12; Ramos Fernández y Ramos Molina, 1992: 35 s., fig. 6-7, lám. 12; Chapa y Belén, 2011), por el nuevo estilo jonio-ibérico que presentan las esfinges de Agost, Bogarra, Corral de Saus y el Llano de la Consolación, y la sirena de El Monastil, probablemente emplazada en un pilar estela sobre una gola con volutas (Izquierdo, 2000: 142-144, fig. 61-62; Poveda, Soler y Márquez, 2002). A estas piezas se puede añadir la llamada Bicha de Balazote, aunque también existen piezas de estilo mixto, como las de El Salobral en Albacete y Alarcos en Ciudad Real (Chapa, 1980: passim; Almagro-Gorbea y Torres, 2010: 385 s.).

Este cambio estilístico refleja influjos focenses, señalados en la escultura desde hace más de 50 años (Blanco Freijeiro, 1960: 110 s.; Langlotz, 1966; Kukahn, 1967; Almagro-Gorbea, 1982; AlmagroGorbea y Ramos Fernández, 1986; Chapa, 1986: 239; Blech y Ruano, 1992; etc.). Este cambio permite diferenciar una plástica "tartesio-ibérica» orientalizante, derivada de prototipos sirio-fenicios, documentada desde el siglo VII hasta fines del VI a. C., de la escultura «jonio-ibérica» (Almagro-Gorbea y Torres, 2010: 366 s.), desarrollada a partir de c. 500 a. C. o poco antes, pues al cambio estilístico se asocia la sustitución de los modelos orientales fenicios por modelos griegos, como evidencia la comparación del monumento y los relieves orientalizantes de Pozo Moro, de c. 500 a. C. (Almagro-Gorbea, 1983a: 235 s.) con el heroon de estilo jonio arcaico de Porcuna, de c. 480 a. C. (González Navarrete, 1987; Negueruela, 1990), apenas una generación posterior.

Este estilo jonio-ibérico caracteriza las mejores esculturas ibéricas de los primeros decenios del siglo $\mathrm{V}$ a. C. Alguna pieza se debe atribuir a artesanos griegos, como la soberbia leona arcaica de La Alcudia de Elche (Chapa, 1980: 192 s.), recientemente interpretada como un león ${ }^{12}$ (Fig. 8,3), la cabeza femenina de la provincia de Alicante (Fig. 8,1) (Blech, 2001: lám. 217; Verdú, 2009), la esfinge de Agost (Fig. 8,4) del Museo Arqueológico Nacional (García Bellido, 1948: 135 s., lám. 63; Chapa, 1985: 40, lám. 3) y el grifo de Redován (Fig. 8,2), todas ellas de Alicante (Chapa, 1980: 223 s., fig. 4.25; 1985: 52, lám. 7; 1986, 211 s.), que pueden datarse hacia el 500 a. C. Ya una generación posterior, c. 480-470 a. C., es el gran conjunto del Heroon de Porcuna (Fig. 8,5), en la antigua Obulco (Negueruela, 1990) y la Dama de Elche (Figs. 8,6 y 12), cuyo estilo severo permite datarla $c .470-460$ a. C. Otras esculturas, como la esfinge de Agost del Louvre (Chapa, 1980: 135 s.; 1985: 41), el león de La Alcudia de Elche (Fig. 11,5) (Chapa, 1980: 171 s.), la cabeza femenina de Úbeda la Vieja (Blech y Ruano, 1992; Blech, 2001: fig. 249), la leona de Bocairente (Chapa, 1985: 35) o el jinete completo de Los Villares, que todavía mantiene elementos estilísticos orientalizantes (Blánquez, 1997; Blánquez y Sanz Gamo, 2010; Blech, 2001: 612, lám. 207), son de estilo jonio-ibérico, pero algunas ofrecen características mixtas, propias de una fase de transición, como el león orientalizante con elementos de estilo jonio-focense de Coy (Chapa, 1980: 260 s., fig. 4.36, lám. 26; 1985: 57, lám. 5). También es significativa la aparición de esculturas ecuestres, como la citada de Los Villares de $c$. 500-490 a. C. (Blánquez, 1993: 117-118; 1997; Blech, 2001, lám. 207; Blánquez y Sanz Gamo, 2010), del

12. Agradecemos a T. Chapa y a M. Pérez Blasco la información sobre su trabajo en proceso de elaboración. 


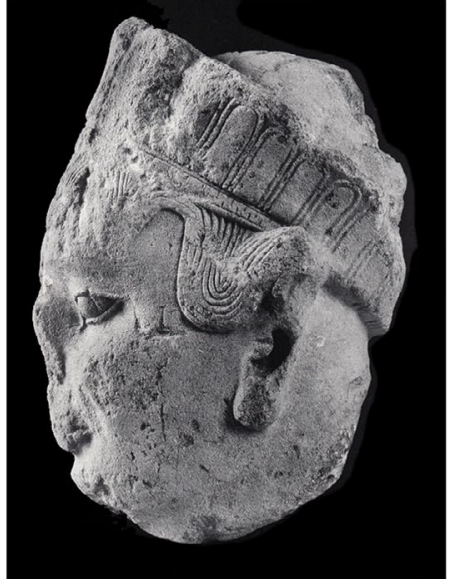

1

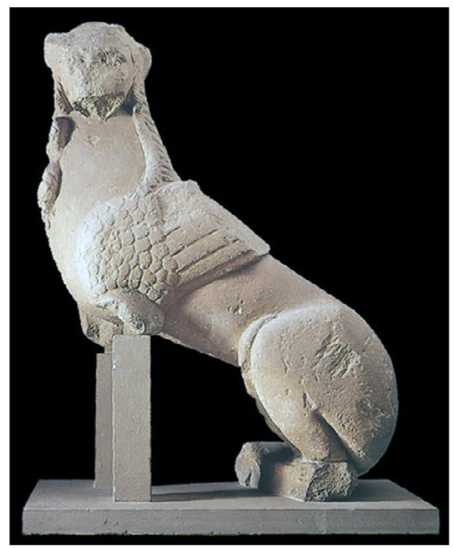

4

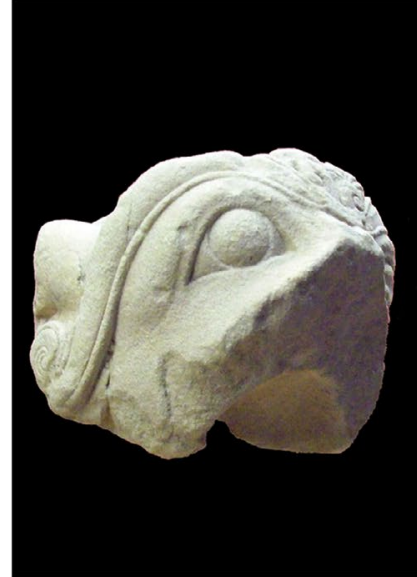

2

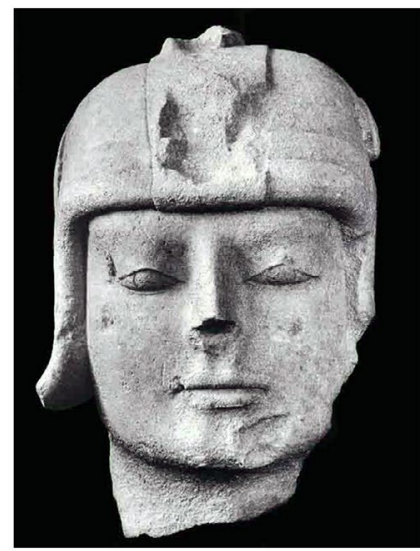

5

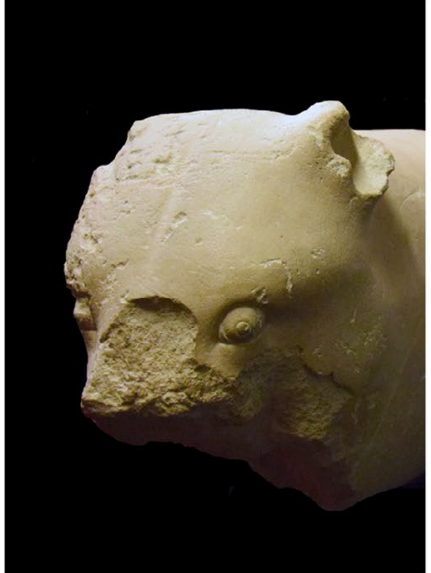

3

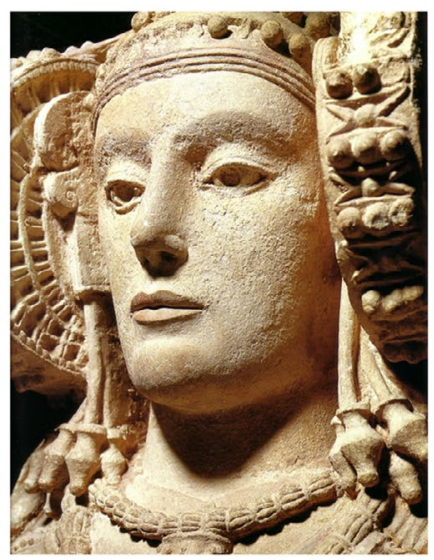

6

Figura 8: Escultura jonio-ibérica de fines del siglo VI e inicios del V a. C.: 1, Cabeza femenina de la Provincia de Alicante; 2, Grifo de Redován; 3, Leona del Parque Infantil de Elche; 4, Esfinge de Agost en el Museo Arqueológico Nacional; 5, Cabeza de guerrero del heroon de Porcuna, Jaén; 6, Dama de Elche. (Según: 1 y 5, Foto Peter Witte, DAI Madrid; 2 y 4, Foto MAN; 3, Foto Museo Arqueológico y de Historia de Elche «Alejandro Ramos Folqués» - MAHE; 6, Foto Domínguez)

heroon de Porcuna, de c. 480 a. C. (Negueruela, 1990), o el caballo de Casas de Juan Núñez (Chapa, 1985: 63 y 273 foto 12; Blech, 2001: lám. 219), éste ya datado hacia el 450 a. C. A este mismo horizonte estilístico parecen corresponder las «Damitas de Mogente» (AlmagroGorbea, 1987; Almagro-Gorbea y Torres, 2010: 122 s.), cuyo chitón con pariphé central y pliegues curvos a los lados refleja una moda de origen frigio (Prayon, 1987: 41 s.) llegada desde Lidia a Focea, modelo que debió ser introducido por un artesano focense del tercer cuarto del siglo VI a. C., posterior a la conquista de Focea el 545 a. C. y a la batalla de Alalia c. 540 a. C. (Hdt. I, 163-164, 166,2), pues este vestido, que también lleva la Diosa de Carmona de c. 550 a. C. (Almagro-Gorbea y Torres, 2010: 122 s.), desaparece en el último tercio del siglo VI a. C. con el International Style del arcaísmo tardío (Gombrich, 1962: 99 s.; Ridgway, 1977: 90). El mismo estilo ofrecen igualmente los mejores bronces ibéricos de Sierra Morena (Nicolini, 1969; 1977), como los del «taller de los rizos largos», fechados a partir del 490 a. C., entre ellos «el guerrero sacrificando un carnero» de la Puerta de Segura (Almagro-Gorbea y
Lorrio, 2011: 28 s.) y los mejores signa equitum de tipo «Jinete de La Bastida» (Almagro-Gorbea et al., 2019) (Fig. 13,1 y 2,A-B).

Esta asimilación de los influjos helénicos focenses asociada a alianzas filohelenas, como denotan las importaciones y monumentos jonio-ibéricos hacia el 500 a. C., se vería favorecida por un substrato ideológico indoeuropeo originario de los Campos de Urnas afín al mundo griego arcaico, que se analiza más adelante. Pozo Moro refleja también ese cambio ideológico. El monumento es obra de artesanos fenicios, como evidencia su arquitectura, su estilo y su iconografía (Almagro-Gorbea, 1983a; López Pardo, 2006), pero el kylix, el lekythos y el Schnabelkanne del ajuar, datados hacia el 500 a. C., proceden del comercio focense e indican creencias en la heroización y en mitos dionisiacos llegados del mundo heleno (Almagro-Gorbea, 1983a: 185 y 265, lám. 15, a-b; 2009a; Graells, 2008). Los mejores monumentos escultóricos jonio-ibéricos, introducidos por artesanos jonios al servicio de los intereses coloniales focenses, reflejan las mismas influencias coloniales. Estos artesanos, capaces de 
construir los mejores monumentos y de formar talleres indígenas a cambio de beneficios políticos y económicos, serían los «bienes de prestigio» más preciados en las relaciones comerciales y políticas entre los focenses y las elites indígenas que las cerámicas, bronces, vinos y perfumes (vid. también Domínguez Monedero, 1984: 154 s. y 158). La alta calidad del heroon de Porcuna o de la Dama de Elche resaltaría el prestigio social y político del dinasta, quien podría costearlo por su mayor poder económico y político.

Estos artesanos jonios introducirían novedades estilísticas y formarían talleres locales, lo que permitió a la escultura ibérica seguir las grandes corrientes artísticas circunmediterráneas del arcaísmo final. Pero pronto aparecen talleres locales independientes de los centros coloniales, pues dependerían de las elites ibéricas, seguramente regias, como evidencian los heroa de Ilici y de Obulco (Negueruela, 1990; Almagro-Gorbea, 1999). Estos talleres acrecentarían el poder político y económico de los dinastas regios al resaltar su autoridad respecto a aristócratas y reguli menores que integraban la pirámide social del territorio controlado por medio de relaciones políticas y económicas clientelares. Obras como el heroon de Porcuna o la Dama de Elche pueden considerarse encargos específicos a artesanos jonios al servicio de los reges ibéricos que controlaban las vías de comunicación, en cuyos puntos estratégicos se situaban los monumentos como símbolo de su poder y del control del comercio con los pueblos coloniales, en este caso con los focenses. En consecuencia, la escultura ibérica sería un elemento de máximo prestigio y tendría claras implicaciones políticas, comparables a las importaciones suntuarias del Mediterráneo llegadas a las elites regias celtas, como la crátera de Vix (Mohen et al., 1988; Brun, 1987: 96 s.; Rolley (Ed.), 2003; Fougère, 2016), pues serían verdaderos «regalos políticos» a dinastas indígenas para facilitar alianzas que se traducirían en beneficios comerciales y políticos con los pueblos coloniales ( $c f$. Domínguez Monedero, 1984: 155). En consecuencia, los monumentos jonioibéricos serían el instrumento para establecer alianzas políticas que facilitarían a los focenses obtener beneficios económicos, mercenarios y apoyo logístico en los conflictos coloniales, sin olvidar que este proceso de helenización, que indica un realineamiento político de las elites ibéricas basado en una nueva concepción ideológica filohelénica, trajo aparejado un aumento en la prosperidad en el Sureste y en Andalucía Oriental, que se refleja en estos monumentos escultóricos y en la mayor riqueza de las necrópolis a partir del 450 a. C. (Izquierdo, 2009: 10, tabla 3).

En resumen, a fines del siglo VI a. C. se introdujo en el Sureste un estilo jonio en la plástica ibérica que se generalizó y penetró rápidamente hacia el interior de la Meseta (Blánquez, 1995; 1997) y hacia Andalucía Oriental, como evidencia el heroon de Obulco (Negueruela, 1990: 302-303; Almagro-Gorbea, 1996: 93; Almagro-Gorbea et al., 2004: 228 s.). Este nuevo estilo denota un ambiente filoheleno que alcanzó el centro de Andalucía y que parece ir asociado a movimientos militares que documenta la expansión de «Jinetes de tipo La Bastida», como se analiza más adelante (Almagro-Gorbea et al., 2019: fig. 23).

\section{LA INTRODUCCIÓN DE LA ESCRITURA GRECO-IBÉRICA}

Otro testimonio de las intensas relaciones de los focenses con las poblaciones del Sureste, especialmente en el campo comercial, es la llamada escritura «greco-ibérica» (Fig. 9), identificada por Manuel Gómez Moreno (1922) al estudiar el Plomo de La Serreta de Alcoy. De esta escritura greco-ibérica, repetidas veces analizada (Maluquer de Motes, 1968; Untermann, 1990: 133; de Hoz, 1987; 1998; 2009; 2010-2011: 175 s.; Rodríguez Ramos, 2001: 21 s.; 2004: 137 s.; 2005: 24 s.; Velaza, 2011), se conocen unos treinta de epígrafes aparecidos en la actual provincia de Alicante y el norte de Murcia (Rodríguez Ramos, 2001: 21 s.). Son grafitos cerámicos y tablillas de plomo relacionadas con documentos comerciales, que se datan desde el siglo IV hasta la segunda mitad del III a. C.

Maluquer de Motes (1968: 90 s.) y Untermann (1990: 133, n. 5) observaron que esta escritura procede de un alfabeto jonio tardoarcaico originario de la Grecia Oriental, que atribuyeron a Focea. La introducción de esta escritura en el Sureste, de la que sólo se conocen 16 signos, ha sido muy discutida, pues no hay testimonios posteriores al siglo $\mathrm{V}$ a. C. en los alfabetos griegos para algunos de los signos que forman parte de la misma (Jeffery, 1990: 287 y 340 s.). Así, el signo eta abierto en forma de $\mathrm{H}$ con valor de «e» se documenta en ciudades jonias del Asia Menor desde mediados del siglo VII hasta mediados del V a. C. (Jeffery, 1990: 28) y el signo sampi (Foat, 1905; 1906; Jeffery, 1990: 38

\begin{tabular}{|c|c|c|c|c|c|}
\hline $\mathrm{A}$ & $A$ & $\mathrm{G}$ & $\Gamma$ & $\mathrm{s}$ & $\mathbb{T}$ \\
\hline $\mathrm{E}$ & $\mathrm{H}$ & $\mathrm{K}$ & $\mathrm{K}$ & $\mathrm{s}$ & $\Sigma$ \\
\hline $\mathrm{I}$ & $\mathrm{I}$ & $\mathrm{T}$ & $\mathrm{T}$ & $\mathrm{R}$ & $D^{\prime}$ \\
\hline $\mathrm{O}$ & $\diamond$ & $\mathrm{D}$ & $\Delta$ & $\mathrm{R}$ & $D$ \\
\hline $\mathrm{U}$ & $\vee$ & $\mathrm{B}$ & $\mathrm{B}$ & $\mathrm{L}$ & $\wedge$ \\
\hline
\end{tabular}

Figura 9: Alfabeto jonio-ibérico del Sureste. (Según http://hesperia.ucm.es/) 
s.; Woodard, 1997: 179; Ghinatti, 1999: 39-42), probablemente derivado de la samekh fenicia y situado en el alfabeto griego detrás del ómega, se usó desde mediados del siglo VII hasta el $\mathrm{V}$ a. C. en poblaciones jonias del Asia Menor, además de en Náucratis, en la colonia milesia de Cícico y en colonias jonias del Mar Negro (Jeffery, 1990: 39, 325 y 368; Dana, 2009: 74 s.; del Barrio, 2018: 515). En Occidente aparece en ambientes jonios de la Magna Grecia y de Sicilia (Dubois, 1989: 9, n. ${ }^{\circ}$ 1, etc.) fechados desde el siglo VI hasta la segunda mitad del V a. C., pero la mayoría de los testimonios sículos son de inicios del siglo $\mathrm{V}$ a. C., aunque aún aparece en acuñaciones massaliotas datadas con dudas $c$. 425-400 a. C. (Jeffery, 1990: 464; Willi, 2008: 419 s.).

Sin entrar en un análisis epigráfico profundo, el carácter arcaico de los signos eta y sampi indica que su introducción no pudo ser posterior a inicios del siglo $\mathrm{V}$ a. C., aunque los primeros epígrafes documentados en escritura greco-ibérica sean del siglo IV a. C. Rodríguez Ramos (2001: 21) ha relacionado su introducción con «el 'boom'de importaciones áticas» de finales del siglo $\mathrm{V}$ a. C., pero en esa época ya habría desaparecido el uso de la sampi. En consecuencia, la introducción de esta escritura jonia tardo-arcaica en el Sureste se debe de relacionar con los contactos comerciales y fuertes influjos jonios a inicios del siglo $\mathrm{V}$ a. C. que testimonian los hallazgos arqueológicos y que confirma el contexto histórico, contexto que explica la introducción de este alfabeto greco-ibérico en el Sureste.

\section{EL CONTEXTO HISTÓRICO: LA «CRISIS DEL 500 A. C.» EN LOS CONFLICTOS COLONIALES DEL MEDITERRÁNEO OCCIDENTAL}

El asentamiento fenicio de La Fonteta se abandona en el tercer cuarto del siglo VI a. C., al mismo tiempo que el gran núcleo indígena de Peña Negra (vid. supra). Estos abandonos indican un periodo de inseguridad en la segunda mitad del siglo VI a. C. que se refleja igualmente en la disminución de importaciones griegas en La Fonteta en esos años. Sin embargo, a fines del siglo VI a. C., se constata una repentina revitalización de la actividad focense en el Sureste, en un momento histórico muy determinado. Hacia el 500 a. C. coinciden el horizonte de importaciones suntuarias con la introducción del estilo jonio-ibérico en la plástica y de la escritura greco-ibérica, lo que hace suponer que el control de la Vía Salaria Ibérica pasó al mundo focense, a la vez que se observa un profundo cambio ideológico con la asimilación de influencias filohelenas. Es evidente que tras el abandono y desaparición de La Fonteta y Peña Negra entre el 540-520 a. C., el control de este territorio pasó del ámbito comercial y político fenicio a la órbita del comercio focense, organizado desde Ampurias y con Massalia como principal ciudad focense en Occidente. Este cambio trajo consigo una clara reestructuración del territorio (Fig. 10), que se transforma profundamente a finales del siglo VI a. C. al aparecer nuevos poblados, ya característicos de la cultura ibérica y de marcada tendencia helenizante, aunque tradiciones orientalizantes prosiguieron en esculturas y otros elementos.

Hacia esas fechas, en torno a finales del siglo VI a. C., surge el pequeño oppidum ibérico de El Oral, en el término de San Fulgencio, situado a 40 m s.n.m. en la prolongación suroriental de la Sierra del Molar. Es un pequeño asentamiento con una superficie en torno a 1 ha, rodeado de una muralla perimetral y dos torres cuadrangulares en el flanco norte que defenderían la puerta de acceso al poblado. Su urbanismo es regular, con viviendas adosadas a la muralla y abiertas a una calle que recorre longitudinalmente el poblado, junto a otras de disposición transversal que permiten individualizar grandes manzanas. Junto a viviendas sencillas se han identificado casas pluricelulares con patio de gran complejidad, que evidencian una clara jerarquización social (Abad y Sala, 1993: 233-241; Sala y Abad, 1994; Sala, 2001: 146; Grau y Moratalla, 2001: 195 s.; 2004: 109-118; Abad et al., 2003; Sala y Abad, 2006; Abad y Sala, 2009; Abad et al., 2017: 235 s.). Su inicio se ha fechado en el Ibérico Antiguo, hacia finales del siglo VI, abandonándose de forma pacífica en las «últimas décadas del siglo V a. C.» (Abad et al., 2017: 240), pues su población parece haberse trasladado al cercano poblado de La Escuera, de 2,5 ha, datado entre fines del siglo V y el siglo II a. C. y situado a unos $1500 \mathrm{~m}$ al occidente de El Oral, igualmente en el borde de la antigua área lagunar, entre sólo 7 y 14 m s.n.m. (Abad y Sala, 2001: 205). El Oral, por su posición estratégica próxima a la desembocadura del Segura, debió jugar a finales del siglo VI a. C. un importante papel como centro de los intercambios comerciales que hasta ese momento había ejercido La Fonteta (Abad y Sala (Eds.), 2001: 265; Sala y Abad, 2014: 604; Abad et al., 2017: 238), toda vez que su entorno era poco apto para actividades de subsistencia (Grau y Moratalla, 2001: 198).

El poblado de El Oral tenía su necrópolis a unos $600 \mathrm{~m}$ hacia el sur al pie de la vertiente meridional de la Sierra del Molar (Abad y Sala, 1993: 4), en un cerro situado a unos $30 \mathrm{~m}$ s.n.m. que domina la antigua albufera y las marismas del estuario del Segura y el remanso del río antes de desembocar en el mar cruzando las dunas litorales, entre el término municipal de San Fulgencio y el de Guardamar del Segura. La necrópolis de El Molar se desarrolla desde mediados del siglo VI a fines del V a. C. (Lafuente, 1929; Senent, 1930; Monraval, 1992; Sala, 1996; Peña, 2003). En ella apareció un pilar-estela rematado por un toro de factura antigua, datable $c .500$ a. C., y resulta significativa la ausencia de importaciones fenicias, a pesar de su proximidad al poblado de La Fonteta, situado justo enfrente, en la margen contraria del Segura, lo que confirma su posterioridad al asentamiento fenicio (vid. Graells y Bottini, 2017, con la discusión sobre la cronología de la necrópolis al atribuir a la misma un jarro rodio de mediados del siglo VI a. C., vid. supra). No obstante, en 


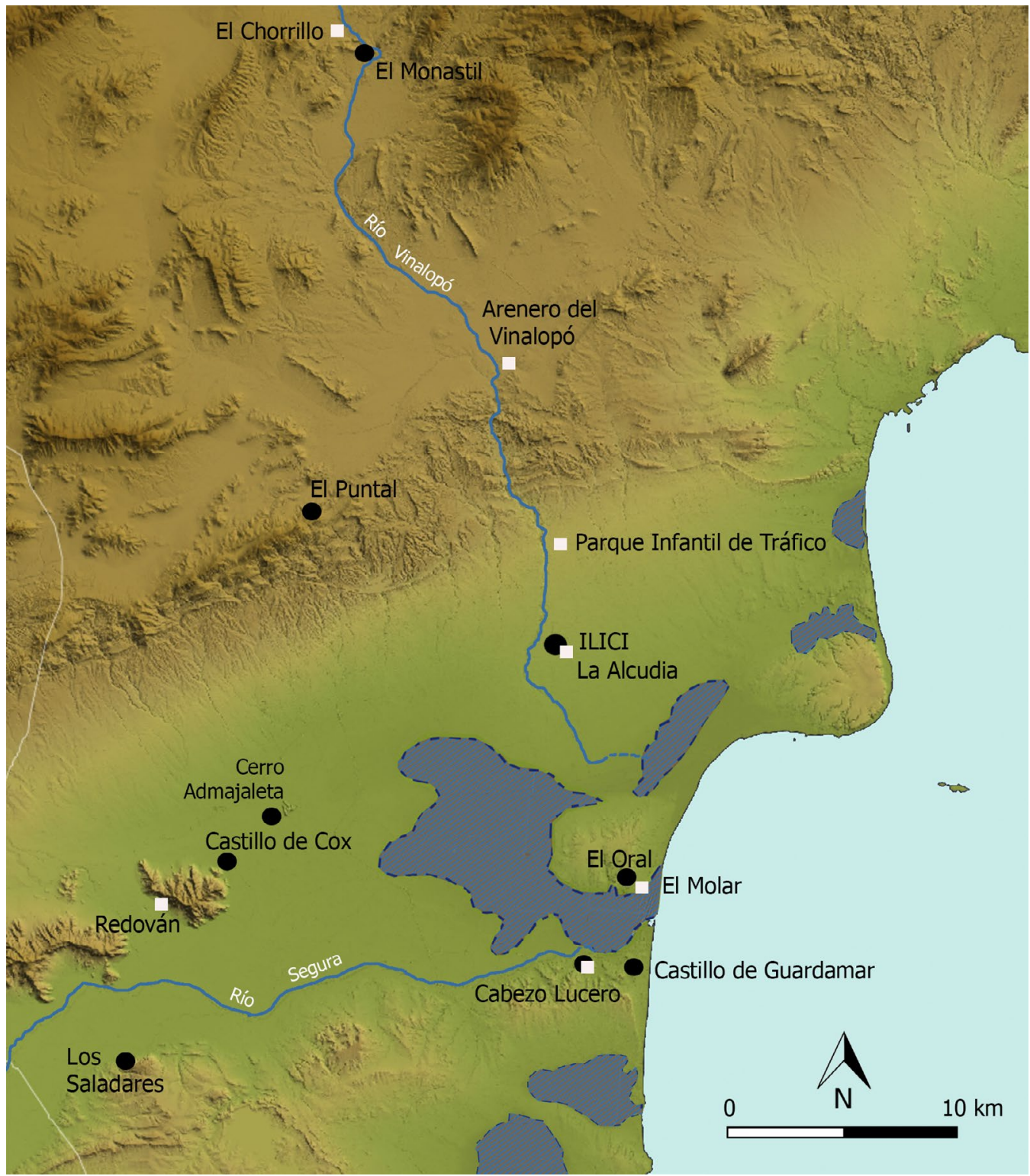

Figura 10: El poblamiento del Bajo Segura en el Ibérico Antiguo, con los yacimientos con elementos jonio-ibéricos (ca. 500 a. C.): Poblados $(\bullet)$ y necrópolis con esculturas $(\square)$. (Cartografía: S. Pernas)

esta necrópolis se documentan algunas piezas anteriores al último cuarto o tercio del siglo VI a. C., que pueden haber sido atesoradas y depositadas en contextos de cronología posterior, como suele ocurrir con objetos de prestigio, como un aríbalo naucratita (Padró, 1975: 138 s., fig. 2; Shefton, 1982: 359, nota 61), dos escarabeos (Padró, 1975: 136-138, lám. I), varios fragmentos de una copa ática de tipo Siana, fechada c. 550-530 a. C., atribuida al Griffin-bird Painter (Nordström, 1969: 27 s., n. ${ }^{\circ}$ 20-23; Rouillard, 1976: 8 s., lám. I: 1; Shefton, 1982: 355, nota 51, fig. 6:a) y, quizá, el asa de un jarro rodio, ya citada (Graells y Bottini, 2017).

También hacia el 500 a. C. surgen nuevos poblados ibéricos en la margen derecha del tramo final del río Segura (Grau y Moratalla, 2001: 196 s., fig. 115), de los que conocemos en ocasiones sus necrópolis, como es el caso de Cabezo Lucero, en el término de Guardamar del Segura. Es un pequeño asentamiento de algo menos de
1 ha situado sobre un espolón que domina el río Segura, cercano a la desembocadura del río, en el borde de la antigua albufera, probablemente navegable, frente al poblado de El Oral. En su necrópolis, situada al sur (Aranegui et al., 1993; Uroz y Uroz, 2010) han aparecido pilares-estela e importaciones griegas de prestigio que indican elites filohelenas (vid. supra) ${ }^{13}$. Aguas

13. Sin embargo, del campo de batalla de Himera (480 a. C.) proceden dos cnémides (Vassallo, 2010) como las halladas en Cabezo Lucero y Arroyo Judío (Cártama, Málaga), que reforzarían la vinculación con esta zona del Sureste de mercenarios ibéricos enrolados en las filas cartaginesas según las evidencias arqueológicas, ya que la participación directa de mercenarios iberos en estos grandes conflictos siempre fue en el bando cartaginés, pues no hay constancia en esas fechas de participación en el bando griego (Graells, 2014: 74; 2016: 41 s. y comunicación personal). 


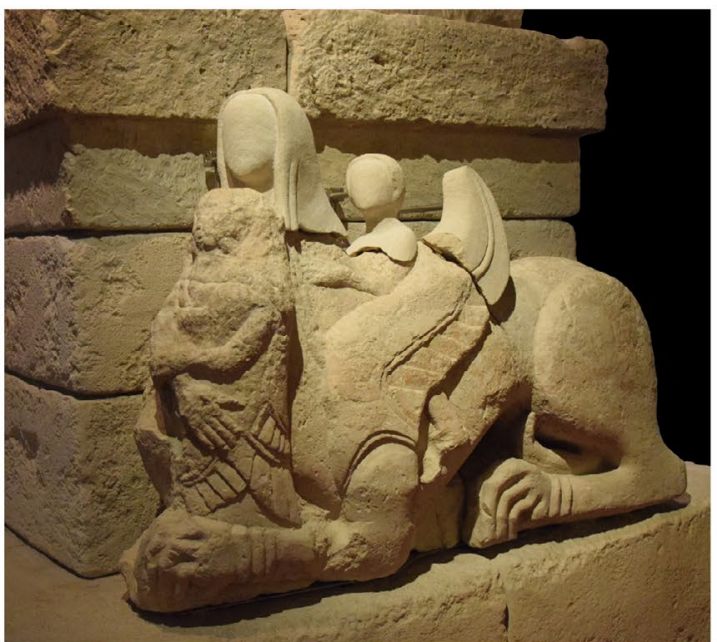

1

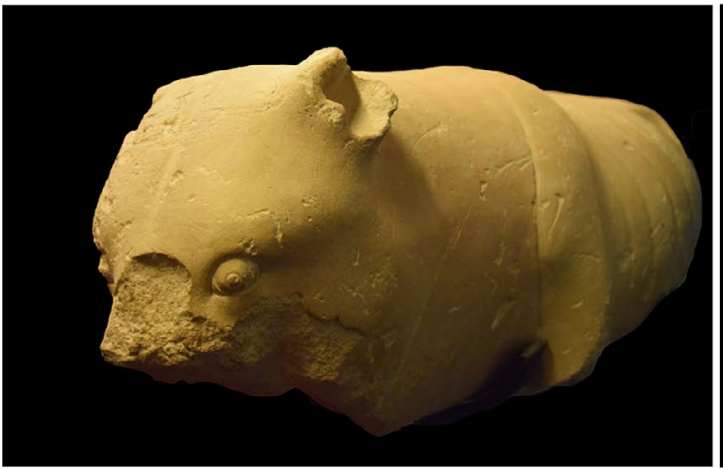

3

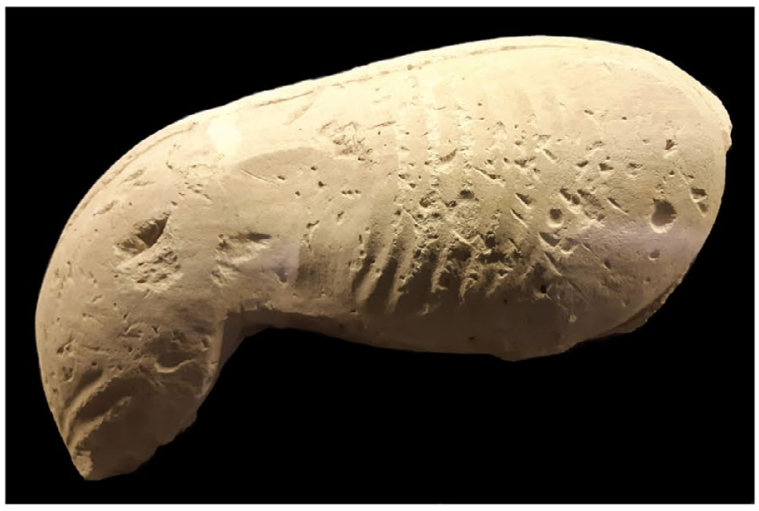

5

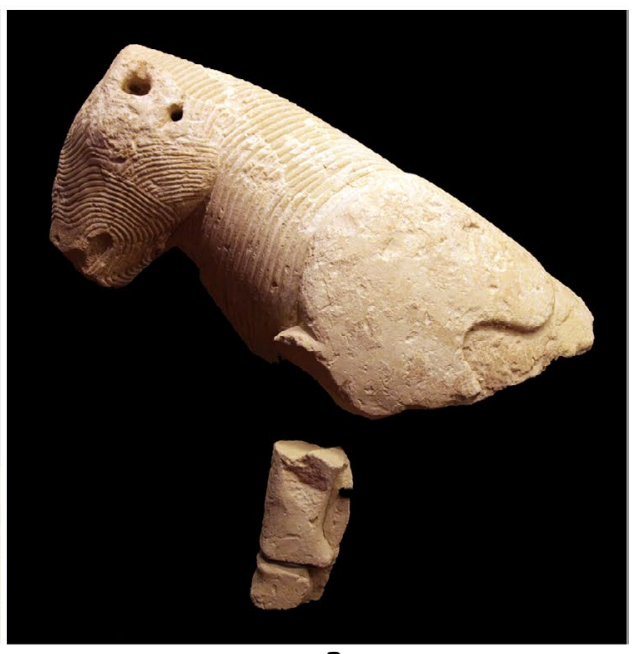

2

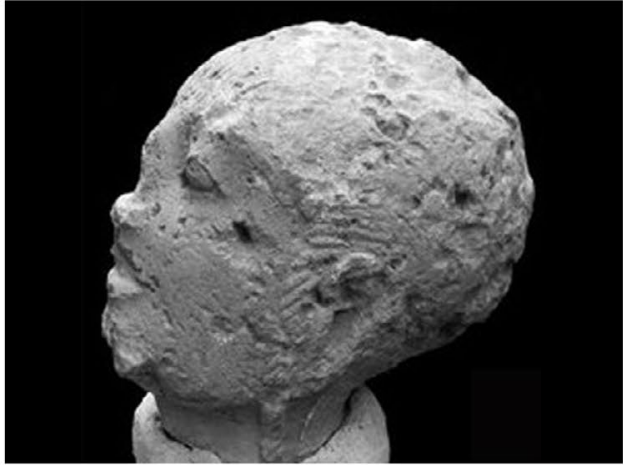

4

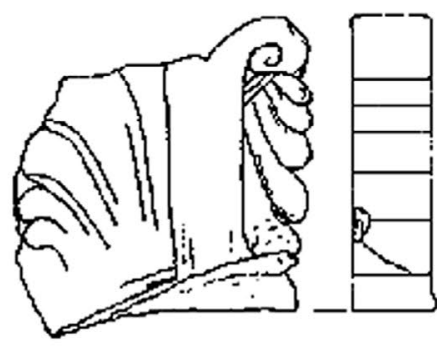

6

Figura 11: Esfinge y toro orientalizantes (1-2) y leona jonio-ibérica (3) del Parque Infantil de Elche. Esculturas (4-5) y palmeta (6) arcaicas de La Alcudia de Elche. (Según: 1-3, Foto Museo Arqueológico y de Historia de Elche «Alejandro Ramos Folqués» - MAHE; 4, Foto T. Chapa; 5, foto A. Lorrio; 6, Izquierdo, 2000: fig. 70: 1)

arriba, en el entorno de las sierras de Orihuela y Callosa existían pequeños poblados (Grau y Moratalla, 2001: fig. 114) como Los Saladares, cuya extensión debió ser notablemente mayor que en la actualidad, alcanzando época bárquida, según los datos de nuestras excavaciones de 2021, El Cabezo de la Aparecida, también en Orihuela, fechado en el siglo V a. C. e igualmente de reducidas dimensiones (Moratalla, 2004: 81 s.), o El Castillo de Santa Bárbara, en Cox, de unas 0,3 ha de superficie, con niveles que se remontan al siglo VI a. C. (Torres Salinas, 1995b; Moratalla, 2004: 136 s.).
Mayores dimensiones parece haber tenido Ladera de San Miguel, que podría ser un pequeño oppidum, hoy prácticamente destruido y muy mal conocido, cuya superficie se calcula en unas 2 ha (Moratalla, 2004: 82 s.). Ocupa un estratégico emplazamiento desde el Bronce Final hasta época romana, aunque los datos disponibles indican que sólo en época Ibérica Plena, hacia los siglos V-IV a. C., debió de convertirse en el principal asentamiento de la zona, entre Ilici, situada a unos $30 \mathrm{~km}$ al noreste, y el siguiente núcleo de importancia a unos $25 \mathrm{~km}$ al sureste que era el oppidum de 
Santa Catalina del Monte, Verdolay, Murcia, de unas 7 ha y con una amplia cronología del siglo VII al I a. C. (Ramos Martínez, 2018: 59-61, 105 s.). A estos asentamientos cabe añadir alguna necrópolis, como la de Redován (Moratalla, 2004: 83-85), de donde procede una espléndida cabeza de grifo jonio-ibérico de fines del siglo VI a. C. (Fig. 8,2) (Chapa, 1980: 223 s., fig. 4.25; 1986: 211 s.).

Sin embargo, el hecho más significativo en la transformación de la estructura de la población de este territorio debe considerarse la consolidación de La Alcudia de Elche, la antigua Ilici, que surge como nuevo centro del territorio y como lugar de control de la Via Salaria Ibérica, papel en el que sustituye al que tenían hasta el periodo orientalizante La Fonteta y Herna/Peña Negra. A la existencia de un espacio sacro, como evidencia el hallazgo de un capitel protoeólico, y de la escultura monumental aparecida en La Alcudia, debe añadirse el hallazgo en las excavaciones de 2017-2020 de una muralla de cajones atribuida al Ibérico Antiguo, lo que sugiere que La Alcudia/Ilici ya ofrecería una estructura urbana en un momento temprano del siglo $\mathrm{V}$ a. $\mathrm{C}$.

El capitel protoeólico se ha relacionado con el templo situado bajo la basílica paleocristiana (Ramos Fernández, 1995), en la que apareció reutilizado (Ramos Fernández, 1995: 12), lo que deja incierta su procedencia exacta (Peña, 2015: 536). Según sus excavadores, el templo presentaba dos fases constructivas, datándose la más antigua (A), con la que se relacionó el citado capitel, entre finales del siglo VI y finales del III a. C., aunque el material recuperado se ha considerado posterior a mediados del siglo V a. C. (Grau y Moratalla, 2001: 196). El templo más reciente (B), superpuesto al primero, se habría mantenido en uso hasta el último cuarto del siglo I a. C. El hallazgo de este capitel protoeólico es de gran interés, pues, en cualquier caso, se debe relacionar con la pareja de capiteles protoeólicos que se colocaban simbólicamente a la entrada a un espacio sacro, fuera un templo o una regia (AlmagroGorbea y Torres, 2010: 245 s., 253), como los hallados en La Quéjola, Albacete (Blánquez y Olmos, 1993), que deben de fecharse hacia el siglo VI a. C.

Más concluyentes son las esculturas. Éstas evidencian la existencia de un taller en Ilici desde fines del siglo VI o muy inicios del V a. C., inicialmente de estilo orientalizante, pero que muy pronto crea las mejores obras de estilo jonio-ibérico. En el Parque Infantil de Elche, a unos $5 \mathrm{~km}$ de La Alcudia, se levantó un monumento funerario turriforme (Fig. 11,1) (Ramos Fernández y Ramos Molina, 1992: 21-23, fig. 2) con una esfinge de estilo orientalizante (Ramos Fernández y Ramos Molina, 1992: 35 s., fig. 6-7, lám. 12; AlmagroGorbea y Torres, 2010: 385, fig. 293:e), aunque también había una escultura de toro de estilo tartesio-ibérico (Fig. 11,2) (Chapa, 1980: 183 s.; Ramos Fernández y Ramos Molina, 1992: 44-47, fig. 9-10, lám. 21; Almagro-Gorbea y Torres, 2010: 382, fig. 303:f) y una espléndida escultura de estilo jonio arcaico de leona o león fechable hacia el 500 a. C. (Fig. 11,3)
(Sala, 2007: 58, fig. 5:3; Almagro-Gorbea y Torres, 2010: fig. 293B). Todo ello sugiere la existencia de una necrópolis, aunque las esculturas y los elementos arquitectónicos aparecieron reutilizadas en un posible espacio cultual, sin que el material publicado permita precisar su cronología (Moratalla, 2004: 218-224). Este yacimiento debía depender de La Alcudia, de donde proceden piezas de estilo jonio arcaico de gran calidad, de inicios del siglo $\mathrm{V}$ a. C., como una escultura, hoy acéfala, de león o esfinge (Fig. 11,5) (Chapa, 1980: 171 s., fig. 4.13:1; Sala, 2007: 58, fig. 5:3), una palmeta (Fig. 11,6) (Izquierdo, 2000: 150, fig. 70:1, lám. 51), una cabeza femenina (Fig. 11,4) (Chapa y Belén, 2011: fig. 18:3) y la famosa Dama de Elche, la escultura más destacada de la estatuaria ibérica, que por su estilo severo se data $c$. 470-460 a. C. (Fig. 12).

Las cerámicas ibéricas halladas en La Alcudia se han fechado en el Ibérico Antiguo, de mediados del siglo $\mathrm{V}$ a. C. en adelante, por lo que se han relacionado con el abandono de El Oral (Tendero, 2005: 315), aunque algunos materiales permiten una datación, no segura, algo anterior, en la primera mitad del siglo $\mathrm{V}$ a. C., como las urnas de orejetas (Tendero, 2005: 309, fig. 5), las ollas de cocina a torno con incisiones o cordones en el hombro (Tendero, 2005: 313, fig. 10:2-3) y los anforiscos (Tendero, 2005: 307, fig. 2), que ya aparecen en el poblado de El Oral (Abad y Sala, 1993: 211, fig. 160, 222-224, fig. 167; Abad et al., 2001: 68, fig. $52: 5$, respectivamente), estando también documentados en La Picola, en contextos más recientes de finales del siglo V y la primera mitad del IV a. C., tanto las ollas, aunque ya sin incisiones en el hombro, pues sólo una tiene un cordón (Gailledrat y Rouillard, 2000: 166-167, fig. 58), como los anforiscos (Gailledrat y Rouillard, 2000: 155, fig. 41:6-7).

Por su parte, las producciones griegas del yacimiento ilicitano proporcionan una fecha de mediados o la segunda mitad del siglo V a. C., destacando las copas Cástulo y las copas de la Clase Delicada ${ }^{14}$, lo que resulta de gran interés para establecer su posible relación con El Oral, para el que se ha propuesto una fecha final en las últimas décadas del siglo V a. C. Esta

14. Al trabajo publicado por C. Sánchez (2004), cabe añadir la revisión de R. Esteve de un amplio lote descontextualizado de las producciones griegas de La Alcudia, a quien agradecemos la información. La totalidad de los vasos que forman este conjunto son de fábrica ática y de formas significativas de tipos variados con una cronología genérica en el siglo IV a. C. Las formas más antiguas incluyen varios ejemplares del sigo $\mathrm{V}$ a. C., como bordes y fondos de las denominadas copas Cástulo (Sparkes y Talcott, 1970: fig. 5, 471 —stemless inset lip-) con una cronología entre 470/450-400, las copas de la Clase Delicada (Sparkes y Talcott, 1970: fig. 5, 483, 484, 487 -stemless Delicate Class-), con una cronología genérica del 450-400 a. C., a falta de precisar en el estudio, un fragmento de pie de un bolsal (Sparkes y Talcott, 1970: fig. 6, 541) datable en el 425-400 a. C. y un fragmento de un asa de una neck-amphora posiblemente de finales del siglo $\mathrm{V}$. 


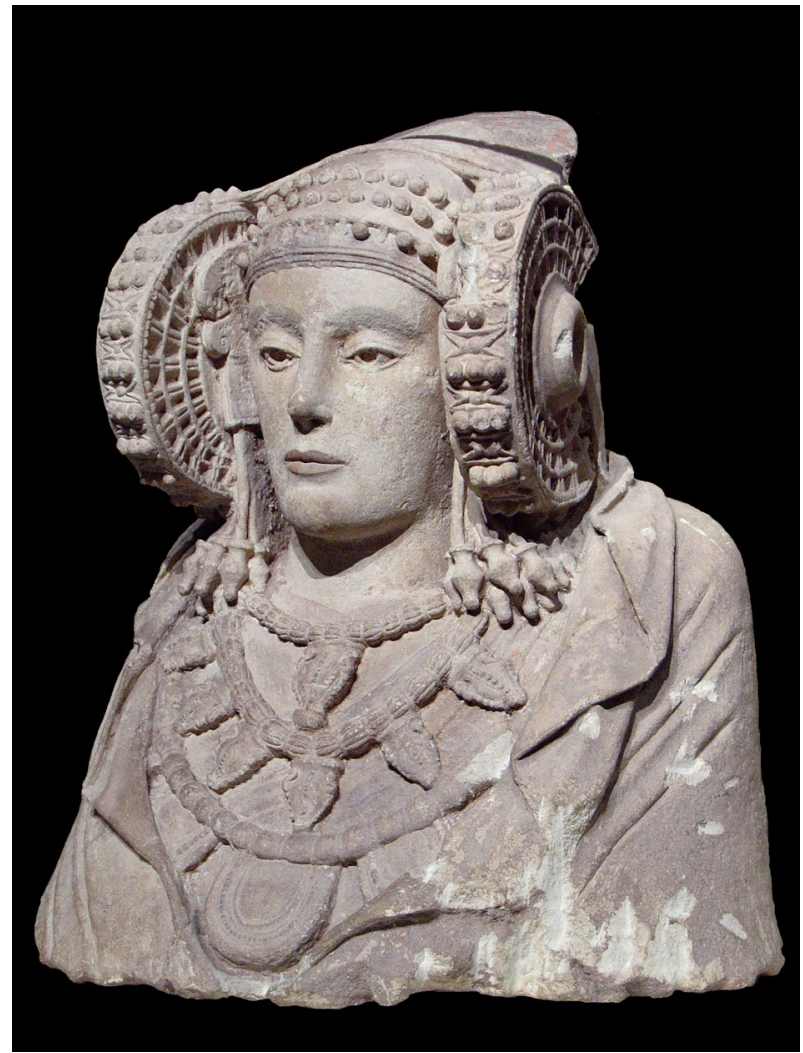

Figura 12: Dama de Elche (Foto Wikipedia)

cronología sus excavadores la ven confirmada por la «ausencia de cerámica ática de la Clase Delicada o copas Cástulo» (Abad et al., 2017: 240). También se ha señalado la presencia en La Alcudia de una copa ática de barniz negro de borde cóncavo de tipo $\mathrm{C}$ fechada en la primera mitad del siglo V a. C. (Rouillard, 1978: 278; Aranegui, 1981: 59; Domínguez Monedero y Sánchez, 2001: 41; García Martín 2003: 97), aunque este tipo de copa, en algún caso, ha sido hallado en contextos más recientes de finales del siglo $\mathrm{V}$ a mediados del IV a. C., como en La Picola, donde se menciona una pieza (Gailledrat y Rouillard, 2000: 174 y 177) y en el depósito votivo de la calle Zacatín, Granada (Adroher et al., 2016: 9-10, fig. 3:1 $)^{15}$.

15. Al margen de la mencionada ánfora fenicia occidental del estrato H (vid. supra), han resultado infructuosas nuestras pesquisas para identificar en los fondos del Museo de La Alcudia otras piezas cerámicas anteriores a mediados del siglo V a. C. (agradecemos a la Dra. A. Ronda su colaboración). Oswaldo Arteaga hace referencia a materiales expuestos en el citado museo de «un «estilo» bastante peculiar y, cuando menos, algo parecido al de las producciones jonias» (Arteaga, 1976-78: 60). No sabemos si estas cerámicas se pueden relacionar con las que Ramos Folqués (1990: 38, lám. 5) denomina «jónicas» y describe como «muy similares a las jónicas», aunque el material publicado es ibérico. Precisamente, esa vinculación «jónica» explicaría las altas cronologías, de la segunda mitad o de finales del siglo VI a. C., propuestas para el inicio del uso del témenos del Parque
Por último, de gran relevancia es el hallazgo de una muralla datada en el Ibérico Antiguo descubierta en recientes excavaciones en el Sector 11D-E, al sureste de la población, todavía en fase de estudio (Uroz Rodríguez et al., e.p.). Esta muralla de La Alcudia de Elche presenta cajones de distintas características, algunos con un zócalo formado por una o dos hiladas de grandes piedras o de guijarros a modo de $\lambda_{1} \theta 0 \lambda$ ó $\gamma \varepsilon \mu \alpha$ para aislarla de la humedad del suelo y un alzado de tierra y adobes, sin que falten los realizados enteramente con tierra amasada, lo que encuentra ciertas similitudes con la muralla de El Oral (Abad y Sala, 1993: 198, figs. 13 y 147, con ejemplos que evidencian en cada caso una distinta fábrica; Sala, 2006: 132-137). Responde a una técnica ya conocida en el mundo ibérico (Moret, 1996: $73 \mathrm{~s}$.), pero que debe de relacionarse con las murallas de adobe, presumiblemente de origen oriental (Aurenche, 1993; de Chazelles, 2011), documentadas en Grecia, Sicilia y la Magna Grecia (Winter, 1971: 69-73; Tréziny, 2010: 82 s.), como las de Gela (Morciano, 2001; Panvini, 2008), Mozia, Eraclea Minoa, Camarina, Reggio, Elea y Locri (Tréziny, 1986: 185-200), si bien el ejemplo más próximo, por evidenciar influencias griegas de Massalia, podría considerarse la muralla de adobes de la acrópolis de Heuneburg, en Alemania, construida sobre una base de piedra caliza de $50 \mathrm{~cm}$ de altura para evitar la humedad del suelo, muralla fechada c. 540-530 a. C. (Gerbach, 1995; Ays, 2013: 34 s.), además de los restos aparecidos en La Picola, en Santa Pola, ya de fines del siglo V a. C. (Badié et al., 2000: 95 s., lám. 19-20).

Estos profundos cambios en el patrón de asentamiento de la zona del Bajo Segura-Bajo Vinalopó coincide con el horizonte de reactivación de la actividad focense ampuritana en torno al 500 a. C. al que se ha hecho repetidas referencias. No es una casualidad, y menos si se analizan desde una perspectiva amplia. Estos cambios prácticamente coinciden con el enfrentamiento entre griegos y persas en las Guerras Médicas, que finaliza con las batallas de Salamina y de Platea el (480 y 479 a. C. respectivamente), fecha que también coincide en Occidente con el enfrentamiento entre griegos y púnicos en Sicilia que concluye con la victoria griega en Himera el 480 a. C. En este contexto internacional se deben encuadrar estos hechos documentados en el Sureste, pues testimonian en Iberia un esfuerzo bélico y político paralelo (Almagro-Gorbea y Lorrio, 2007; Almagro-Gorbea, 2009a) en el que, quizá por primera vez en la Historia con claridad, la península ibérica se vería directamente implicada en los conflictos generales del Mediterráneo, aunque su significado

Infantil de Elche (Ramos Fernández y Ramos Molina, 1992: 29) y de la primera fase del templo ibérico de La Alcudia (Ramos Fernández, 1995: 13 s.). Otro caso distinto es una copa ática de c. 550-525 a. C. procedente de la Colección de Pedro Ibarra conservada en el MAHE, que probablemente debe proceder del mercado anticuario (vid., con la discusión, de Hoz, 2014: 269 s., n. ${ }^{\circ} 261$ ). 
histórico hasta ahora haya pasado desapercibido, pues las fuentes escritas no hacen referencia a estos acontecimientos, que sólo revela la Arqueología.

El inicio de este conflicto quizás deba buscarse en la irrupción del poder naval focense a lo largo del siglo VI a. C. por las costas de Iberia, basado en sus pentecónteres, con las que descubrieron Occidente (Hdt. I,163,1-2), pues estos barcos de guerra eran rápidos, podían navegar contra el viento y su espolón facilitaba hundir barcos enemigos, además de la superioridad que suponía enfrentarse a naves de carga. Esta táctica de navegación facilitaba a los focenses practicar el comercio o la piratería según las circunstancias, lo que les permitió constituir la 'talasocracia focense', hacia el 584-540 a. C. (García Bellido, 1948: 113 s.) o $577-$ 534 a. C. (Miller, 1971: 62 s. y 106 s.) y establecerse en Tartessos (Hdt. I,163 y 165), como documenta el emporion jonio en Onuba/Huelva (Cabrera, 1988-1989; 2000; González de Canales, 2014) que, al menos desde finales del siglo VII a. C., existe en paralelo al emporion o karum fenicio, ambos bajo la autoridad política indígena (cf. Torres, 2018: 47-49, con bibliografía), y cuyas cerámicas de producción local (González de Canales y Llompart, 2017) hacen pensar en que llegó a alcanzar un desarrollo casi colonial.

Sin embargo, la conquista de Focea por Ciro el 546 a. C. (Hdt. I,163-164; para la fecha, Antonelli, 1997: 81 s.) parece haber tenido como consecuencia la casi contemporánea desaparición hacia el 545 a. C. del comercio jonio en Huelva/Tartessos, hechos que se reflejan en el final del «horizonte colonial focense» documentado por importaciones griegas en las costas de Iberia hasta mediados del siglo VI a. C. (AlmagroGorbea et al., 2018). Además, las prácticas piráticas de los focenses huidos de Focea, que habían fundado en Córcega la colonia de Alalia, provocaron que hacia el 540 a. C. una flota aliada formada por 60 naves etruscas y otras 60 naves púnicas se enfrentase a 60 naves focenses en la batalla de Alalia. Heródoto $(\mathrm{I}, 166)$ señala la victoria de los focenses, aunque perdieron 40 naves y las 20 naves restantes quedaron inservibles, lo que les obligó a abandonar Córcega (vid. supra).

Estos enfrentamientos deben relacionarse con crisis en los yacimientos coloniales fenicios de las costas meridionales de Hispania y con cambios de emplazamiento hacia puntos mejor fortificados, quizás a causa de ataques focenses durante la segunda mitad del siglo VI a. C. (Almagro-Gorbea y Guerrero, 2009: 352 s.), conflictos que también evidenciaría la caída del comercio colonial focense arcaico durante la segunda mitad del siglo VI a. C. Un posible reflejo puede verse en Malaka, donde ha aparecido una muralla bajo el actual Museo Picasso construida probablemente hacia el segundo cuarto del siglo VI a. C., y una segunda muralla de fines de dicha centuria o inicios de la siguiente (Arancibia y Escalante, 2006: 60-78, fig. 17-19 y 26-27). Además, la llamada «Tumba del Guerrero» (Martín Ruiz, 2009; García González et al., 2013; 2018), extraña a la población fenicia local, se ha atribuido a un hegemon de mercenarios, que debió participar en la defensa de la ciudad hacia $c$. 550-525 a. C. a juzgar por el casco corintio de un taller griego de la Italia meridional (Graells, 2014: 97 s. y 102, notas 413-418 $)^{16}$, depositado como sema sobre su tumba (Torelli, 2018: 22 s.) hacia el 525 a. C. (Quesada y García González, 2018: 206 y 217). En estos conflictos se enmarcaría el abandono del asentamiento fenicio de La Fonteta hacia el 525 a. C. y el final de la población de Peña Negra/Herna en esas mismas fechas.

El «horizonte del 500 a. C.» en una zona del Sureste tan estratégica, controlada previamente por los fenicios, documenta una política expansionista de los focenses paralela a las actividades piráticas del focense Dionisio y a los duros enfrentamientos entre griegos y púnicos en Sicilia que concluyen en la batalla de Himera, situación bélica en el Mediterráneo Occidental que coincide con las Guerras Médicas en Grecia. No parece ser una coincidencia casual, pues los elementos arqueológicos analizados atestiguan una presencia expansiva focense en el Sureste y desde aquí hacia el oriente de la Meseta y la Andalucía Oriental.

Tras la conquista por Ciro de todas las ciudades jonias el 546 a. C. (Hdt. I,141), el 499 a. C. se sublevó Mileto seguido del resto de Jonia. La Revuelta Jonia del 499493 a. C. inicia un enfrentamiento mantenido durante 20 años por los griegos contra el Imperio Persa, del 499 al 479 a. C., que cristalizó en las Guerras Médicas en el decenio que va desde la batalla de Maratón el 490 a. C. a las batallas de Salamina y Platea (480 y 479 a. C. respectivamente). En la Revuelta Jonia contra los persas, el focense Dionisio fue nombrado jefe de la flota de la Liga Jonia, a pesar de que Focea sólo aportó 3 naves (Hdt. VI,11). Tras ser derrotados los jonios en la batalla de Lade el 494 a. C., Dionisio huyó en tres naves enemigas capturadas y se dirigió a Fenicia, donde pirateó obteniendo un cuantioso botín (Cozzoli, 1978; Domínguez Monedero, 2009: 141 s.). Desde Fenicia fue a Sicilia, donde se estableció dedicándose a la piratería contra cartagineses y etruscos (Hdt. VI,17), lo que evidencia la inestabilidad de las costas del Mediterráneo, que proseguía 20 años después, el 474 a. C., cuando una flota conjunta de Siracusa y de Cumas derrotaba a los etruscos en la batalla de Cumas (Diod. Sic. XI,51; Pind. Pitica I,140) y aún hay noticia de un enfrentamiento naval posterior entre los focenses de Massalia contra una flota púnica (Tucid. 1,14). De manera paralela, en Sicilia el enfrentamiento entre griegos y púnicos se acentúa el 510 a. C., cuando el espartano Dorieo pretendió conquistar territorios del occidente siciliano (Krings, 1998: 168 y 231), intento que preludia la expansión griega de Gelón una generación después,

16. Agradecemos a R. Graells la idea de que esta tumba no parece griega, sino que recuerda las de los grandes jefes guerreros suritálicos, como en Braida di Vaglio, Ginosa, etc., que ofrecen este tipo de ajuares, lo que podría indicar una relación con la Magna Grecia más que con la Grecia peninsular. 
que condujo al enfrentamiento definitivo que finaliza en la batalla de Himera con la victoria griega el 480 a. C.

Este ambiente de enfrentamientos también se refleja en el Primer Tratado entre Roma y Cartago, que se considera firmado el año 509 a. C. por Lucio Junio Bruto y Marco Horacio, los primeros cónsules de la República tras la caída de Tarquinio el Soberbio, y que Polibio (III,22,1.2) sitúa 28 años antes de que Jerjes cruzara el Helesponto para invadir Grecia al inicio de las Guerras Médicas, por lo que se fecha en el 508-507 a. C. Una referencia más imprecisa ofrece Tito Livio (VII,27) y Aristóteles (Pol. III,9,1280a) también recoge una noticia sobre pactos entre los etruscos y Cartago y un pacto similar documentan hacia el 500 a. C. las láminas de oro descubiertas en el templo B de Pyrgi, puerto de la antigua Caere, Cerveteri (Espada, 2013: 61 s.; Xella, 2015-2016).

El texto del Primer Tratado entre Roma y Cartago parece ser, en parte al menos, una reconstrucción posterior de Polibio (III,22-23), por lo que desde el siglo XIX se discute su antigüedad, que algunos rebajan a mediados del siglo V a. C. o al 348 a. C., aunque la mayoría de los autores, desde Mommsen, lo consideran del siglo VI, discusión que prosigue en la actualidad (Espada, 2013: 264-266). Los estudios recientes lo consideran del primer año de la República Romana (Espada, 2009; 2013), pues se enmarca en los conflictos bélicos surgidos desde la batalla de Alalia, c. 540 a. C., a las de Hímera el 480 a. C. y de Cumas el 474 a. C., que reflejan los continuos enfrentamientos entre púnicos y griegos por el dominio del Mediterráneo Occidental (Domínguez Monedero, 2010; Vassallo, 2010; Espada, 2013: 169 s.). Polibio reconoce que estaba escrito en un latín muy arcaico difícil de entender, lo que hace sospechar que pudo recomponer el texto original con tratados similares, como el Segundo Tratado entre Roma y Cartago del año 348 a. C., cuya redacción resulta parecida. El Primer Tratado hace referencia a un «Cabo Bello», situado al norte de Cartago, quizás el Cabo Harina, por lo que Blázquez (1981) desconoce su repercusión en la península ibérica, pero el Segundo Tratado menciona junto al «Cabo Bello» de forma explícita a Mastia de Tarsis como límite de la navegación para los romanos (Ferrer, 2011-2012). Esta referencia a Mastia hay que valorarla, porque se relaciona con los intereses púnicos en el Sureste, ya que indica que el territorio del Bajo Segura - Bajo Vinalopó quedó fuera del límite de influencia de Cartago que señala el tratado, lo que hace suponer que la presencia focense en el Bajo Segura - Bajo Vinalopó quizás estuviera asegurada por pactos de Massalia con Roma, que se habrían mantenido hasta las Guerras Púnicas (Polibio III,95). En este contexto internacional deben de enmarcarse e interpretarse los hechos analizados en el Sureste de Iberia.

En Iberia, ese largo enfrentamiento bélico, arrastrado desde la caída de Focea, debió proseguir hasta los últimos años del siglo VI a. C., cuando el «horizonte de importaciones griegas de c. 500 a. C.» documenta una nueva y agresiva política comercial de los focenses centrada en el Sureste, que buscaba penetrar desde esas costas hacia el interior por vía terrestre para alcanzar los mercados de la Alta Andalucía y la Celtiberia en la Meseta Oriental, esfuerzo que prosigue a lo largo del siglo $\mathrm{V}$ a. C. hasta la reacción púnica de la segunda mitad del siglo IV a. C. Este deseo expansivo de los focenses en el Sureste explica el florecimiento de las importaciones, asociadas a influjos estilísticos e ideológicos, transformaciones que son la clave para entender la personalidad de la Cultura Ibérica, cuando surgen las ciudades-estado características de la misma tras el periodo orientalizante. También con este proceso se podrían relacionar algunas discutidas fundaciones que mencionan las fuentes con poca precisión, como la supuesta colonia focense de Mainake (OM 426-431) en la Costa del Sol (Niemeyer, 1979-1980; Aubet, 2005; García Alfonso, 2018: 60-62) y, más próximas a la desembocadura del Segura, las tría políchnia Massaliotōn, de las que la más conocida y antigua sería Hemeroskopeion, citada en la Ora Maritima de Avieno (OM 476), por lo que pudiera corresponde a este horizonte cronológico (Pena, 2002: 25 s.), además de Alonis y Akra Leuke, de cronología más discutible (Str. III,4,6; García Bellido, 1948: I, 239 s.; Rouillard, 1982; 1991: 303-306.; Privitera, 2007: 47 s.). Igualmente, se podría enmarcar en este contexto la tan discutida batalla del Cabo Artemesión de fecha y lugar muy inciertos, pero que algunos relacionan con el cabo de la Nao (Bosch Gimpera, 1950, cf. Krings, 1998: 217 s.).

La expansión focense desde el Sureste hacia la Meseta Oriental y Andalucía debió asociar intereses económicos, influjos culturales y presiones políticas y militares y aprovecharía el control de las vías de comunicación, proceso que favorecía una creciente helenización. Uno de los mejores testimonios de este proceso son los estandartes conocidos como «Jinetes de tipo La Bastida», que se extienden desde el Levante Meridional hasta la Meseta Oriental, Andalucía y Extremadura (Almagro-Gorbea y Lorrio, 2007; Almagro-Gorbea et al., 2019). Estos signa equitum eran símbolos de poder de elites ecuestres, seguramente de tipo regio. Estas elites regias, que citan los textos históricos (Caro Baroja, 1971; Almagro-Gorbea, 1996: $84 \mathrm{~s}$.), mandaban pequeños ejércitos formados por una turma de jinetes acompañados de clientes y siervos como infantes, como los hegemones, duces, «caudillos» o «condottieri» griegos e itálicos del arcaísmo final, por lo que la expansión de estos signa equitum pudiera indicar movimientos militares de los que no informan las fuentes escritas. En la Italia arcaica se conoce bien la existencia de ejércitos gentilicios y de fortuna, capaces de apoderarse de una ciudad-estado y de cambiar su dinastía al imponer un nuevo soberano (Torelli, 2011; Almagro-Gorbea et al., 2019), como es el caso de Porsenna en Roma (Ehlers, 1953; Ridley, 2015; 2017) y el de ejércitos privados como el de los Claudios (Serv. ad Verg. 7,706) o el de los Fabios en su guerra contra Veyes (Liv. 2,197-198; Serv. ad Verg. 


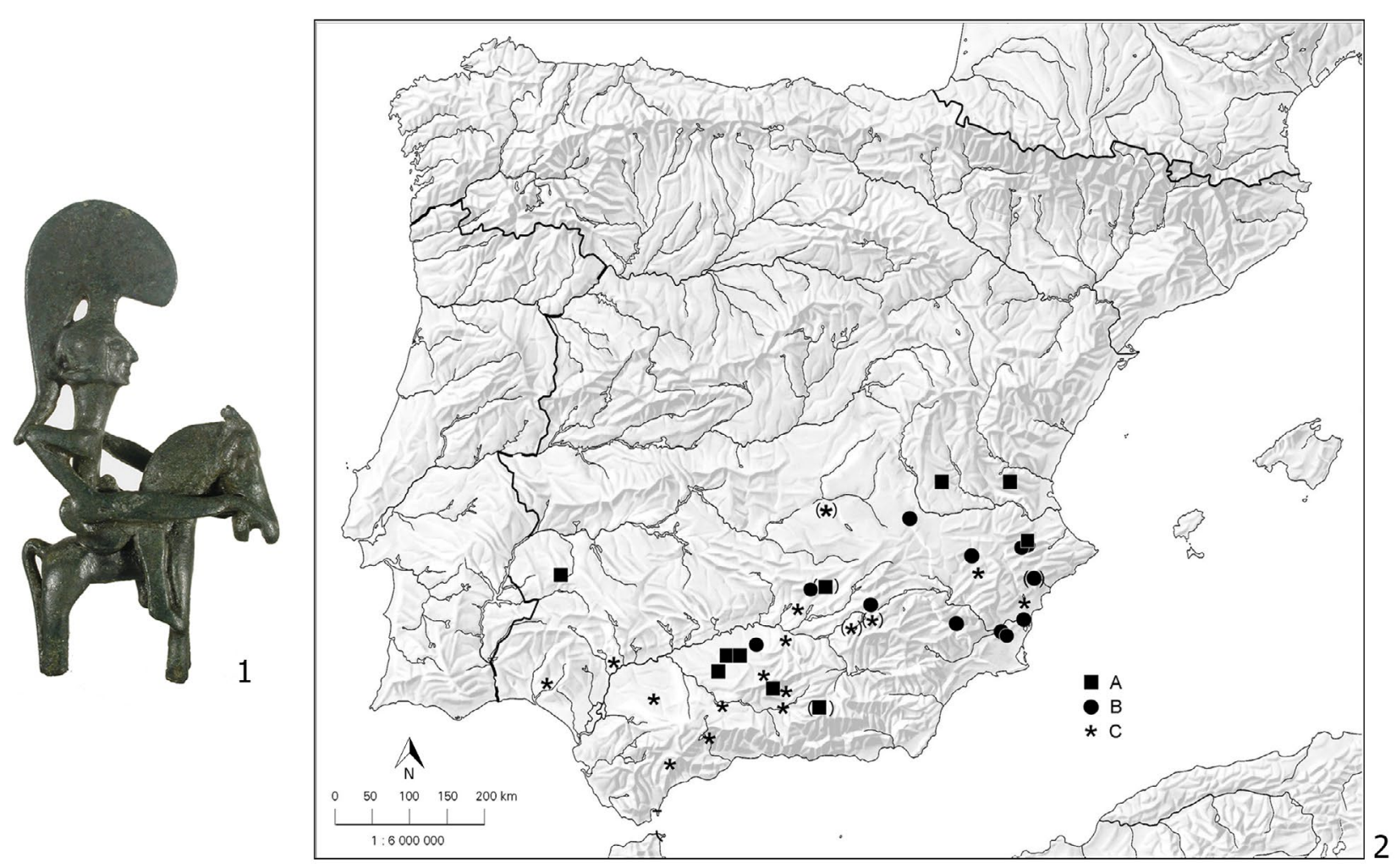

Figura 13: 1, Jinete de La Bastida. 2, Dispersión de los «Jinetes tipo La Bastida» (A) y plástica del estilo de los «rizos largos» (B). Los asteriscos (C) indican los topónimos en Ili- al Sur del Júcar (1, Jinete de La Bastida, Foto Museu de Prehistòria de Valencia; 2, según Almagro-Gorbea et al., 2019 (A y C) y Almagro-Gorbea y Lorrio, 2011 (B)

6,845), proceso que se veía favorecido por el desarrollo demográfico de las ciudades-estado a fines del siglo VI a. C.

Los ejemplares más antiguos de signa equitum ibéricos son de estilo jonio-ibérico y su jinete lleva casco y grebas de la primera mitad del siglo $\mathrm{V}$ a. C., lo que supone un nuevo influjo focense relacionado con el horizonte del 500 a. C. (Fig. 13,1). En consecuencia, los «Jinetes de tipo La Bastida» indicarían una expansión ibérica filohelena en la primera mitad del siglo $\mathrm{V}$ a. C. (Fig. 13,2,A), pues hay que suponer que, dentro de presiones políticas y militares constatadas a partir del 500 a. C., en Hispania también se producirían expediciones militares dirigidas por reges al frente de ejércitos de sus ciudades-estado o por hegemones o caudillos de fortuna de carácter más o menos gentilicio con ejércitos formados por familiares y clientes similares a los de Italia. Estos ejércitos ibéricos serían menos numerosos que los itálicos, dada la menor demografía de los oppida ibéricos (Almagro-Gorbea, 1988; Moret, 1996: $133 \mathrm{~s}$.), pero igualmente podrían apoderarse de una ciudad-estado con su territorio e introducir una nueva dinastía. Un testimonio pudiera ser el heroon jonioibérico de Porcuna (Negueruela, 1990), construido hacia el 480 a. C. quizás para enaltecer al fundador de una nueva dinastía ibérica filohelena instalada en Obulco. Los focenses favorecerían a estas monarquías heroicas frente a las anteriores monarquías sacras de tradición orientalizante de tendencia filopúnica en su enfrentamiento por el control del Sureste y sus vías de comunicación hacia Andalucía y la Celtiberia. Este contexto histórico permite comprender el significado de estos «Jinetes de tipo La Bastida» como insignias de los reges y hegemones ibéricos, quienes, favorecidos por la tradición de la devotio ibérica, podrían hacer la guerra por su cuenta o actuar como mercenarios (Graells, 2014). Esta tradición perduró hasta la Guerra Civil entre César y Pompeyo, pues todavía el 45 a. C. pereció en combate un «rey llamado Indo mientras conducía sus tropas al frente de la caballería» (b.H.10: rex nomine Indo qui cum equitatu suas copias adduxerat...).

Otra evidencia de este fenómeno de inestabilidad en Andalucía Oriental puede considerarse la fortificación con turres de la frontera entre la Campiña de Jaén y la Vega del Guadalquivir en el siglo VI a. C., a la vez que se abandonaron los pequeños núcleos de colonización agraria orientalizantes y la población se concentró en oppida o ciudades fortificadas ibéricas (Ruiz y Molinos, 1992: 107), hecho que pudiera deberse a la actividad de las citadas elites ibéricas de tipo heroico guerrero. Además, la aparición de estas elites se asociaría a un creciente proceso de iberización en la cultura material que se extiende desde el Sureste hacia el valle del Guadalquivir y que pudiera explicar la introducción en Andalucía de topónimos ibéricos en $I l i-$, indicativos de «ciudad» en ibérico (de Hoz, 2010-11: 466 s.; Silgo, 2013: 155 s.), topónimos que se extienden desde Cataluña hasta Ilici (La Alcudia de Elche), y de aquí hasta Ilipla (Fig. 13,2,C), Niebla, en la provincia 
de Huelva, ya que en Andalucía se superponen a los topónimos en -ipo y en -uba del substrato tartesio (Untermann, 1985: 15, mapas 1, 2 y 5; Almagro-Gorbea et al., 2019; fig. 24).

La penetración de estos topónimos por Andalucía Oriental y Central parece reflejar el mismo proceso de «iberización» del substrato orientalizante tartesio que los monumentos de estilo jonio-ibérico y los signa equitum, probablemente favorecido por conflictos bélicos y quizás por pequeños movimientos étnicos dirigidos por elites guerreras ibéricas filohelenas, proceso que impulsaría la iberización helenizante de la Andalucía tartesia, como atestiguan los «Jinetes de tipo La Bastida». En estos enfrentamientos entre íberos, griegos y púnicos durante el siglo $\mathrm{V}$ a. C. podría situarse la expedición contra Gades del rey ibérico, Theron, rex Hispania Citerioris (Alvar, 1986; Almagro-Gorbea, 2013: 223 s.), a la que igualmente pudiera aludir una escueta noticia de Justino $(44,5,1)$ de que los gaditanos, atacados por sus vecinos ante su creciente poder, salieron vencedores con ayuda de Cartago. En efecto, el episodio mitificado del ataque del rey Terón a Cádiz, transmitido por Macrobio (Sat. I,20,12), puede interpretarse como una penetración de elites ibéricas filohelenas desde el Sureste hacia Andalucía a inicios del siglo V a. C. A pesar del carácter mítico de la noticia, reflejaría un enfrentamiento entre íberos y fenicio-púnicos a inicios del siglo V a. C. pues, según Macrobio, Terón era rey de la Hispania Citerior, es decir, que procedía de Andalucía Oriental, del Sureste o del Levante, como ya supuso J. Alvar (1986), que lo consideró un régulo contestano que, quizás al servicio de los griegos, pretendería conquistar Cádiz, fracasando en el intento, aunque Alvar situó el hecho a mediados del siglo IV a. C., lo que parece menos probable.

\section{CAMBIOS IDEOLÓGICOS E INDOEUROPEI- ZACIÓN}

La reactivación del comercio focense con el horizonte de importaciones del 500 a. C., la introducción de la plástica jonio-ibérica y la introducción de la escritura greco-ibérica asociadas al control de la Vía Salaria Ibérica se vio favorecida por un profundo cambio ideológico en las elites ibéricas.

A fines del siglo VI a. C., la sociedad ibérica evoluciona hacia nuevas concepciones políticas basadas en dinastas cuyo poder radicaba en su carácter guerrero y su pertenencia a un grupo gentilicio que se consideraba descendiente de un héroe mítico, protector del dinasta y de toda la sociedad (Almagro-Gorbea, 1996: $84 \mathrm{~s}$; 2009c; Almagro-Gorbea y Lorrio, 2011: 60 s.). Esta nueva concepción política pasó a ser el fundamento de la estructura política e ideológica de la sociedad ibérica en sustitución del basileus de tradición orientalizante (Almagro-Gorbea, 1996: 70 s.), cambio ideológico comparable al que se documenta en la Grecia arcaica, Etruria y Lacio a inicios del siglo VI a. C. (Alföldi,
1965; AA.VV., 1990; Torelli, 1993: 174 s.; Jannot, 1976: 192 s.; Giangiulio, 2016; Cerchiai, 2017; Lulof y Smith (Eds.), 2017; etc.). Estas nuevas elites se reflejan en el ritual funerario y en heroa con escultura monumental, con escenas de lucha, caza y otros temas heroicos que resaltaban al antepasado mítico, como en los heroa jonio-ibéricos de Obulco en Porcuna (Negueruela, 1990), de Huelma, Jaén (Molinos et al., 1998) y de Ilici en La Alcudia de Elche (Ramos Folqués, 1950; 1955). Esta ideología guerrera heroica, asociada a la creencia en el héroe fundador, debe de proceder del mundo ibérico septentrional, derivado de los Campos de Urnas (Almagro-Gorbea, 1996: 84 s.; Graells, 2007; Almagro-Gorbea y Lorrio, 2011: 86 s.). Su origen es, por lo tanto, indoeuropeo, como el concepto del héroe fundador, que organiza la sociedad e impone una cultura urbana (Almagro-Gorbea, 2009c; 2013: 269 s.) y da su nombre a su pueblo, como Edecón a los Edetanos (Liv. 27,17,1). También creencias indoeuropeas refleja el «Rey-Lobo» de La Alcudia, que supone mitos en un héroe fundador de carácter lobuno comparable a Rómulo o a Ciro (Almagro-Gorbea, 1999), lo mismo que son indoeuropeos los mitos explicativos del guerrero heroico de Porcuna, del «Guerrero sacrificando un carnero» de La Puerta de Segura, Jaén (AlmagroGorbea y Lorrio, 2011: 17 s.) y de otros mitos ibéricos narrados en cerámicas figuradas de fechas ya posteriores (Álvarez Peña, 2007; Pérez Blasco, 2014).

El mismo influjo puede documentar la extensión en el siglo VI a. C. de necrópolis de incineración de tipo Can Canyís-Solivella desde la Cataluña meridional hasta el Sureste (Oliver, 2014: fig. 2), que parece ir asociada a la difusión de una panoplia de prestigio con nuevas armas, como soliferrea y grebas de bronce (Farnié y Quesada, 2005) y posiblemente kardiophylakes (Graells, 2012), que indicarían la expansión de elites guerreras originarias de los Campos de Urnas del Noreste. También a partir de fines del siglo VI a. C. el caballo pasa a definir el estatus de estas nuevas aristocracias guerreras de tipo heroico, y jinetes y caballos se representan en signa equitum, en heroa y en monumentos funerarios, cuyo estilo jonio-ibérico refleja la helenización del arte ibérico, paralela a su transformación ideológica, dada la profunda relación de estas esculturas con las elites sociales y políticas. Estos jinetes representarían al antepasado ecuestre heroizado, lo que confirma esa nueva ideología heroica, siguiendo el proceso documentado en Grecia, Etruria y Roma, donde el caballo pasó a ser el nuevo símbolo de estatus, como refleja el arte griego arcaico y la decoración de las regiae etruscas y laciales (Torelli, 1983). Estas nuevas aristocracias ecuestres surgidas en el mundo arcaico jugaron un papel esencial en la desaparición de las monarquías en Grecia y Roma, lo que hace suponer un fenómeno similar en Iberia al sustituir a las monarquías orientalizantes, dentro de un fenómeno general en todo el Mediterráneo (de Sanctis, 1984: 103 s.; Alföldi, 1965). Los focenses apoyarían a estos nuevos dinastas de tipo heroico, más afines a su cultura y sus intereses, 
frente a las monarquías sacras orientalizantes, de ideología e intereses afines al mundo feno-púnico, como se ha señalado. Esta nueva ideología, asociada al nuevo estilo estético e iconográfico, sustituye hacia el 500 a. C. a la orientalizante, aún vigente en el monumento de Pozo Moro, pero una generación más tarde, hacia el 480 a. C., el heroôn de Porcuna ofrece escenas características del mundo heroico arcaico, en las que el jinete representa siempre al vencedor (Almagro-Gorbea, 1996: 79 s.).

La llegada de elites surgidas en los últimos Campos de Urnas, ya en la Edad del Hierro, también se evidencia en nuevos cultos domésticos basados en el hogar y asociados a la ideología del héroe fundador (AlmagroGorbea y Moneo, 2000: 130 s.; Moneo, 2003: 371 s. y 418-423; Almagro-Gorbea y Lorrio, 2011: 86 s.), que probablemente prosiguen los influjos registrados en la zona desde el Bronce Final, como evidencian la aparición de necrópolis de incineración, el enterramiento de neonatos bajo el suelo de las casas y los sacrificios de ovicápridos, rituales perfectamente documentados en Peña Negra/Les Moreres durante el Hierro Antiguo (González Prats, 2002; 1990: 94; de Miguel, 2002).

Junto a estas novedades pudo llegar el «poblado cerrado» caracterizado por casas rectangulares de medianiles comunes cuyos muros posteriores refuerzan la muralla. Esta innovación urbanística, que procede de los Campos de Urnas del Bronce Final (Maya et al. (Eds.), 1998: 23 s.), se extendió tanto hacia el Levante como hacia la Meseta y supuso un notable avance técnico y social (Almagro-Gorbea, 1995: fig. 8:2, 10 y 13; Moret, 1996: 145 s.; Lorrio, 2005: 103), que evolucionó al multiplicarse las calles con una estructura urbana cada vez más compleja, ya de auténticos oppida. Este urbanismo, que suponía planificar el poblado, frente al urbanismo «aglutinante» orientalizante, constituye uno de los elementos más característicos de la «iberización». Esta innovación urbanística no se constata en Herna/Peña Negra durante el Hierro Antiguo, pues las viviendas orientalizantes aparecen aisladas y sólo presentan medianiles comunes las habitaciones de la misma unidad doméstica (González Prats, 1983; Lorrio, 2020), como ocurre en las fases del Hierro Antiguo de Los Saladares (Arteaga y Serna, 1979-1980: figs. 10 y 12), mientras que en La Fonteta, las viviendas de la fase reciente se adosan a la muralla, teniendo igualmente medianiles comunes sólo las diferentes habitaciones de una vivienda (Gailledrat, 2007b; González Prats (Coord.), 2011).

Tras la desaparición de La Fonteta y Herna/Peña Negra, sólo El Oral ofrece información sobre el urbanismo de los asentamientos surgidos en esta nueva etapa. El Oral (vid. supra) presenta características propias de un «poblado cerrado» con medianiles comunes (Fig. 14), pero ofrece singularidades como la presencia de viviendas con patio, el enlucido de las paredes con pintura roja, suelos de conchas, etc., que evidencian la fuerte influencia oriental todavía presente, en gran medida, por su más que posible relación con los

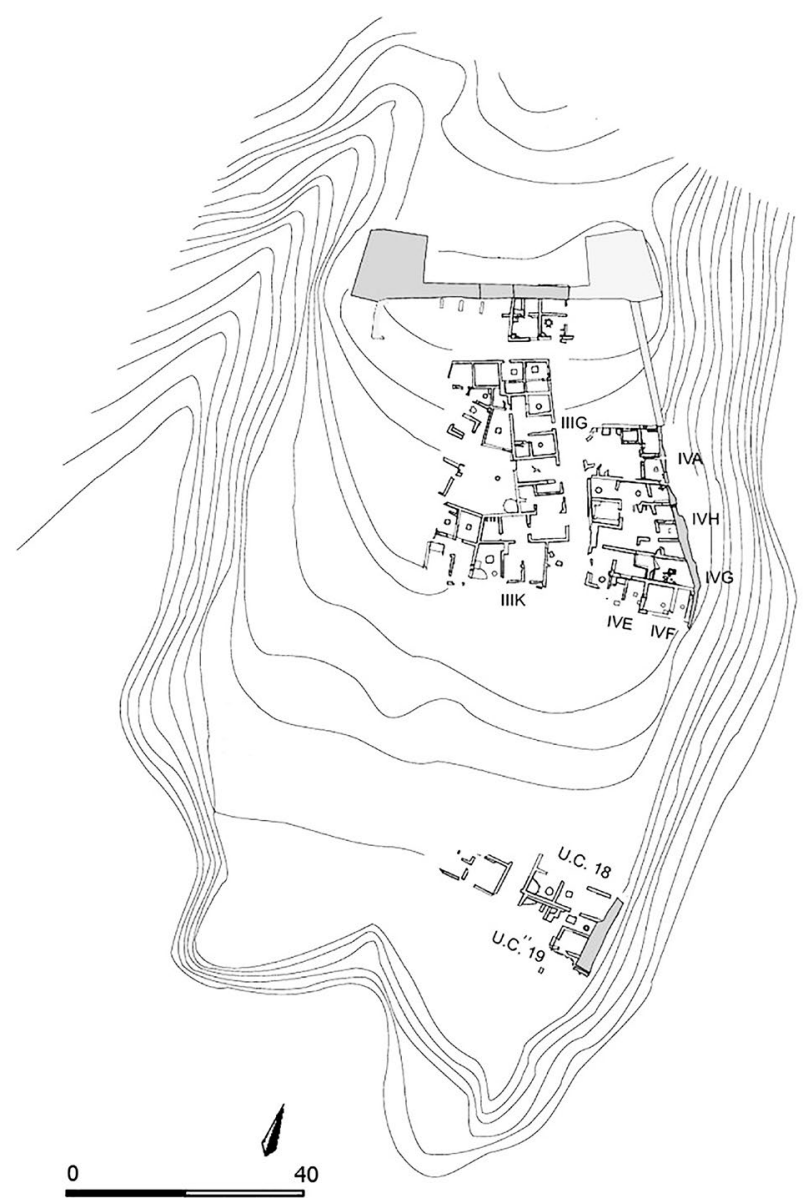

Figura 14: Planta del yacimiento de El Oral (Según Sala y Abad, 2006)

habitantes de La Fonteta, que explicaría el carácter oriental repetidamente señalado por sus excavadores (Abad y Sala, 2009; Abad et al., 2017: 236-238), mientras que su muralla era una novedad en la zona hasta la reciente aparición de la muralla de La Alcudia de Elche, con la que parece que puede relacionarse (vid. supra).

\section{LA CRISTALIZACIÓN DEL CAMBIO: DE LA CIUDAD ORIENTALIZANTE A LA CIUDAD «IBÉRICA»}

Desde los años 1980, ya González Prats (1983) observó una importante reordenación del poblamiento orientalizante en la zona de Bajo Segura entre el 550 y el 535 a. C., marcado por la desaparición del núcleo urbano de Peña Negra. Desde entonces, las causas de este hecho se han interpretado dentro del profundo cambio cultural que supuso la desaparición de Tartessos y su sustitución en el Sureste por la Cultura Ibérica (Almagro-Gorbea, 1996: 77 s.).

Este cambio permite comprender cómo surge la Cultura Ibérica (Almagro-Gorbea, 1996: 77 s.; Grau y Moratalla, 2001: 195). Del proceso de aculturación greco-focense en el Sureste peninsular sobre el precedente substrato orientalizante, de origen fenicio, 
surgió un nuevo foco cultural que puede considerarse inicio de la iberización en sentido estricto, aunque no se deba separar de la precedente fase orientalizante de la cultura ibérica en la que se forjaron sus principales características, tanto de cultura material como de su organización económica, social, religiosa e ideológica, heredadas del mundo fenicio y tartésico, por lo que este proceso constituye un ciclo cultural único, surgido del substrato orientalizante transformado ulteriormente por influjo de la colonización focense. Esta nueva fase, que ya cabe denominar como 'Cultura Ibérica', se extendió desde el Sureste hasta el Herault y paralelamente penetró desde el Sureste hacia Andalucía Occidental, cuna de la cultura tartésica, transformada, tras la crisis del siglo VI a. C., en el mundo turdetano, heredero de Tartessos. Las diferencias geográficas y culturales del substrato orientalizante del mundo ibérico se vieron acentuadas por la diferente calidad e intensidad de contactos con el ámbito griego focense, cuyo influjo fue particularmente intenso en el Sureste, pero menor hacia el interior y en el Noreste, donde era más intenso el substrato de Campos de Urnas afín al mundo indoeuropeo celtoligur. De este modo se pueden explicar las variaciones culturales, sociales e ideológicas del mundo ibérico, relacionables con las diversas etnias documentadas por las fuentes históricas de la Antigüedad, desde el Herault hasta la Alta
Andalucía, cuyas peculiaridades lingüísticas, onomásticas y arqueológicas traslucen la diversidad de su substrato cultural y de los distintos contactos recibidos (Almagro-Gorbea, 2014: 288 s.).

Las recientes excavaciones en tres yacimientos clave del Bajo Segura y el Bajo Vinalopó en el entorno de la antigua albufera de Elche y las marismas que la rodeaban, el fenicio de La Fonteta, el orientalizante de Peña Negra/Herna y el ibérico de La Alcudia de Elche/Ilici, permiten comprender mejor estos cambios y precisar y contextualizar sus causas en su contexto histórico.

En este marco geográfico, un hecho fundamental es la desaparición de La Fonteta y Peña Negra como centros territoriales hacia el 525 a. C., constatándose a partir de ese momento la aparición de pequeños núcleos como El Oral hacia finales del siglo VI a. C. o de Cabezo Lucero en una fecha algo posterior, a la vez que se configura Ilici/La Alcudia hacia el 500 a. C. como el nuevo centro de poder de este territorio. Este profundo cambio político y cultural debe de relacionarse con una activa política focense que hemos denominado «horizonte del 500 a. C.», que incluye importaciones de vasos áticos y bronces itálicos de calidad, la introducción de una nueva plástica de estilo e iconografía jonio-focense y, muy probablemente, de la escritura «greco-ibérica», además de cambios ideológicos,

\begin{tabular}{|l|l|}
\hline & \multicolumn{1}{|c|}{ CONTEXTO HISTÓRICO } \\
\hline 600 & Fundación de Massalia \\
\hline 580 & Fundación de Emporion \\
\hline 573 & Nabucodonosor II de Babilonia conquista Tiro \\
\hline 560 & Establecimiento de Emporion en tierra firme \\
\hline 546 & Ciro conquista Focea. Fin de Tartessos \\
\hline $540-535$ & Los focenses piratean en Occidente. Batalla de Alalia \\
\hline $540-525$ & Inestabilidad en las poblaciones fenicias costeras de Hispania \\
\hline 525 & Destrucción de La Fonteta (Guardamar de Segura) \\
\hline 525 & Abandono de Herna (Peña Negra, Crevillent) \\
\hline 509 & I Tratado entre Roma y Cartago (Polyb. Hist. III,1,22) \\
\hline 499 & Jonia se rebela contra Persia \\
\hline $494-490$ & El focense Dionisio piratea Fenicia y el Tirreno \\
\hline $500-480$ & Expansión focense en el Sureste \\
\hline & Horizonte de importaciones áticas \\
\hline & Influjos estilísticos jonio-ibéricos \\
\hline & Introducción de la escritura «greco-ibérica» \\
\hline & Aparición de ciudades-estado ibéricas: Ilici/La Aludia \\
\hline 480 & Expansión íberos filofocenses \\
\hline 480 & Batallas de Salamina y de Himera \\
\hline $470-460$ & Heroon de Porcuna \\
\hline $425-400$ & Dama de Elche \\
\hline c. 410 & ¿Destrucción de heroa y pilares-estela? (sin referencias históricas) \\
\hline
\end{tabular}

Figura 15: Contexto histórico de la expansión focense en el Sureste de Iberia (600-400 a. C.) 
horizonte que confirma la importancia de los influjos helénicos focenses en el sistema económico, cultural y social del mundo ibérico (Fig. 15).

El eje estratégico de esta política focense sería dominar la Vía Salaria Ibérica, pues era la vía hacia los recursos militares de la Celtiberia y hacia los recursos mineros de Andalucía Oriental en unos años de enfrentamientos cruciales de los griegos con los persas en el Mediterráneo Oriental y con púnicos y etruscos en el Occidental. Esta expansiva política focense no se limitó al campo económico, pues incidió también en la ideología, las creencias y el sistema del poder político dinástico gentilicio basado en el Héroe Fundador. Las ricas panoplias y el uso del caballo como nuevo símbolo de la elite social, como evidencian esculturas y signa equitum, indican la aparición de una nueva elite, guerrera y ecuestre, que, a juzgar por sus armas y por su ideología, procede del mundo ibérico septentrional, derivado directamente de los Campos de Urnas del Noreste pero ya en la Edad del Hierro. Este hecho explicaría la profunda indoeuropeización ideológica del mundo ibérico, que hasta ahora no se había planteado ni explicado. También de los Campos de Urnas procede el culto al hogar doméstico y la nueva urbanística del «poblados cerrados» con casas de medianiles comunes. A ello se pudiera añadir la difusión de topónimos en Ili-, entre los que destaca Ilici en La Alcudia de Elche, que pasó a ser el nuevo centro de poder del territorio y el punto de control de la Vía Salaria Ibérica a partir de esos años.

Este conjunto de cambios, acaecidos en torno al 500 a. C., explican la evolución política y cultural del Bajo Vinalopó - Bajo Segura, con el paso de la hegemonía fenicia en la anfictionía de hecho que suponía el eje Fonteta-Peña Negra a la hegemonía focense basada en una anfictionía focense-ibérica con Ilici como nuevo centro de poder en ese territorio. Este profundo cambio, político y cultural, representa también la consolidación de la ciudad-estado ibérica en el Sureste, que marca el paso del mundo orientalizante proto-ibérico de raíces fenicias al mundo ibérico de componentes indoeuropeas y helénicas, que prosiguió hasta la romanización de este territorio.

\section{REFERENCIAS}

AA.VV. (1976). Situación actual y perspectivas de desarrollo de la región valenciana: Infraestructuras y recursos. Valencia: Confederación Española de Cajas de Ahorro.

AA.VV. (1990). Crise et transformations des societés archaïques de l'Italie antique au V sièche av. J.-C. Actes de la table ronde de Rome (19-21 novembre 1987). Publications de l'École Française de Rome, 137. Roma: École Française de Rome.

Abad, L. (1988). Un tipo de olpe de bronce de yacimientos ibéricos levantinos. Archivo de Prehistoria Levantina, 18, 329-345.
Abad, L. (2004). La Alcudia Ibérica. En busca de la ciudad perdida. En M. S. Hernández y L. Abad (Coms.). Iberia, Hispania, Spania. Una mirada desde Ilici (catálogo de exposición) (pp. 69-78). Alicante: Caja de Ahorros del Mediterráneo.

Abad, L., Grau, I., Sala, F. y Moratalla, J. (2003). Ancient trade in south-eastern Iberia: the lower Segura river as focus of exchange activities. Ancient West \& East, 2(2), 265-282.

Abad, L. y Sala, F. (1993): El poblado ibérico de El Oral (San Fulgencio, Alicante). Serie de Trabajos Varios del SIP, 90. Valencia: Diputación Provincial de Valencia.

Abad, L. y Sala, F. (Eds.). (2001). Poblamiento ibérico en el Bajo Segura: El Oral (II) y La Escuera. Bibliotheca Archaeologica Hispana, 12. Madrid: Real Academia de la Historia.

Abad, L. y Sala, F. (2009). La arquitectura y el urbanismo de El Oral (San Fulgencio, Alicante). Un ejemplo de asimilación de la arquitectura fenicia y púnica. En S. Helas y D. Marzoli (Eds.). Phönizisches und punisches Städtewesen (pp. 499-514). Iberia Archaeologica, 13. Mainz-am-Rhein: Philipp von Zabern.

Abad, L., Sala, F., Grau, I., Moratalla, J., Pastor, A. y Tendero, M. (2001): La excavación. En L. Abad y F. Sala (Eds.). Poblamiento ibérico en el Bajo Segura: El Oral (II) y La Escuera (pp. 17-100). Bibliotheca Archaeologica Hispana, 12. Madrid: Real Academia de la Historia.

Abad, L., Sala, F. y Moratalla, J. (2017). El Bajo Segura hasta la II Guerra Púnica. Nuevas investigaciones. En F. Prados y F. Sala (Eds.). El Oriente de Occidente. Fenicios y púnicos en el área ibérica. VIII Coloquio Internacional del CEFYP (Alicante - Guardamar del Segura, 7-9 de noviembre de 2013) (pp. 233-256). Alicante: Universidad de Alicante.

Alcalá-Zamora, L. (2004). La necrópolis ibérica de Pozo Moro. Bibliotheca Archaeologica Hispana, 23. Madrid: Real Academia de la Historia.

Adroher, A., López, A. y Pachón, J. A. (2002): Granada arqueológica. La Cultura Ibérica. Granada: Diputación de Granada.

Adroher, A., Sánchez Moreno, A. y Torre, I. de la. (2016). Cerámica ática de barniz negro de Iliberri (Granada, España). Portugalia, 37, 5-38.

Alföldi, A. (1965). Die Herrschaft der Reiterei in Griechenland und Rom nach dem Sturz der Könige. En Gestalt und Geschichte. Festchrift K. Schefold (pp. 13-47). Bern: Francke.

Almagro-Gorbea, M. (1982). La «colonización» focense en la Península Ibérica. Estado de la cuestión. La Parola del Passato, 104-107, 432-444.

Almagro-Gorbea, M. (1983a). Pozo Moro. El monumento orientalizante, su contexto socio-cultural y sus paralelos en la arquitectura funeraria ibérica. Madrider Mitteilungen, 24, 177-293.

Almagro-Gorbea, M. (1983b). Pilares-estela ibéricos. En Homenaje al Prof. Martín Almagro Basch III (pp. 7-20). Madrid: Ministerio de Cultura. 
Almagro-Gorbea, M. (1987). El pilar-estela de las «Damitas de Mogente» (Corral de Saus, Mogente, Valencia). En Homenaje a Domingo Fletcher, I (pp. 199-228). Archivo de Prehistoria Levantina, 17. Valencia: Institución Alfonso El Magnánimo - Consejo Superior de Investigaciones Científicas.

Almagro-Gorbea, M. (1988). El área superficial de las poblaciones ibéricas. En Coloquio sobre Los asentamientos ibéricos ante la romanización (Madrid, 1986) (pp. 21-34). Madrid: Ministerio de Cultura - Casa de Velázquez.

Almagro-Gorbea, M. (1992). La romanización de Segóbriga. En F. Coarelli, M. Torelli y J. Uroz (Eds.). Conquista romana y modos de intervención en la organización urbana y territorial. I Congreso histórico-arqueológico Hispano-Italiano (Elche, 1989) (pp. 275-288). Dialoghi di Archeologia, 10(12). Roma: Quasar.

Almagro-Gorbea, M. (1994). El urbanismo en la Hispania Céltica: castros y oppida en la Península Ibérica. En M. Almagro-Gorbea y A. M. ${ }^{a}$ Martín (Eds.). Castros y oppida de Extremadura (pp. 13-75). Complutum Extra, 4. Madrid: Servicio de Publicaciones de la Universidad Complutense de Madrid.

Almagro-Gorbea, M. (1996). Ideología y Poder en Tartessos y el mundo ibérico. Discurso de ingreso en la Real Academia de la Historia. Madrid: Real Academia de la Historia.

Almagro-Gorbea, M. (1999). El rey-lobo de La Alcudia de Ilici. Alicante: Museo de la Universidad de Alicante.

Almagro-Gorbea, M. (2008): Cerámicas griegas. En M. Almagro-Gorbea, A. J. Lorrio, A. Mederos y M. Torres. La necrópolis de Medellín. II, Estudio de los hallazgos (pp. 577-592). Bibliotheca Archaeologica Hispana, 26(2) - Studia Hispano-Phoenicia, 5(2). Madrid: Real Academia de la Historia.

Almagro-Gorbea, M. (2009a). El kýlix de figuras rojas arcaicas de Pozo Moro (Albacete). Cuadernos de Prehistoria y Arqueología de Castellón, 27, 63-81.

Almagro-Gorbea, M. (2009b). Una pelike del Pintor de Euchárides procedente de Cabezo Lucero, Alicante. Lucentum, XXVIII, 9-22. DOI: https://doi.org/10.14198/ LVCENTVM2009.28.01

Almagro-Gorbea, M. (2009c). El culto al Héros Ktístes en Hispania prerromana: ensayo de mitología comparada. En F. Delpech y M. García Quintela (Eds.). Veingt ans après Georges Dumèzil (1898-1986) (pp. 227-250). Budapest: Archaeolingua.

Almagro-Gorbea, M. (2013). Literatura Hispana Prerromana. Las creaciones fenicias, tartesias, iberas, celtas y vascas. Clave Historia, 39. Madrid: Real Academia de la Historia.

Almagro-Gorbea, M. (2014). Iberia mediterránea: los pueblos ibéricos. En M. Almagro-Gorbea (Ed.). Protohistoria de la Península Ibérica del Neolítico a la Romanización (pp. 285-318). Burgos: Universidad de Burgos - Fundación Atapuerca.

Almagro-Gorbea, M. (2015). Un kýlix del Pithos-Painter hallado en Mengíbar en la Real Academia de la Historia. En J. García Sánchez, I. Mañas y F. Salcedo (Eds.). Navigare necesse est. Estudios en homenaje a José María Luzón Nogué (pp. 417-433). Madrid: Universidad Complutense de Madrid, Facultad de Geografía e Historia.

Almagro-Gorbea, M., Casado, D., Fontes, F., Mederos, A. y Torres, M. (2004). Prehistoria. Antigüedades españolas, I. Catálogo del Gabinete de Antigüedades, I.2.1. Madrid: Real Academia de la Historia.

Almagro-Gorbea, M., González de Canales, F. y Llompart, J. (2018). Un ánfora ática de la 'Botkin Class' en Huelva y la fecha final del emporion focense. Madrider Mitteilungen, 59, 299-313.

Almagro-Gorbea, M. y Graells, R. (2011). Escarabeos del noreste de Hispania y del sur de la Galia. Catálogo, nuevos ejemplares e interpretaciones. Lucentum, $X X X, 25-88$. DOI: https://doi.org/10.14198/LVCENTVM2011.30.02

Almagro-Gorbea, M. y Guerrero, V. M. (2009). La guerra en el mar. En M. Almagro-Gorbea (Coord.). Prehistoria y Antigüedad, Historia Militar de España, I (pp. 347-364). Madrid: Ediciones del Laberinto - Ministerio de Defensa.

Almagro-Gorbea, M. y Lorrio, A. J. (2007). El signum equitum ibérico del Museo de Cuenca y los bronces ibéricos tipo «Jinete de la Bastida. En J. M. Millán y C. Rodríguez Ruza (Eds.). Arqueología de Castilla-La Mancha. I Jornadas (Cuenca, 2005) (pp. 17-51). Cuenca: Universidad de CastillaLa Mancha - Junta de Comunidades de Castilla la Mancha.

Almagro-Gorbea, M. y Lorrio, A. J. (2011). Teutates. El Héroe Fundador y el culto heroico al antepasado en Hispania y en la Keltiké. Bibliotheca Archaeologica Hispana, 36. Madrid: Real Academia de la Historia.

Almagro-Gorbea, M., Lorrio, A. J., Mederos, A. y Torres, M. (2008). La necrópolis de Medellín. III, Estudios analíticos. Interpretación. El marco histórico de Medellín-Conisturgis. Bibliotheca Archaeologica Hispana, 26, 3. Studia HispanoPhoenicia 5, 3. Madrid: Real Academia de la Historia.

Almagro-Gorbea, M., Lorrio, A. J. y Simón, J. L. (20152016). Los pilares-estela de la Necrópolis de Capuchinos (Caudete, Albacete). Anales de Prehistoria y Arqueología de la Universidad de Murcia, 31, 59-84.

Almagro-Gorbea, M., Lorrio, A. J. y Vico, A. (2019). Los signa equitum o estandartes ibéricos de tipo «jinete de La Bastida». Saguntum, 51, 86-119. DOI: https://doi.org/10.7203/ SAGVNTVM.51.13826

Almagro-Gorbea, M. y Moneo, T. (2000). Santuarios urbanos en el mundo ibérico. Bibliotheca Archaeologica Hispana, 4. Madrid: Real Academia de la Historia.

Almagro-Gorbea, M. y Ramos Fernández, R. (1986). El monumento ibérico de Montforte del Cid (Alicante). Lucentum, V, 45-63. DOI: https://doi.org/10.14198/ LVCENTVM1986.5.03

Almagro-Gorbea, M. y Torres, M. (2006). Plástica siriofenicia en Occidente: la sirena de Villaricos y el origen de la plástica ibérica. Madrider Mitteilungen, 47, 59-82.

Almagro-Gorbea, M. y Torres, M. (2010). Escultura Fenicia en Hispania. Bibliotheca Archaeologica Hispana, 32. Madrid: Real Academia de la Historia. 
Altekamp, S. (1991). Zu griechischer Architekturornamentik im sechsten und fünften Jahrhundert v. Chr. Exemplarische archäologische Auswertung der nicht-dorischen Blattornamentik. Frankfurt am Main: Lang.

Alvar, J. (1986). Theron, rex Hispaniae Citerioris (Macr. Sat. I,20,12). Gerión, 4, 161-175.

Álvarez Ossorio, F. (1941). Museo Arqueológico Nacional. Catálogo de los exvotos de bronce ibéricos, Madrid: Museo Arqueológico Nacional.

Álvarez Peña, A. (2007). Elementos de la Antigüedad celta en la tradición oral asturiana. En Pasado y presente de los estudios celtas (pp. 243-258). Ortigueira: Fundación Ortegalia - Instituto de Estudios Celtas.

Álvarez-Sanchís J., Lorrio, A. J. y Ruiz Zapatero, G. (2016). Los primeros elementos de hierro en Iberia. En Homenaje a la Profesora Concepción Blasco Bosqued (pp. 149-165). Anejos a Cuadernos de Prehistoria y Arqueología de la Universidad Autónoma de Madrid, 2. Madrid. Universidad Autónoma de Madrid. DOI: https://doi.org/10.15366/ane2. blasco2016.012

Antonelli, L. (1997). I Greci oltre Gibilterra. Rappresentazioni mitiche dell'estremo occidente e navigazioni commerziali nello spazio atlantico fra VIII e IV secolo a. $C$. Hespería, 8. Roma: L’Erma di Bretschneider.

Antonelli, L. (1998). Il periplo nascosto: lettura stratigrafica e commento storico-archeologico dell'Ora maritima di Avieno. Padova: Esedra.

Antonelli, L. (2006). Da Taršiš a Tartesso. Riflessioni sulla presenza greca oltre Gibilterra durante l'età arcaica. Gerión, 24(1), 7-26.

Antonelli, L. (2008). Traffici focei di età arcaica: dalla scoperta dell'Occidente alla battaglia del mare sardonio. Hespería, 23. Roma: L'Erma di Bretschneider.

Aquilué, X., Castanyer, P., Santos, M. y Tremoleda, J. (2000). Les ceràmiques gregues arcaiques de la Palaià Polis d'Empòrion. En P. Cabrera y M. Santos (Eds.). Ceràmiques jònies d'època arcaica: centres de producción $i$ comercialització al Mediterrani occidental (Empúries, 1999) (pp. 285-338). Barcelona: Museu d'Arqueologia de Catalunya.

Arancibia, A., Escalante, M. ${ }^{a}$ del M. (2006). Génesis y consolidación de la ciudad de Malaka. En Memoria arqueológica del Museo Picasso de Málaga: desde los orígenes hasta el siglo V d.C. (pp. 41-78). Málaga: Museo Picasso Málaga.

Aranegui, C. (1981). Las influencias mediterráneas. En M. Gil-Mascarell y C. Aranegui. El Bronce Final y el comienzo de la Edad del Hierro en el País Valenciano. Monografias del laboratorio de arqueologia de Valencia, 1. Valencia: Universitat de Valencia.

Aranegui, C., Jodin, A., Llobregat, E., Rouillard, P. y Uroz, J. (1993). La nécropole ibérique de Cabezo Lucero. Guardamar del Segura, Alicante. Collection de la Casa de Velázquez, 41. Madrid - Alicante: Casa de Velázquez - Diputación Provincial de Alicante.
Arasa, F. (2009). Els camins antics de la partida de Ferriol d'Elx (el Baix Vinalopó). Lucentum, XXVIII, 75-90. DOI: https://doi.org/10.14198/LVCENTVM2009.28.05

Arribas, A. (1967). La necropolis bastitana del Mirador de Rolando (Granada). Pyrenae, 3, 67-105.

Arteaga, O. (1976-78). Problemática general de la iberización en Andalucía oriental y en el sudeste de la península. En Simposi Internacional Els Origens del món ibèric. Ampurias, 38-40, 23-60.

Arteaga, O. (1979-1980). Las primeras fases del poblado de Los Saladares. Una contribución al estudio del Bronce Final en la Península Ibérica. Ampurias, 41-42, 65-137.

Arteaga, O. y Serna, M. R. (1975). Los Saladares-71. Noticiario Arqueológico Hispano, 3, 7-140.

Arteaga, O. y Serna, M. R. (1979-80). Las primeras fases del poblado de los Saladares (Orihuela, Alicante). Una contribución al estudio del Bronce Final en la Península Ibérica (Estudio crítico 1). Ampurias, 41-42, 65-137.

Aubet, M. ${ }^{\text {a }}$ E. (2005). Mainake. The legend and the new archaeological evidence. Proceedings of the British Academy, 126, 187-202. DOI: https://doi.org/10.5871/ bacad/9780197263259.003.0009

Aurenche, O. (1993). L'origine de la brique dans le Proche Orient ancien. En M. Frangipane, H. Hauptmann, M. Liverani, P. Matthiae y M. Mellink (Eds.). Between the rivers and over the mountains. Archaeologica Anatolica et Mesopotamica Alba Palmieri Dedicata (pp. 71-86). Roma: Universita di Roma «La Sapienza».

Ays, H. (2013). Die alten Griechen in Schwaben. Norderstedt: Books on Demand.

Azuar, R., Rouillard, P., Gailledrat, E., Moret, P., Sala Sellés, S. y Badie, A. (1998). El asentamiento orientalizante e ibérico antiguo de «La Rábita», Guardamar del Segura (Alicante). Avance de las excavaciones 1996-1998. Trabajos de Prehistoria, 55(2), 111-126. Recuperado de: http://tp.revistas.csic. es/index.php/tp/article/view/306/306

Azuar, R., Rouillard, P., Gailledrat, E., Moret, P. y Sala Sellés, S. (2000). L'établissement orientalisant et ibérique ancien de «La Rábita». Guardamar del Segura (Alicante, Espagne). En Scripta in honorem Enrique Llobregat Conesa (pp. 265-285). Alicante: Instituto de Estudios Alicantinos Juan Gil-Albert.

Badie, A., Gailledrat, E., Moret, P., Rouillard, P., Sánchez, M. P. y Sillières, P. (2000). Le site antique de La Picola à Santa Pola (Alicante, Espagne). Madrid: Casa de Velázquez.

Bardelli, V. (2017). Die wahre italische Faszination. Die Funde aus dem keltischen Grab von Bad Dürkheim und ihre Geschichten. Mosaiksteine, 14. Mainz: Römisch-Germanischen Zentralmuseums.

Bardelli, G. y Graells, R. (2012). Wein, Weib und Gesang. A propósito de tres apliques de bronce arcaicos entre la Península y Baleares. Archivo Español de Arqueología, 85, 23-42. DOI: https://doi.org/10.3989/aespa.085.012.002

Barrier, B. y Montenat, Ch. 2007. Le paysage de l'époque protohistorique à l'embouchure du Segura. Approche 
paléogéographique. En P. Rouillard, E. Gailledrat y F. Sala Sellés (Eds.). L'établissement protohistorique de La Fonteta (fin VIII ${ }^{e}$-fin $V^{e}$ siècle av. J.-C.) (pp. 9-21). Collection de la Casa Velázquez, 96, Madrid: Casa Velázquez.

Barrio Vega, M. L. del. (2018). The Greek Language of the Black Sea. En G. Giannakis, E. Crespo y P. Filos (Eds.). Studies in Ancient Greek Dialects: From Central Greece to the Black Sea (pp. 511-530). Trends in Classics, Supplementary Volumes, 49. Berlin - Boston: De Gruyter. DOI: https://doi. org/10.1515/9783110532135-026

Belén, M. ${ }^{\text {a }}$ (1993). Mil años de historia de Coria: la ciudad prerromana. En Arqueología de Coria del Río y su entorno (pp. 35-62). Revista Azotea, 11-12. Coria del Río: Ayuntamiento de Coria del Río.

Bernardini, P. (2001). La battaglia del Mare Sardo: una rilettura. Rivista di Studi Fenici 29(2), 135-158.

Bernardini, P., Spanu, P. G. y Zucca, R. (Eds.). (2000). Machè. La battaglia del mare sardonio. Studi e ricerche (catálogo de exposición). Cagliari: Oristano.

Blanco Freijeiro, A. (1960). Die klassische Würzeln der iberischen Kunst. Madrider Mitteilungen, 1, 101-121.

Blánquez, J. (1990a) La Vía Heraklea y El Camino de Aníbal. Nuevas interpretaciones de su trazado en las tierras del interior. En Simposio sobre la red Viaria en la Hispania Romana (Tarazona, 1987) (pp. 65-76). Zaragoza: Institución Fernando El Católico.

Blánquez, J. (1990b). La formación del mundo ibérico en el sureste de la Meseta (estudios arqueológicos de las necrópolis ibéricas de la provincia de Albacete). Albacete: Instituto de Estudios Albacetenses.

Blánquez, J. (1993). El mundo funerario albacetense y el problema de la escultura ibérica: la necrópolis de Los Villares.

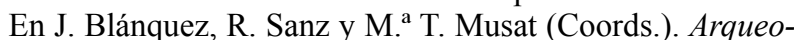
logía en Albacete: jornadas de arqueología albacetense en la Universidad Autónoma de Madrid (pp. 85-108). Albacete: Junta de Comunidades de Castilla-La Mancha.

Blánquez, J. (1997). Caballeros y aristócratas del siglo V a. C. en el mundo ibérico. En R. Olmos y J. A. Santos (Eds.). Iconografia ibérica, iconografia itálica: propuestas de interpretación y lectura (Roma, 1993) (pp. 211-234). Madrid: Universidad Autónoma de Madrid.

Blánquez, J. y Olmos, R. (1993). El poblamiento ibérico antiguo en la provincia de Albacete: el timiaterio de La Quéjola (San Pedro) y su contexto arqueológico. En J. Blánquez, R. Sanz y M. ${ }^{\mathrm{a}}$ T. Musat (Coords.). Arqueología en Albacete: jornadas de arqueología albacetense en la Universidad Autónoma de Madrid (pp. 85-108). Albacete: Junta de Comunidades de Castilla-La Mancha.

Blánquez, J. y Sanz Gamo, R. (2010). Caballeros ibéricos en torno a la Vía Hercúlea. Una mirada sobre la escultura ibérica. En P. Bueno, A. Gilman, C. Martín y F. J. Sánchez Palencia (Eds.). Arqueología, sociedad, territorio y paisaje. Estudios sobre Prehistoria reciente, Protohistoria y transición al mundo romano en homenaje a $M^{a}{ }^{a}$ Dolores Fernández Posse (pp. 253-278), Madrid: Consejo Superior de Investigaciones Científicas.
Blázquez, J. M. (1981). El mundo ibérico en los siglos inmediatos al cambio de Era. En La Baja época de la cultura ibérica. Actas de la mesa redonda celebrada en conmemoración del décimo aniversario de la Asociación Española de Amigos de la Arqueología (pp. 17-29). Madrid: Asociación Española de Amigos de la Arqueología.

Blech, M. (2001). Die Iberer. En M. Blech, M. Koch y M. Kunst (Eds.). Denkmäler der Frühzeit (Hispania Antiqua) (pp. 423-470). Mainz-am-Rhein: Zabern.

Blech, M. y Ruano, E. (1992). Zwei iberische Skulpturen aus Úbeda la Vieja (Jaén). Madrider Mitteilungen, 33, 70-101.

Boardman, J. (2006). Early Euboean settlements in the Carthage area. Oxford Journal of Archaeology, 25(2), 195-200. DOI: https://doi.org/10.1111/j.1468-0092.2006.00256.x

Bosch Gimpera, P. (1950). Una guerra entre cartagineses y griegos en España. La ignorada batalla del cabo Artemisión. Cuadernos de Historia Primitiva, 5, 4-55.

Botto, M. y Vives-Ferrándiz, J. (2006). Importazioni etrusche tra le Baleari e la Penisola Iberica (VIII-prima metà del V sec. a. C.). En G. M. della Fina (Ed.). Gli Etruschi e il Mediterraneo. Commerci e politica. Atti del XIII Convegno Internazionale di Studi sulla Storia e l'Archeologia dell'Etruria (Orvieto, 2005) (pp. 117-196). Annali della Fondazione per il Museo C. Faina, 13. Roma: Edizioni Quasar.

Bruhl, A. (1953). Liber Pater: origine et expansion du culte dionysiaque à Rome et dans le monde romain. Paris: De Boccard.

Brun, P. (1987). Princes et princesses de la Celtique. Le Premier Âge du Fer (850-450 av. J. C.). Paris: Errance Editions.

Cabrera, P. (1988-1989). El comercio foceo en Huelva: cronología y fisonomía. Huelva Arqueológica, 10-11(3), 41-100.

Cabrera, P. (2000). El comercio jonio arcaico en la Península Ibérica. En P. Cabrera y M. Santos (Eds.). Ceràmiques jònies d'època arcaica. Centres de producció i comercialització al Mediterrani occidental (Empúries, 1999) (pp. 165-177). Barcelona: Museu d'Arqueologia de Catalunya.

Cáceres, Y. (1997). Cerámicas y tejidos: Sobre el significado de la decoración geométrica del Bronce Final en la Península Ibérica. Complutum, 8, 125-140.

Caro Baroja, J. (1971). La 'realeza' y los reyes en la España Antigua. Cuadernos de la Fundación Pastor, 17, 51-159.

Carrasco, J., Pachón, J. A., Montero, I., González Prats, A. y Gámiz, J. (2013). ¿Fíbulas peninsulares de codo «sículas» o de tipo «Monachil»? Novedades y revisión. Lucentum, XXXII, 31-52. DOI: https://doi.org/10.14198/ LVCENTVM2013.32.02

Casas, J. y Soler, V. (2000). Materials arcaics del jaciment de Mas Gusó (Bellcaire d'Empordà). En P. Cabrera y M. Santos (Eds.). Ceràmiques jònies d'època arcaica: centres de produció i comercialització al Mediterrani Occidental (Empúries, 1999) (pp. 347-360). Barcelona: Museu d'Arqueologia de Catalunya.

Castanyer, P., Esteba, Q., Pons, E, Santos, M. y Tremoleda, J. (1999). La segunda etapa de l'hàbitat de l'Edat del Ferro: 
fase IIB. En X. Aquilué (Dir.). Intervencions arqueològiques a Sant Marti d'Empúries (1994-1996). De l'assentament precolonial a l'Empùries actual (pp. 139-215). Monografies Ampuritanes, 9. Barcelona: Museu d'Arqueologia de Catalunya.

Castillo, L. (2020). El espacio ibérico del sur de Albacete entre el s. VI y II a. C.: el ejemplo de los oppida de La Peña (Peñas de San Pedro) y Saltigi/Chinchilla y sus territorios. (Tesis doctoral inédita). Universidad de Alicante. Alicante.

Cerchiai, L. (2017). Urban civilisation. En A. Naso (Ed.). Etruscologia (pp. 617-644). Boston - Berlin: De Gruyter. DOI: https://doi.org/10.1515/9781934078495-035

Chapa, T. (1980). La escultura zoomorfa ibérica en piedra. (Tesis doctoral). Universidad Complutense. Madrid.

Chapa, T. (1985). La escultura ibérica zoomorfa. Madrid: Ministerio de Cultura.

Chapa, T. (1986). Influjos griegos en la escultura zoomorfa ibérica. Iberia Graeca. Serie Arqueologica 1. Madrid: Consejo Superior de Investigaciones Científicas.

Chapa, T. (2005). Las primeras manifestaciones escultóricas ibéricas en el oriente peninsular. Archivo Español de Arqueología, 78, 23-47. DOI: https://doi.org/10.3989/aespa.2005. v78.72

Chapa, T. y Belén Deamos, M. (2011). Viaje a la eternidad. El grupo escultórico del Parque Infantil de Tráfico (Elche, Alicante). Spal, 20, 151-174. DOI: https://doi.org/10.12795/ spal.2011.i20.10

Chazelles, C. A. de. (2011). La construction en brique crue moulée dans les pays de la Méditerranée, du Néolithique à l'époque romaine. En C. A. de Chazelles, A. Klein y N. Pousthomis (Eds.). Les cultures constructives de la brique crue. Echanges transdisciplinaires sur les constructions en terre crue (table ronde de Toulouse, $n^{\circ} 3$, mai 2008) (pp. 153164). Montpellier: Editions de l'Espérou.

Cisneros, M. ${ }^{\text {a } I ., ~ S u a ́ r e z, ~ J ., ~ M a y o r g a, ~ J . ~ y ~ E s c a l a n t e, ~ M . ~}{ }^{a}$ del M. (2000). Cerámicas griegas arcaicas en la bahía de Málaga. En P. Cabrera y M. Santos (Eds.). Ceràmiques jònies d'època arcaica: centres de produció i comercialització al Mediterrani Occidental (Empúries, 1999) (pp. 188-206). Barcelona: Museu d'Arqueologia de Catalunya.

Cozzoli, U. (1978). Dionisio di Focea. En Scritti Storicoepigrafici in memoria di Marcello Zambelli (pp. 87-102). Roma: Centro Editoriale Internazionale.

Croissant, F. y Rouillard, P. (1996). Problème de l'art 'grécoibère': état de la question. En R. Olmos y P. Rouillard. Formes archaïques et arts ibériques $=$ Formas arcaicas $y$ arte ibérico (pp. 55-66). Madrid: Casa de Velázquez.

Cuadrado, E. (1987). La necrópolis ibérica de «El Cigarralejo» (Mula, Murcia). Bibliotheca Praehistorica Hispana, 23. Madrid: Consejo Superior de Investigaciones Científicas.

Cutillas, B. y Ros Sala, M. ${ }^{a}$ M. (2020). Asentamientos polinucleares y resiliencia urbana entre el Bronce Final y la Edad del Hierro en el Sureste ibérico: nuevos datos a partir del
Castellar de Librilla. Complutum, 31(1), 71-96. DOI: https:// doi.org/10.5209/cmpl.71650

Dana, D. (2009). Alphabets et exercices scolaires dans deux cités du Pont ouest: Istros et Tyras. Zeitschrift für Papirologie und Epigraphik, 171, 74-75.

Daremberg, Ch. y Saglio, E. (Eds.). (1877). Dictionnaire des Antiquités grecques et romaines, I. Paris: Hachette.

Delibes, G., Rodríguez Marcos, J. A. y Santonja, M. (1991). Cuatro hallazgos de oro de la Edad del Bronce en la Meseta norte. Trabajos de Prehistoria, 48, 203-213. DOI: https://doi. org/10.3989/tp.1991.v48.i0.520

Deonna, W. (1953). Le symbolisme de l'acrobatie antique. Collection Latomus, IX. Bruxelles: Latomus.

Díes Cusí, E. (1994). Aspectos técnicos de las rutas comerciales fenicias en el Mediterráneo occidental (siglos IX-VII a. C.). Archivo de Prehistoria Levantina, 21, 311-336.

Diz, E. y Yus, S. (2014). El ídolo de Orihuela (Alicante). En Orihuela, arqueología y museo. Museos municipales en el MARQ (MARQ, febrero 2014-mayo 2014) (pp. 104-113). Alicante: Museo Arqueológico de Alicante - Museo Arqueológico de Orihuela.

Domínguez Monedero, A. (1984). La escultura animalística contestana como exponente del proceso de helenización del territorio. En Coloquio sobre distribución y relaciones entre los asentamientos. Del Bronce Final a Época Ibérica (pp. 141-160). Arqueología Espacial, 4. Teruel: Colegio Universitario de Teruel.

Domínguez Monedero, A. (1991). El enfrentamiento etrusco-foceo en Alalia y su repercusión en el comercio con la península ibérica. En J. Remesal y O. Musso (Eds.). La presencia de material etrusco en la Península Ibérica (pp. 239-273). Barcelona: Universitat Barcelona.

Domínguez Monedero, A. (2000). Los mecanismos del emporion en la práctica comercial de los foceos y otros griegos del Este. En P. Cabrera y M. Santos (Eds.). Ceràmiques jònies d'època arcaica. Centres de producció $i$ comercialització al Mediterrani occidental (Empúries, 1999) (pp. 165-177). Barcelona: Museu d'Arqueologia de Catalunya.

Domínguez Monedero, A. (2001-2002). Cerámica griega en la ciudad ibérica. Anales de Prehistoria y Arqueología, 17-18, 189-204.

Domínguez Monedero, A. (2009). El final del Arcaísmo y la transformación de los mecanismos de intercambio en el Mediterráneo. Gerión, 27(1), 127-146.

Domínguez Monedero, A. (2010). Cartago y Sicilia durante los siglos VI y V a. C. Mainake, 32(2), 735-759.

Domínguez Monedero, A. (2013). Los primeros griegos en la península ibérica: mitos, probabilidades, certezas. En M. ${ }^{\mathrm{a}}$ P. de Hoz y G. Mora (Eds.). El oriente griego en la península ibérica. Epigrafía e Historia (pp. 11-42). Bibliotheca Archaeologica Hispana, 39. Madrid: Real Academia de la Historia.

Domínguez Monedero, A. (2014). (Algunos) griegos (más) en Tarteso. En P. Bádenas, P. Cabrera, M. Moreno, A. Ruiz 
Rodríguez, C. Sánchez Fernández y T. Tortosa (Eds.). Homenaje a Ricardo Olmos. Per speculum in aenigmate. Miradas sobre la Antigüedad (pp. 249-255). Madrid: Asociación Cultural Hispano-Helénica.

Domínguez Monedero, A. y Sánchez, C. (2001). Greek Pottery from the Iberian Peninsula. Archaic and Classical Periods. Leiden: Brill.

Dridi, H. y Duboeuf, P. (2007). Les élements architecturaux antiques réemployés dans La Rabita d'époque califal. En P. Rouillard, E. Gailledrat y F. Sala Sellés (Eds.). L'établissement protohistorique de La Fonteta (fin VIII'-fin $V I^{e}$ siècle av. J.-C.) (pp. 155-183). Collection de la Casa Velázquez, 96, Madrid: Casa de Velázquez.

Dubois, L. (1989). Inscriptions grecques dialectales de Sicile. Contribution à l'étude du vocabulaire grec colonial. Collection de l'École Française de Rome, 119. Rome: École Française de Rome.

Ehlers, W. (1953). Porsenna. En Pauly-Wissowa (Eds.). RealEncyclopädie der classischen Altertumswissenschaft, 22 (pp. 315-322). Stuttgart: J. B. Metzler.

Escacena, J. L.y Izquierdo, R. (1996). Caura protohistórica. Revista de Arqueología, 184, 16-25.

Espada, J. (2009). El primer tratado romano-cartaginés: análisis historiográfico y contexto histórico. (Tesis doctoral). Universidad de Valencia. Valencia. Recuperado de: http://hdl. handle.net/10803/9962

Espada, J. (2013). Los dos primeros tratados romano-cartagineses. Análisis historiográfico y contexto. Col·lecció Instrumenta, 43. Barcelona: Universitat de Barcelona.

Esquembre, M. A. y Ortega, J. R. (2017). El poblado fortificado del Castellar (Villena, Alicante). En F. Prados y F. Sala (Eds.). El Oriente de Occidente. Fenicios y púnicos en el área ibérica. VIII Coloquio Internacional del CEFYP (Alicante - Guardamar del Segura, 7-9 de noviembre de 2013) (pp. 129-154). Alicante: Universidad de Alicante.

Farnié, C. y Quesada, F. (2005). Espadas de hierro, grebas de bronce. Símbolos de poder e instrumentos de guerra a comienzos de la Edad del Hierro en la Península Ibérica. Monografías del Museo de Arte Ibérico de El Cigarralejo, 2. Murcia: Museo de Arte Ibérico El Cigarralejo.

Fernández Flores, A y Rodríguez Azogue. A. (2007). Tartessos desvelado: Origen y ocaso de Tartessos. Córdoba: Almuzara.

Fernández Jurado, J., Rufete, P. y García Sanz, C. (1994). Cerámicas griegas del solar $n^{\circ} 5$ de la C/ Méndez Núñez de Huelva. En P. Cabrera, R. Olmos y E. Sanmartí (Coords.). Iberos y Griegos: lecturas desde la diversidad (pp. 67-96). Huelva Arqueológica, XIII. Huelva: Diputación provincial de Huelva.

Fernández Montoro, J. L., Lostal, J. y Rodríguez Morales, J. (2011). La calzada romana de Carthago Nova a Complutum: síntesis de su recorrido. El Nuevo Miliario, 13, 32-54.

Ferrer, C. 2010: El medio físico de la Vega Baja y el litoral de Guardamar: la génesis cultural de un paisaje. En Guardamar del Segura, arqueología y museo. Museos municipales en el MARQ (MARQ, diciembre 2010-febrero 2011) (pp. 32-45). Alicante: Museo Arqueológico de Alicante - Museo Arqueológico de Guardamar del Segura.

Ferrer, C. y Blázquez, A. M. (1999). Algunos aspectos de la dinámica sedimentaria durante el Holoceno superior de un sector del Baix Vinalopó (Alicante). En L. Pallí y C. Roqué (Eds.). Avances en el estudio del Cuaternario español (pp. 95-105). Girona: Universidad de Girona.

Ferrer Albelda, E. (2011-2012). Más acá y más allá de las Columnas de Heracles. Mastia Tarseion y las limitaciones al comercio en Iberia. En Homenaje al profesor Manuel Bendala Galán, II. (pp. 431-445). Cuadernos de Prehistoria y Arqueología de la Universidad Autónoma de Madrid, 37-38. Madrid: Universidad Autónoma de Madrid. DOI: https://doi. org/10.15366/cupauam2012.38.021

Florido, D. D., García Alfonso, E., Navarrete, V., Ruiz, N. y Sabastro, M. A. (2012). Varar y comerciar en la marisma. Guadalmar y el entorno del Cerro del Villar en época tardoarcaica. En E. García Alfonso (Eds.). Diez años de arqueología fenicia en la provincia de Málaga (2001-2010). María del Mar Escalante Aguilar in memoriam (pp. 137-170). Sevilla: Consejería de Cultura y Deporte.

Foat, F. W. G. (1905). Tsade and Sampi. Journal of Hellenic Studies, 25, 338-365. DOI: https://doi.org/10.2307/624245

Foat, F. W. G. (1906). Fresh evidence for T [Sampi]. Journal of Hellenic Studies, 26, 286-287. DOI: https://doi. org/10.2307/624245

Fougère, F. (2016). La tombe de Vix: un trésor celte entre histoire et légende. Lyon: Fage.

Fundoni, G. y Bulla, C. (2015). Alcuni bronzi atlantici nelle isole Baleari e Pitiuse: tracce lungo le rotte tra la Sardegna e la Penisola Iberica tra Bronzo Finale e prima età del Ferro. En C. Andreu, C. Ferrando y O. Pons. L'entreteixit dels temps. Miscel lania d'estudis en homenatge a Lluís Plantalamor Massanet (pp. 175-184). Palma de Mallorca: Museu de Menorca.

Gadolou, A. (2017). Thapsos-class pottery style: a language of common communication between the Corinthian Gulf communities. En S. Handberg y A. Gadolou (Eds.). Material koinai in the Greek Iron Age and Archaic period (pp. 323-342). Monographs of the Danish Institute at Athens, 22. Aarhus: Aarhus University Press - The Danish Institute at Athens.

Gailledrat, E. (2007a). La stratigraphie. En P. Rouillard, E. Gailledrat y F. Sala (Eds.). L'établissement protohistorique de La Fonteta (fin VIII ${ }^{e}$-fin VI siècle av. J.-C.) (pp. 23-92). Collection de la Casa de Velázquez, 96. Madrid: Casa de Velázquez.

Gailledrat, E. (2007b). Architecture domestique et urbanisme des phases IV et V (v. 600-525/500 av. J.-C. En P. Rouillard, E. Gailledrat y F. Sala (Eds.). L'établissement protohistorique de La Fonteta (fin VIII'-fin VI siècle av. J.-C.) (pp. 140-155). Collection de la Casa de Velázquez, 96. Madrid: Casa de Velázquez. 
Gailledrat, E. y P. Rouillard. (2000). Le mobilier. En A. Badie, E. Gailledrat, P. Moret, P. Rouillard, M. P. Sánchez y P. Sillières. Le site antique de La Picola à Santa Pola (Alicante, Espagne) (pp. 145-220). Madrid: Casa de Velázquez.

Ganzert, J. (1983). Zur Entwicklung lesbischer KymationForme. Jahrbuch des Deutschen Archäologischen Instituts, 98, 123-202.

García Alfonso, E. (2018). Malaka en los siglos VII-VI a. C. Los orígenes de una ciudad-estado fenicia occidental. En D. García González, S. López Chamizo y E. García Alfonso (Eds.). La tumba del guerrero. Un enterramiento excepcional de la Málaga fenicia del siglo VI a. C. (pp. 25-74). Sevilla: Consejería de Cultura.

García Alonso, J. L. (1996). Nombres griegos en -oussa en el Mediterráneo occidental. Complutum, 7, 105-124.

García Bellido, A. (1943). La Dama de Elche y el conjunto de piezas reingresadas en España en 1941. Madrid: Consejo Superior de Investigaciones Científicas, Instituto Diego Velázquez.

García Bellido, A. (1948). Hispania Graeca, I-II. Barcelona: Casa de Caridad.

García Bellido, A. (1952). Los mercenarios españoles en Cerdeña, Sicilia, Grecia, Italia y Norte de África. En R. Menéndez Pidal (Ed.). Historia de España, I, 3 (pp. 647680). Madrid: Espasa Calpe.

García Borja, P., Carrión, Y., Collado, I., Montero, I. Muñoz, M., Pérez, G. y Vives-Ferrándiz, J. (2010). Campaña de excavación arqueológica de urgencia en Caramoro II (Elx, Alacant). MARQ, Arqueología y Museos, 4, 37-66.

García Borja, P., Verdasco, C., Muñoz, M., Carrión, Y., Pérez, G., Tormo, C. y Trelis, J. (2007). Materiales arqueológicos del Bronce final aparecidos junto al Barranc del Botx (Crevillent, Alacant). Recerques del Museu d'Alcoi, 16, 89-112.

García Cano, J. M. (1991). El comercio arcaico en Murcia. En J. Remesal y O. Musso (Eds.), La presencia de material etrusco en la Península Ibérica. (pp. 369-382). Barcelona: Universidad de Barcelona.

García Gelabert, M. ${ }^{a}$ P. y Blázquez, J. M. ${ }^{\text {a }}$ (1987-1988). Mercenarios hispanos en las fuentes literarias y en la arqueología. Habis, 18-19, 257-270.

García González, D., López Chamizo, S., Cumpián, A. y Sánchez Bandera, P. J. (2013). La Tumba del Guerrero. Un hallazgo de época protohistórica en Málaga. Mainake, 34, 277-292.

García González; D., López Chamizo, S y García Alfonso, E. (2018). La tumba del guerrero. Un enterramiento excepcional de la Málaga fenicia del siglo VI a. C. Sevilla: Junta de Andalucía, Consejería de Cultura.

García Martín, J. M. (2000). El comercio de cerámicas griegas en el sur del País Valenciano en época arcaica. En P. Cabrera y M. Santos (Eds.), Ceràmiques jònies d'època arcaica. centres de producción i comercialització al Mediterrani occidental (pp. 207-223). Barcelona: Museu d'Arqueologia de Catalunya.
García Martín, J. M. (2003). La distribución de cerámica griega en la Contestanía ibérica. El puerto comercial de La Illeta dels Banyets. Alicante: Diputación Provincial de Alicante, Instituto Alicantino de Cultura Juan Gil-Albert.

García Martín, J. M. (2011). Las cerámicas griegas. En A. González Prats (Ed.) La Fonteta. Excavaciones de 1996-2002 en la colonia fenicia de la actual desembocadura del río Segura (Guardamar del Segura, Alicante), Vol. 1 (pp. 531560). Alicante: Universidad de Alicante.

García Martín, J. M. y Llopis, M. T. (1995). Una crátera de columnes de figures negres a la Necròpolis de l'Albufereta d'Alacant (l'Alacantí). Actas del XXIII Congreso Nacional de Arqueología (Elche, 1995), Vol. I (pp. 473-480): Elche: Ajuntament d'Elx.

García Menárguez, A. y Prados, F. (2014). La presencia fenicia en la Península Ibérica: el Cabezo Pequeño del Estaño (Guardamar del Segura, Alicante). Trabajos de Prehistoria, 71(1), 113-133. DOI: https://doi.org/10.3989/ tp.2014.12127

García Menárguez, A. y Prados, F. (2017). Las defensas y la trama urbana del Cabezo del Estaño de Guardamar. Un encuentro fortificado entre fenicios y nativos en la desembocadura del río Segura (Alicante). En F. Prados y F. Sala (Eds.). El Oriente de Occidente. Fenicios y púnicos en el área ibérica. VIII Coloquio Internacional del CEFYP (Alicante - Guardamar del Segura, 7-9 de noviembre de 2013) (pp. 51-78). Alicante: Universidad de Alicante.

Gerbach, E. (1995). Baubefunde der Perioden IVc-IVa des Heuneburg. Heuneburgstudien, IX. Römisch-Germanische Forschungen, 53. Mainz-am-Rhein: Verlag Philip von Zabern.

Ghinatti, F. (1999). Alfabeti greci. Torino: Paravia Scriptorium.

Giangiulio, M. (2016). Le politeiai delle città della Magna Grecia: peculiarità e dinamiche. En Poleis e politeiai nella Magna Grecia arcaica e classica. Atti del 53 convegno di studi sulla Magna Grecia (Taranto, 2013) (pp. 203-214). Taranto: ISAMG - Istituto per la Storia e l'Archeologia della Magna Grecia.

Gombrich, E. H. (1962). Art and Illusion. A Study in the Psychology of Pictorial Representation ${ }^{2}$. London: Pantheon Book.

Gómez Bellard, C. (1990). La colonización fenicia de la isla de Ibiza. Excavaciones Arqueológicas en España, 157. Madrid: Ministerio de Cultura.

Gómez-Moreno, M. (1922). De Epigrafía ibérica: el plomo de Alcoy. Revista de filología española, 9, 341-366.

González de Canales, F. (2014). Tarshish-Tartessos, the Emporium Reached by Kolaios of Samos. En A. Lemaire (Ed.). Phéniciens d'Orient et d'Occident. Mélanges Josette Elayi (pp. 559-576). Cahiers de l'Institut du Proche-Orient Ancien du Collège de France, 2. Paris: Librairie d'Amérique et d'Orient Adrien Maisonneuve.

González de Canales, F. y Llompart, J. (2017). Producción de cerámicas griegas arcaicas en Huelva. Archivo Español 
de Arqueología, 90, 125-145. DOI: https://doi.org/10.3989/ aespa.090.017.006

González de Canales, F., Serrano, L. y Llompart, J. (2004). El emporio fenicio precolonial de Huelva (ca. 900-770 a. C.). Madrid: Biblioteca Nueva.

González Navarrete, J. A. (1987). Escultura ibérica de Cerrillo Blanco: Porcuna, Jaén. Jaén: Diputación Provincial de Jaén.

González Prats, A. (1976). Breve noticia sobre el tesorillo orientalizante de la Sierra de Crevillente (Alicante). Pyrenae, $12,173-175$.

González Prats, A. (1978). El tesorillo de tipo orientalizante de la Sierra de Crevillente. En Symposium dels Origens del Món Ibèric (pp. 349-360). Ampurias, 38-40 (1976-78). Barcelona: Museu d'Arqueologia de Catalunya.

González Prats, A. (1979). Excavaciones en el yacimiento protohistórico de la Peña Negra, Crevillente (Alicante) $\left(1^{a}\right.$ y $2^{a}$ campañas. Excavaciones Arqueológicas en España, 99. Madrid: Ministerio de Cultura.

González Prats, A. (1982). La Peña Negra IV. Excavaciones en el Sector VII de la ciudad orientalizante 1980-1981. Noticiario Arqueológico Hispánico, 13, 305-418.

González Prats, A. (1983). Estudio arqueológico del poblamiento antiguo de la Sierra de Crevillente (Alicante). Anejo I de la revista Lucentum. Alicante: Universidad de Alicante.

González Prats, A. (1985). La Peña Negra II-III. Campañas de 1978 y 1979. Noticiario Arqueológico Hispánico. Arqueología, 21, 13-150.

González Prats, A. (1986). Las importaciones y la presencia fenicia en la sierra de Crevillente (Alicante). Aula Orientalis, 4, 279-302.

González Prats, A. (1990). Nueva luz sobre la Protohistoria del Sudeste. Alicante: Universidad de Alicante.

González Prats, A. (1991). La presencia fenicia en el Levante peninsular y su influencia en las comunidades indígenas. En I-IV Jornadas de arqueología fenicio-púnica (Ibiza, 1986-89) (pp. 109-118). Treballs del Museu Arqueologic d'Eivissa i Formentera, 24. Eivissa: Govern de Les Illes Balears.

González Prats, A. (1992). Una vivienda metalúrgica en La Peña Negra (Crevillent, Alicante). Aportaciones al conocimiento del Bronce Atlántico en la Península Ibérica. Trabajos de Prehistoria, 49, 243-257. DOI: https://doi.org/10.3989/ tp.1992.v49.i0.544

González Prats, A. (1993). Quince años de excavaciones en la ciudad protohistórica de Herna (La Penya Negra, Crevillente, Alicante). Saguntum, 26, 181-188.

González Prats, A. (1998). La Fonteta. El asentamiento fenicio de la desembocadura del río Segura (Guardamar, Alicante, España). Resultados de las excavaciones de 199697. Rivista di Studi Fenici, 26(2), 191-228.

González Prats, A. (2001). Arquitectura orientalizante en el Levante peninsular. En D. Ruiz Mata y S. Celestino (Eds.). Arquitectura Oriental y Orientalizante en la Península
Ibérica (pp. 173-193). Madrid: CEPO-Consejo Superior de Investigaciones Científicas.

González Prats, A. (2002). La necrópolis de cremación de "Les Moreres». Crevillente, Alicante, España (S. IX-VII a. C.). Alicante: Universidad de Alicante.

González Prats, A. (2005). Balanç de vint-i-cinc anys d'investigació sobre la influència i presència fenícia a la província d'Alacant. Fonaments, 12, 41-64.

González Prats, A. (2010a). La presencia fenicia en el Bajo Segura. En Guardamar del Segura, arqueología y museo. Museos municipales en el MARQ (MARQ, diciembre 2010-febrero 2011) (pp. 58-65). Alicante: Museo Arqueológico de Alicante - Museo Arqueológico de Guardamar del Segura.

González Prats, A. (2010b). La colonia fenicia de La Fonteta. En Guardamar del Segura, arqueología y museo. Museos municipales en el MARQ (MARQ, diciembre 2010-febrero 2011) (pp. 66-79). Alicante: Museo Arqueológico de Alicante - Museo Arqueológico de Guardamar del Segura.

González Prats, A. (Coord.). (2011). La Fonteta. Excavaciones de 1996-2002 en la colonia fenicia de la actual desembocadura del río Segura (Guardamar del Segura, Alicante), Vol. 1. Alicante: Universidad de Alicante.

González Prats, A. (2011a). Memoria de las excavaciones. En A. González Prats (Coord.) La Fonteta. Excavaciones de 1996-2002 en la colonia fenicia de la actual desembocadura del río Segura (Guardamar del Segura, Alicante), Vol. 1 (pp. 7-86). Alicante: Universidad de Alicante.

González Prats, A. (2011b). Elementos simbólicos y arquitectónicos: estelas betiliformes y cornisas en gola egipcia. En A. González Prats (Coord.) La Fonteta. Excavaciones de 1996-2002 en la colonia fenicia de la actual desembocadura del río Segura (Guardamar del Segura, Alicante), Vol. 1 (pp. 658-672). Alicante: Universidad de Alicante.

González Prats, A. (Coord.). (2014a). La Fonteta-2: estudio de los materiales arqueológicos hallados en la colonia fenicia de la actual desembocadura del río Segura (Guardamar, Alicante), Tomo I. Alicante: Universidad de Alicante.

González Prats, A. (Coord.). (2014b). La Fonteta-2: estudio de los materiales arqueológicos hallados en la colonia fenicia de la actual desembocadura del río Segura (Guardamar, Alicante), Tomo II. Alicante: Universidad de Alicante.

González Prats, A. (2014a). Útiles y objetos suntuarios. En A. González Prats (Coord.). La Fonteta-2: estudio de los materiales arqueológicos hallados en la colonia fenicia de la actual desembocadura del río Segura (Guardamar, Alicante), Tomo I (pp. 239-313). Alicante: Universidad de Alicante.

González Prats, A. (2014b). La cerámica a torno: tipos 23-32, 35-42 y 44-48. En A. González Prats (Coord.). La Fonteta-2: estudio de los materiales arqueológicos hallados en la colonia fenicia de la actual desembocadura del rio Segura (Guardamar, Alicante), Tomo II (pp. 573-671). Alicante: Universidad de Alicante.

González Prats, A. y Ruiz Segura, E. (1992). Un poblado fortificado del Bronce Final en el Bajo Vinalopó. Homenaje a Enrique Pla Ballester (pp. 17-27). Trabajos Varios del SIP, 89. Valencia: Diputación Provincial de Valencia. 
González Prats, A. y Ruiz Segura, E. (2000). El yacimiento fenicio de La Fonteta (Guardamar del Segura, Alicante, Comunidad Valenciana). Serie Popular, 4. Valencia: Real Academia de Cultura Valenciana.

Graells, R. (2006). El aryballos corintio de la necrópolis de Milmanda (Vimbodí, Tarragona) y su cronología. Archivo Español de Arqueología, 79, 207-216. DOI: https://doi. org/10.3989/aespa.2006.v79.10

Graells, R. (2007). ¿Culto heroico durante la primera edad del Hierro e Ibérico antiguo en el Noreste peninsular? Algunas consideraciones a partir del registro funerario. Cuadernos de Prehistoria y Arqueología de la Universidad Autónoma de Madrid, 33, 91-115. DOI: https://doi.org/10.15366/ cupauam2007.33.005

Graells, R. (2008). Vasos de bronce 'a kouroi' en el Occidente arcaico a la luz de un nuevo ejemplar procedente de Cuenca. Archivo Español de Arqueología, 81, 201-212. DOI: https:// doi.org/10.3989/aespa.2008.v81.46

Graells, R. (2009). Banquet funerari i elements de banquet en tombes del nord-est de la Península Ibèrica entre la primera Edat del Ferro i l'Ibèric antic. Citerior. Arqueologia i ciències de l'Antiguitat, 5, 189-218.

Graells, R. (2012). Discos-coraza de la Península Ibérica (s. VI-IV a. C.). Jahrbuch des Römisch-Germanischen Zentralmuseums, 59, 85-244.

Graells, R. (2014). Mistophoroi ex iberias. Una aproximación al mercenariado hispano a partir de las evidencias arqueológicas (s. $V I-I V$ a. C.). Venosa: Osanna Edizioni.

Graells, R. (2016). La influencia del mercenariado hispánico sobre el armamento de la Península Ibérica (s. VI-IV a. C.) En R. Graells i Fabregat y D. Marzoli (Eds.). Armas de la Hispania prerromana Waffen im vorrömischen Hispanien. Actas del Encuentro Armamento y arqueología de la guerra en la Península Ibérica prerromana (s. VI-I a. C.): problemas, objetivos y estrategias (Madrid, 2014) (pp. 37-77). Römisch-Germanischen Zentralmuseums, Band 24. Mainz: Römisch-Germanischen Zentralmuseums.

Graells, R. y Bottini, A. (2017). Una jarra 'rodia' en la necrópolis de El Molar (San Fulgencio, Alicante). Lucentum, XXXVI, 33-40. DOI: http://dx.doi.org/10.14198/ LVCENTVM2017.36.02

Graells, R. y Lorrio, A. J. (2017). Problemas de cultura material: broches de cinturón decorados a molde de la Península Ibérica (s. VII-VI a. C.). Anejo de la revista Lucentum, 22 , Alicante: Universidad de Alicante.

Gran-Aymerich, J. M. J. (1988). Cerámicas griegas y etruscas de Málaga. Excavaciones de 1980 a 1986. Archivo Español de Arqueología, 61, 201-222.

Gran-Aymerich, J. M. J. (1991). Malaga phénicienne et punique: recherches franco-espagnoles 1981-1988. Paris: Recherche sur les Civilisations.

Grau, I. y Moratalla, J. (2001). Interpretación socioeconómica del enclave. En L. Abad y F. Sala (Eds.). Poblamiento ibérico en el Bajo Segura: El Oral (II) y La Escuera (pp. 173-204). Bibliotheca Archaeologica Hispana, 12, Madrid: Real Academia de la Historia.
Grau, I. y Moratalla, J. (2004). El paisaje antiguo. En M. S. Hernández y L. Abad (Coms.). Iberia, Hispania, Spania. Una mirada desde Ilici (catálogo de exposición) (pp. 111-118). Alicante: Caja de Ahorros del Mediterráneo.

Gutiérrez Lloret, S., Moret, P., Rouillard, P. y Sillières, P. (1998-1999). Le peuplement du Bas Segura de la Protohistoire au Moyen-Âge (prospection 1989-1990). Lucentum, XVII-XVIII, 25-74. https://doi.org/10.14198/ LVCENTVM1998-1999.17-18.02

Herfort-Koch, M. (1986). Archaische Bronzeplastik Lakoniens. Boreas, Suppl., 4. Münster: Archäologisches Seminar der Universität.

Hernández Pérez, M. S. (1997). Desde la periferia de El Argar. La Edad del bronce en las tierras meridionales valencianas. Saguntum, 30, 93-114.

Hernández Pérez, M. S. (2017). Los tesoros de Villena: caracterización, uso y función de una ocultación de la Edad del Bronce. En A. Rodríguez, I. Pavón y D. M. Duque (Eds.). Historias de Tesoros, Tesoros con Historia. (pp. 37-59). Cáceres: Universidad de Extremadura.

Hernández Pérez, M. S. y López Mira, J. A. (1992). Bronce Final en el Medio Vinalopó. A propósito de dos conjuntos cerámicos del Tabaià (Aspe, Alicante). En Estudios de arqueología ibérica y romana: homenaje a Enrique Pla Ballester (pp. 1-15). Trabajos Varios del SIP, 89. Valencia: Diputación Provincial de Valencia.

Hoz, J. de. (1987). La escritura greco-ibérica. En Studia Paleohispanica: Actas del IV Coloquio sobre lenguas y culturas paleohispánicas (Vitoria, 1985) (pp. 285-298). Veleia, 2-3. Vitoria-Gasteiz: Universidad del País Vasco.

Hoz, J. de. (1998). Epigrafía griega de occidente y escritura greco-ibérica. En Los griegos en España, Tras las huellas de Heracles (catálogo de la exposición) (pp. 180-196). Madrid: Ministerio de Educación y Cultura, Secretaría de Estado de Cultura.

Hoz, J. de. (2009). La escritura greco-ibérica. En M. Olcina y J. J. Ramón (Eds.). Huellas Griegas en la Contestania Ibérica (pp. 30-41). Alicante: Museo Arqueológico de Alicante.

Hoz, J. de. (2010-2011). Historia Lingüistica de la Península Ibérica en la Antigüedad I-II. Madrid: Consejo Superior de Investigaciones Científicas.

Hoz, M. ${ }^{a}$ P. de. (2014). Inscripciones griegas de España y Portugal. Bibliotheca Archaeologica Hispana, 40. Madrid: Real Academia de la Historia.

Ibarra y Ruiz, P. (1926). Elche. Materiales para su historia. Ensayo demostrativo sobre su antigüedad e importancia histórica. Cuenca: Talleres tipográficos Ruiz de Lara.

Izquierdo, I. (2000). Monumentos funerarios ibéricos: los pilares-estela. Serie de Trabajos Varios del SIP, 98. Valencia: Diputación Provincial de Valencia.

Izquierdo, P. (2009). Pozo Moro y los cambios socio-económicos de la Protohistoria Ibérica durante los siglos V y IV antes de nuestra era. Arqueologia iberoamericana, $2,5-23$. 
Jannot, J. R. (1976). Les reliefs archaïques de Chiusi de 1 'Institut Archéologique Allemand de Rome. Römische Mitteilungen, 83, 207-225.

Jeffery, L. H. (1990). The local scripts of archaic Greece. A Study of the Greek Alphabet and its Development from the Eight to Fifth Centuries B. C. (Reed. revisada y completada por A. W. Johnston, Oxford).Oxford: Clarendon Press.

Jehasse, J. (1962). La «victoire à la Cadméenne» d'Hérodote (I, 166) et la Corse dans les courants d'expansion grecque. Revue des Études Anciennes, 64(3-4), 241-286. DOI: https:// doi.org/10.3406/rea.1962.3676

Jiménez Ávila, J. (2002). La toréutica orientalizante en la Península Ibérica. Bibliotheca Archaeologica Hispana, 16. Madrid: Real Academia de la Historia.

Jiménez Ávila, F. J. y Ortega, J. (2004). La cerámica griega en Extremadura. Cuadernos Emeritenses, 28. Mérida: Museo Nacional de Arte Romano - Fundación de Estudios Romanos.

Kourou, N. (1994). Corinthian wares and the West. En P. Nickels (Ed.). Ancient and traditional ceramics (pp. 27-53). PACT, 40. Rienxart: PACT Belgium.

Kourou, N. (2002). Phéniciens, Chypriotes, Eubéens et la fondation de Carthage. Cahiers du Centre d'Etudes Chypriotes, 32, 89-114. DOI: https://doi.org/10.3406/cchyp.2002.1406

Kreimerman, I. (2016). Siege Warfare, Conflict and Destruction: How are They Related? En S. Ganor, I. Kreimerman, K. Streit y M. Mumcuoglu (Eds.). From Sha'ar Hagolan to Shaaraim. Essays in Honor of Prof. Yosef Garfinkel (pp. 229-245. Jerusalem: Israel Exploration Society.

Krings, V. (1998). Carthage et les Grecs c. 580-480 av. J.-C. Textes et Histoire. Leiden-Boston-Köln: Brill.

Kukahn, E. (1967). Zur Frühfase der iberischen Bronzen. Madrider Mitteilungen, 8, 159-171.

Lafuente, J. (1929). La necrópolis ibérica de El Molar (provincia de Alicante). Boletín de la Real Academia de Historia, 94, 617-632.

Langlotz, E. (1966). Die kulturelle und künstlerische Hellenisierung der Küsten des Mittelmeers durch die Stadt Phokaia. Köln: Verlag für Sozialwissenschaften. DOI: https://doi. org/10.1007/978-3-322-98799-0

Le Meaux, H. y Sánchez de Prado, M. ${ }^{a}$ D. (2007). Le mobilier non céramique. En P. Rouillard, E. Gailledrat y F. Sala (Eds.) L'établissement protohistorique de La Fonteta (fin VIII -fin $V I^{e}$ siècle av. J.-C.) (pp. 319-337). Collection de la Casa de Velázquez, 96. Madrid: Casa de Velázquez.

Lillo, P. (1981). El poblamiento ibérico en Murcia. Murcia: Universidad de Murcia.

Llobregat, E. (1993). Arquitectura y escultura en la necrópolis de Cabezo Lucero. En C. Aranegui, A., Jodin, E. Llobregat, P. Rouillard y J. Uroz. La nécropole ibérique de Cabezo Lucero. Guardamar del Segura. Alicante (pp. 69-85). Madrid - Alicante: Casa de Velázquez - Diputación Provincial de Alicante.

Lo Schiavo, F. (1991). La Sardaigne et ses relations avec le Bronze Final Atlantique. En C. Chevillot y A. Coffyn (Eds.). Le Bronze Atlantique, 1er Colloque de Beynac-1990 (pp. 213-226). Beynac-Cazenac: Association des musées du Sarladais.

López Domínguez, M. A., Castilla, E. y Haro, J. de. (2006). Intervención arqueológica preventiva en la calle Berdigón $\mathrm{n}^{\mathrm{o}} 13$ de Huelva. Anuario Arqueológico de Andalucía, 2006, 2095-2111.

López Mondéjar. L. (2016). Más allá del valle del Thader: poblamiento y dinámicas territoriales en las comarcas merdionales murcianas entre los siglos V a. C.-II d. C. Archivo Español de Arqueología, 89, 133-162. DOI: https://doi. org/10.3989/aespa.089.016.007

López Pardo, F. (2005). Crono y Briareo en el umbral del Océano: un recorrido por la historia mítica de los viajes al confín del Occidente hasta los albores de la colonización. En A. Mederos, V. Peña y C. G. Wagner (Coords.). La navegación fenicia: tecnología naval y derroteros: encuentro entre marinos, arqueólogos e historiadores (pp. 1-42). Madrid: Centro de Estudios Fenicios y Púnicos.

López Pardo, F. (2006). La torre de las almas. Un recorrido por los mitos y creencias del mundo fenicio y orientalizante a través del monumento de Pozo Moro. Anejos de Gerión, 10. Madrid: Ediciones Complutense.

López Rosendo, E. (2007). El yacimiento arqueológico de Los Villares /Montealto y los orígenes tartésicos y romanos de la población de Jerez. Revista de Historia de Jerez, 13, 9-34.

Lorrio, A. J. (2005). Los Celtíberos. (2 ${ }^{\mathrm{a}}$ edición ampliada y actualizada). Bibliotheca Archaeologica Hispana 25, Complutum Extra, 7. Madrid: Real Academia de la Historia - Universidad Complutense de Madrid.

Lorrio, A. J. (2007). Historiografía y nuevas interpretaciones: la necrópolis de la Edad del Hierro de Haza del Arca (Uclés, Cuenca). En XXVI Congreso Nacional de Arqueología (Zaragoza 2001) (pp. 251-278). Caesaraugusta, 78. Zaragoza: Institución Fernando El Católico.

Lorrio, A. J. (2017). Arquitecturas funerarias y memoria durante el Bronce Final y el periodo orientalizante en el Sureste de la Península Ibérica (ss. X-VI a. C.). En S. Adroit y R. Graells (Dirs.). Arquitecturas funerarias y memoria. La gestión de las necrópolis en Europa occidental (ss. X-III a. C.), Actas del Coloquio del 13-14 marzo 2014 celebrado en La Casa de Velázquez (Madrid) (pp. 275-315). Venosa: Osanna Edizioni.

Lorrio, A. J. (2020). Herna/Peña Negra (Crevillent, Alicante). En I. Fumadó Ortega, A. J. Lorrio y J. Blánquez De Oriente a Occidente: Procesos de aculturación, adaptación y transformación de la arquitectura fenicio-púnica: Los casos de Cartago (Túnez), Peña Negra (Crevillente) y el Cerro de las Cabezas (Valdepeñas, Ciudad Real), VII Seminario Internacional Los Jueves feniciopúnicos. DAI-Madrid, UAM y UCM-CEFyP (Madrid, 2020). Recuperado de: https://www. dainst.org/-/jueves-feniciopunicos

Lorrio, A. J., Montero, I., Pernas, S., Torres, M., Trelis, J., Simón, J. L. y Simón, F. (2020a). Caracterización tecnológica y procedencia del metal de las barras-lingote de Peña Negra (Crevillent, Alicante). En S. Celestino Pérez y E. Rodríguez González (Eds.). Un viaje entre el Oriente y el Occidente del Mediterráneo, Actas del IX Congreso Internacional de 
Estudios Fenicios y Púnicos (Mérida, 2018), Vol. II. (pp. 851-868). MYTRA, 5. Mérida: Instituto Arqueología Mérida.

Lorrio, A. J., Pernas, S., Torres, M., Trelis, J., Castillo, L. y Camacho, P. (2020b). Peña Negra (Crevillent, Alicante): la ciudad orientalizante de Herna y su territorio En S. Celestino Pérez y E. Rodríguez González (Eds.). Un viaje entre el Oriente y el Occidente del Mediterráneo, Actas del IX Congreso Internacional de Estudios Fenicios y Púnicos (Mérida, 2018), Vol. II. (pp. 521-540). MYTRA, 5. Mérida: Instituto Arqueología Mérida.

Lorrio, A. J., Pernas, S. y Torres, M. (2016). Puntas de flecha orientalizantes en contextos urbanos del Sureste de la Península Ibérica: Peña Negra, La Fonteta y Meca. Cuadernos de Prehistoria y Arqueología de la Universidad Autónoma de Madrid, 32, 9-78. DOI: https://doi. org/10.15366/cupauam2016.42.001

Lorrio, A. J., Torres, M. y Pernas, S. (e.p.). Un 'hogar ritual' en la ciudad orientalizante de Herna-Peña Negra (Crevillent, Alicante). En X Coloquio Internacional del CEFYP. Homenaje al Profesor José María Blázquez (Cádiz - San Fernando, 13-15 de diciembre de 2017).

Lorrio, A. J., Trelis, J. y Pernas, S. (2017). La Penya Negra (Crevillent-Alacant): a la recerca de la ciutat d'Herna. $L a$ Rella: Anuari de l'Institut d'Estudis Comarcals del Baix Vinalopó, tardor, 30, 76-116 76-116.

Lorrio, A. J. y Sánchez de Prado, M. ${ }^{a}$ D. (2002). La necrópolis romana de Haza del Arca y el santuario del deus Airoinis en la Fuente Redonda (Uclés, Cuenca)». Iberia. Revista de la Antigüedad, 5, 161-193.

Lorrio, A. J., Simón, J. L. y Sánchez de Prado, M. ${ }^{a}$ D. (2014) La Peña del Castillo (Peñas de San Pedro, Albacete): de oppidum ibérico a fortaleza cristiana. Lucentum, XXXIII, 73-112. DOI: https://doi.org/10.14198/LVCENTVM2014.33.05

Lulof, P. S. y Smith, C. J. (Eds.). (2017). The Age of Tarquinius Superbus. Central Italy in the Late 6th Century. Proceedings of the Conference "The Age of Tarquinius Superbus, A Paradigm Shift?» (Rome, 2013). BABesch Supplements, 29. Leuven: Peeters Publishers.

Maluquer de Motes, J. (1968). Epigrafia prelatina de la Península Ibérica. Barcelona: Instituto de Arqueología y Prehistoria.

Maluquer de Motes, J. (1987). La necrópolis paleoibérica de «Mas de Mussols», Tortosa (Tarragona). En J. Maluquer de Motes. Catalunya: Baix Ebre (pp. 31-110). Programa Investigaciones Protohistóricas 7-9. Barcelona: Departamento de Prehistoria y Arqueología.

Maluquer de Motes, J., Picazo, M. y Rincón, M. A. del. (1973). La necrópolis ibérica de La Bobadilla, Jaén. Programa de investigaciones protohistóricas, 1. Barcelona: Consejo Superior de Investigaciones Científicas, Institución «Milá y Fontanals» - Universidad de Barcelona, Instituto de Arqueología y Prehistoria.

Marcos Pous, A. (1983-1984). Recipientes griegos de bronce en el Museo Arqueológico de Córdoba. Corduba Archaeologica, 14, 27-38.

Marín, A. P. (2016). La génesis del mercenariado ibérico: entre Himera y Sagunto (480-219 a. C.). Historia, recepción y cultura. (Tesis doctoral). Universidad Castilla-La Mancha. Cuenca. Recuperado de: http://hdl.handle.net/10578/12492

Martín Ruiz, J. A. (2009). Estelas funerarias fenicias en Andalucía. Herakleion, 2, 41-59.

Marzoli, D. (1991). Alcune considerazioni su ritrovamenti di brochette etrusche. En J. Remesal y O. Musso (Eds.). La presencia de material etrusco en la Península Ibérica (pp. 215-224). Barcelona: Universidad de Barcelona.

Mas, B., Sala, F. y Prados, F. (2017). Un hipogeo con dromos escalonado de tipología fenicio/púnica tallado a pie de monte en la desembocadura del río Segura. En F. Prados y F. Sala (Eds.). El Oriente de Occidente. Fenicios y púnicos en el área ibérica. VIII Coloquio Internacional del CEFYP (Alicante - Guardamar del Segura, 7-9 de noviembre de 2013) (pp. 329-346). Alicante: Universidad de Alicante.

Mata, C. y Burriel, J. M. (2000). Importaciones de los siglos VI-V a.C en el centro y norte del País Valenciano. En P. Cabrera y M. Santos, (Eds.). Ceràmiques jònies d'època arcaica. Centres de producció i comercialització al Mediterrani occidental (pp. 233-254). Monografies emporitanes, 11. Barcelona: Museu d'Arqueologia de Catalunya.

Maya, J. L., Cuesta, F. y López, J. (Eds.). (1998). Genó. Un poblado del Bronce Final en el Bajo Segre (Lleida). Barcelona: Edicions de la Universitat de Barcelona.

Mederos, A. (1999). La metamorfosis de Villena. Comercio de oro, estaño y sal durante el Bronce Final I entre el Atlántico y el Mediterráneo. Trabajos de Prehistoria, 56(2), 115-136. DOI: https://doi.org/10.3989/tp.1999.v56.i2.278

Mederos, A. y Ruiz, L. A. (2001). Trashumancia, sal y comercio fenicio en las cuencas de los ríos Vinalopó y Bajo Segura (Alicante). Lucentum, XIX-XX, 83-94. DOI: https:// doi.org/10.14198/LVCENTVM2000-2001.19-20.06

Miguel, M. ${ }^{a}$ P. de. (2002). Estudio antropológico de la inhumación infantil de La Peña Negra. En A. González Prats. La necrópolis de cremación de «Les Moreres». Crevillente, Alicante, España (S. IX-VII a. C.) (pp. 471-475). Alicante: Universidad de Alicante.

Miller, M. (1971). The Thalassocracies. Studies in Chronography II. Albany, N.Y.: SUNY Press.

Mohen, J.-P., Duval, A. y Eluère, Chr. (1988). Les Grecs ont-ils tenté de coloniser les Celtes anciens? En Les princes celtes et la Méditerranée (pp. 11-18). Paris: École du Louvre.

Molinos, M., Chapa, T., Ruiz, A., Pereira, J., Rísquez, C., Madrigal, A., y Llorente, M. (1998). El Santuario heroico de «El Pajarillo». Huelma (Jaén). Jaén: Universidad de Jaén.

Moneo, T. (2003). Religio iberica. Santuarios, ritos y divinidades. Bibliotheca Archaeologica Hispana, 20. Madrid: Real Academia de la Historia.

Monraval, M. (1992). Necrópolis ibérica de El Molar. San Fulgencio - Guardamar del Segura. Alicante: Museo Arqueológico de Alicante.

Montero, I. (2017). Metales y metalurgia en el yacimiento de El Tossal de El Mortorum (Cabanes, Castellón). En G. Aguilera (Coord.). Tossal de El Mortorum. Un assentament 
de la Edat de Bronze i del Ferro Antic a la ribera de Cabanes (Castelló) (pp. 97-106). Castellón: Diputació de Castelló, Servei d'Investigacions Arqueològiques i Prehistòriques.

Moratalla, J. (2004). Organización del territorio y modelos de poblamiento en la Contestania Ibérica. (Tesis doctoral). Universidad de Alicante. Alicante. Recuperado de: http://hdl. handle.net/10045/3751

Moratalla, J. (2004-2005). La Alcudia ibérica. Una necesaria reflexión arqueológica. Lucentum, XXIII-XXIV, 89-104. DOI: https://doi.org/10.14198/LVCENTVM2004-2005.23-24.05

Morciano, M. M. (2001). Gela. Osservazioni sulla tecnica costruttiva delle fortificazioni di Capo Soprano. Journal of Ancient Topography, 11, 115-154.

Moret, P. (1996). Les fortifications ibériques de la fin de l'Âge du Bronze à la conquête romaine. Madrid: Casa de Velázquez.

Morote, J. G. (1979). El trazado de la Vía Augusta desde Tarracone a Carthagine Spartaria. Una aproximación a su estudio. Saguntum, 14, 139-164. Recuperado de: https://ojs. uv.es/index.php/saguntum/article/view/6347

Moscati, S. (Ed.). (1988). I Fenici, Milano: Fabbri Bompiani.

Neeft, C. W. (1981). Observations on the Thapos class. Mélanges de l'École française de Rome. Antiquité, 93(1), 7-88. DOI: https://doi.org/10.3406/mefr.1981.1270

Negueruela, I. (1990). Los monumentos escultóricos ibéricos del Cerrillo Blanco de Porcuna (Jaén). Madrid: Ministerio de Educación, Cultura y Deporte.

Nicolini, G. (1969). Les bronzes figurés des sanctuaires ibériques. Paris: Presses universitaires.

Nicolini, G. (1977). Bronces ibéricos. Barcelona: Editorial Gustavo Gili.

Niemeyer, H. G. (1979-1980). A la búsqueda de Mainake. El conflicto entre los testimonios arqueológicos y escritos. Habis, 10-11, 279-302.

Nieto, X. y Santos, M. (2009). El vaixell grec arcaic de Cala Sant Vicenç. Monografies del CASC, 7. Barcelona: Generalitat de Catalunya.

Nordström, S. (1969). La céramique peinte ibérique de la province d'Alicante. Stockholm: Almqvist \& Wiksell.

Oliver, A. (2006). El Puig de la Nau, Benicarló. Castellón: Museu de Belles Arts - Castelló Cultural.

Oliver, A. (2014). La necrópolis ibérica de la Solivella: Nuevas visiones, nuevas propuestas. Cuadernos de Prehistoria y Arqueología de la Universidad Autónoma de Madrid, 40, 67-79. DOI: https://doi.org/10.15366/cupauam2014.40.005

Olmos, R. (1977). El Sileno simposiasta de Capilla (Badajoz). Trabajos de Prehistoria, 34, 371-388.

Olmos, R. (1983). El centauro de Rollos y el centauro en el mundo ibérico. Homenaje al Prof. Martín Almagro Basch, II (pp. 377-388). Madrid: Ministerio de Cultura.

Olmos, R. (2000a). Centauro de Royos. En P. Cabrera y C. Sánchez (Eds.). Los griegos en España. Tras las huellas de Heracles. (p. 269). Madrid: Museo Arqueológico Nacional.
Olmos, R. (2000b). Sátiro itifálico del Llano de la Consolación. En P. Cabrera y C. Sánchez (Eds.). Los griegos en España. Tras las huellas de Heracles (p. 270). Madrid: Museo Arqueológico Nacional.

Olmos, R. y Grau Mira, I. (2005). El ánfora ática de la Cova dels Pilars (Agres, Alicante), una propuesta de lectura iconográfica en su contexto espacial ibérico. Archivo Español de Arqueología, 78, 49-78. DOI: https://doi.org/10.3989/ aespa.2005.v78.73

Olmos, R. y Sánchez, C. (1995). Usos e ideología del vino en las imágenes de la Hispania prerromana. En. S. Celestino (Ed.). Arqueología del vino. Los orígenes del vino en Occidente (pp. 105-136). Jerez de la Frontera: Consejo Regulador de las Denominaciones de Origen Jerez-Xeres-Sherry y Manzanilla Sanlúcar de Barrameda.

Padró, J. (1975). Los objetos de tipo egipcio de la necrópolis de «El Molar» (Sant Fulgenci, Alicante) y su problemática. Cuadernos de Prehistoria y Arqueología castellonenses, 2, 133-142.

Padró, J. y Sanmartí, E. (1992). Áreas geográficas de las etnias prerromanas en Cataluña. Complutum, 2-3, 185-194.

Panvini, R. (2008). Strutture in mattoni crudi dell'antica Gela. En La terra cruda nelle costruzioni: dalle testimonianze archeologiche all'architettura sostenibile, Atti della Giornata di studi Caltanissetta, Museo Archeologico (Contrada Santo, 2007) (pp. 87-98). Collana Politecnico Mediterraneo Architettura 1. Palermo: Nuova Ipsa.

Pena, M. ${ }^{a}$ J. (2002). Colonies et comptoirs grecs archaïques de l'est de la Péninsule ibérique: légendes et réalité. En Pont Euxin et commerce. La genèse de la «route de la soie». Actes du IXe Symposium de Vani (Colchide, 1999) (pp. 23-36). Collection de l'Institut des Sciences et Techniques de l'Antiquité, 853. Besançon: Institut des Sciences et Techniques de l'Antiquité.

Peña, A. (2003). La Necrópolis Ibérica de El Molar (San Fulgencio, Alicante). Revisión de las excavaciones realizadas en

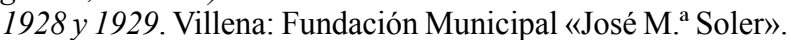

Peña, P. (2015). La recreación virtual de la fase A del Templo Ibérico de la Alcudia de Elche: una estructura por descubrir. En Congreso Internacional Cultura Digital. Sociedady comunicación perspectivas en el siglo XXI (Zaragoza, 2015) (pp. 531-547). Zaragoza: Universidad San Jorge.

Pérez Blasco, M. (2014). Cerámicas ibéricas figuradas (s. $V$-I a. C.): iconografia e iconología. (Tesis doctoral). Universidad de Alicante. Alicante. Recuperado de: http://hdl.handle. net/10045/41124

Pérez Vilatela, L. (1994). Onus(s)a. Toponimia y comercio antiguos en el litoral del Maestrazgo. Polis, 6, 269-306.

Pernas, S. (2008). Las formas de intercambio y las estructuras comerciales orientalizantes en la Vega Baja del Segura: dos variables de estudio arqueológico. Panta Rei, $2^{a}$ época, III, 105-152. DOI: https://doi.org/10.6018/pantarei/2008/7

Perrot, G. y Chipiez, Ch. (1885). Histoire de l'art dans l'Antiquité. III, Phénicie-Chypre. Paris: Hachette.

Poveda, A. (1994). Primeros datos sobre las influencias fenicio-púnicas en el corredor del Vinalopó (Alicante). En 
A. González Blanco, J. L. Cunchillos y M. Molina (Eds.). El mundo púnico. Historia, sociedad y cultura (pp. 489-502). Murcia: Editora Regional de Murcia.

Poveda, A. (1994-1995). La fase del Hierro Antiguo y la influencia fenicia en el corredor del Vinalopó (Alicante). Alebus, 4-5, 49-71.

Poveda, A. (2000). Penetración cultural fenicia en el territorio indígena del valle septentrional del Vinalopó (Alicante). En M. ${ }^{\mathrm{a}}$ E. Aubet y M. Barthélemy (Eds.). Actas del IV Congreso Internacional de Estudios Fenicios y Púnicos, vol. IV (pp. 1863-1874). Cádiz: Universidad de Cádiz.

Poveda, A. M., Soler, M. ${ }^{\text {a }}$ D. y Márquez, J. C. (2002). Elementos de arquitectura funeraria ibérica de El Monastil (Elda, Alicante). Las volutas de gola. Bolskan, 19, 227-235.

Pozo, S. (2003). Recipientes y vajilla metálica de época preromana (fenicia, griega y etrusca) del sur de la Península Ibérica. Antiquitas, 15, 5-50.

Prados, F. (2007). A propósito del pilar-estela ibérico de Monforte del Cid (Alicante): elementos para una discusión. Habis, 38, 79-98.

Prados, F., García Menárguez, A. y Jiménez Vialás, H. (2018). Metalurgia fenicia en el sureste ibérico: el taller del Cabezo Pequeño del Estaño (Guardamar, Alicante). Complutum, 29(1), 79-94. DOI: https://doi.org/10.5209/CMPL.62396

Prayon, F. (1987). Phrygische Plastik. Die früheisenzeitliche und ihre Beziehungen zu Griechenland und zum Alten Orient. Tübingen: E. Wasmuth.

Privitera, S. (2007). Poleis Massalias: da Artemidoro di Efeso a Eustazio di Tessalonica. Mélanges de l'École Française de Rome, 119(1), 41-49. DOI: https://doi.org/10.3406/ mefr.2007.10324

Quesada, F. (2009). Los mercenarios hispanos. En M. Almagro-Gorbea (Coord.). Historia militar de España, I. Prehistoria y Antigüedad. (pp. 165-173). Madrid: Ediciones del Laberinto - Ministerio de Defensa.

Quesada, F. y García González, D. (2018). Las armas de la tumba del guerrero de Málaga. En D. García González, S. López Chamizo y E. García Alfonso (Eds.). La tumba del guerrero. Un enterramiento excepcional de la Málaga fenicia del siglo VI a. C. (pp. 145-230). Sevilla: Consejería de Cultura.

Ramon, J. (1995). Las ánforas fenicio-púnicas del Mediterráneo central y occidental. Col·lecció Instrumenta 2. Barcelona: Universitat de Barcelona.

Ramon, J. (2010). La cerámica fenicia del Mediterráneo centro-occidental y del Atlántico (s. VIII - 1er 1/3 del siglo VI AC). Problemas y perspectivas actuales. En L. Nigro (Ed.). Motya and the Phoenician Ceramic Repertoire between the Levant and the West $9^{\text {th }}-6^{\text {th }}$ Century BC. Proceedings of the International Conference held in Rome, 26th February 2010 (pp. 211-253). Quaderni di Archeologia Fenicio-Punica, 5. Roma: Universitá degli Studi di Roma «La Sapienza».

Ramon, J., Rafel, N., Montero, I., Santos, M., Renzi, M., Hunt, M. A. y Armada, X. L. (2011). Comercio protohistórico: el registro del Nordeste Peninsular y la circulación de mineral de plomo en Ibiza y el Bajo Priorato (Tarragona).
Saguntum, 43, 55-81. DOI: https://doi.org/10.7203/ SAGVNTVM.43.1644

Ramos Fernández, R. (1975). La ciudad romana de Ilici. Alicante: Instituto de Estudios Alicantinos.

Ramos Fernández, R. (1995). El templo ibérico de La Alcudia. La Dama de Elche. Elche: Ayuntamiento de Elche.

Ramos Fernández, R. y Ramos Molina, A. (1992). El monumento y el témenos ibéricos del Parque de Elche. Elche: Ayuntamiento de Elche.

Ramos Folqués, A. (1950). Hallazgos escultóricos en «La Alcudia», de Elche. Archivo Español de Arqueología, 23, 353-359.

Ramos Folqués, A. (1955). Sobre escultura y cerámica ilicitanas. Valencia: Institución Alfonso el Magnánimo.

Ramos Folqués, A. (1990). Cerámica ibérica de La Alcudia (Elche - Alicante). En R. Ramos Fernández y L. Abad Casal (Eds.). Alicante: Diputación Provincial de Alicante.

Ramos Martínez, F. (2018). Poblamiento ibérico (ss. V-III a.n.e.) en el sureste de la península ibérica. Nuevos datos para el estudio a través de la arqueología del paisaje. BAR International Series, 2903. Oxford: BAR Publishing. DOI: https://doi.org/10.30861/9781407316642

Renzi, M. (2010). La producción de 'lingotes-hacha' en el Levante peninsular: nueva valoración a partir de los materiales de La Fonteta (Guardamar del Segura, Alicante). Revista d'Arqueologia de Ponent, 20, 127-144.

Ridgway, B. S. (1977). The Archaic Style in Greek Sculpture. Princeton: University Press.

Ridley, R. (2015). The puzzles of Porsenna. Studi Etruschi, 78, 77-95.

Ridley, R. (2017). Lars Porsenna and the Early Roman Republic. Antichthon, 51, 33-58. DOI: https://doi.org/10.1017/ ann.2017.5

Riis, P. J. (1959). The Danish bronze vessels of Greek, early Campanian, and Etruscan manufactures. Acta Archaeologica, 30, 1-50.

Rodríguez Ramos, J. (2001). La cultura ibérica desde la perspectiva de la epigrafía. Iberia, 4, 17-38.

Rodríguez Ramos, J. (2004). Sobre los fonemas sibilantes en la lengua ibérica. Habis, 35, 135-150.

Rodríguez Ramos, J. (2005). Introducció a l'estudi de les inscripcions ibèriques. Revista de la Fundació Privada Catalana per l'Arqueologia ibèrica, 1, 13-144. DOI: https://doi. org/10.5209/geri.68593

Rolley, C. (Ed.). (2003). La tombe princière de Vix, I-II. Paris: Picard - Société des amis du musée du Châtillonais.

Ros Sala, M. (1986-87). El poblado de Santa Catalina del Monte: una aproximación a la urbanística del s. VI a. C. en el ámbito territorial del eje Segura-Guadalentín. En Homenaje a la Prof. Gratiniano Nieto, vol. II (pp. 77-87). Cuadernos de Prehistoria y Arqueología de la Universidad Autónoma de 
Madrid, 13-14. Madrid: Universidad Autónoma de Madrid. DOI: https://doi.org/10.15366/cupauam1987.14.007

Ros Sala, M. (1989). Dinámica urbanística y cultura material del Hierro Antiguo en el Valle del Guadalentín. Murcia: Universidad de Murcia.

Rouillard, P. (1976). Fragmentos de cerámica griega arcaica en la antigua Contestania. Revista del Instituto de Estudios Alicantinos, 18, 7-16.

Rouillard, P. (1978). Les céramiques peintes de la Grèce de l'Est et leurs imitations dans le Péninsule Ibérique: recherches préliminaires. En Les céramiques de la Grèce de l'Est et leur diffusion en Occident (pp. 274-286). Paris: Editions du Centre National de la Recherche Scientifique. DOI: https:// doi.org/10.4000/books.pcjb.1596

Rouillard, P. (1982). Les colonies grecques du Sud-Est de la Péninsule Ibérique. État de la question. En Velia e i Focei in Occidente (pp. 378-420). La Parola del Passato, 21. Napoli: Gaetano Macchiardi editore

Rouillard, P. (1991). Les grecs et la Péninsule Ibérique du VIIIe au IVe siècle avant J.-Chr. Publications du Centre Pierre Paris, 21. Paris: De Boccard.

Rouillard, P. (1993). Le vase grec à Cabezo Lucero. En C. Aranegui, A., Jodin, E. Llobregat, P. Rouillard y J. Uroz. La nécropole ibérique de Cabezo Lucero. Guardamar del Segura. Alicante (pp. 87-94). Madrid - Alicante: Casa de Velázquez - Diputación Provincial de Alicante.

Rouillard, P. (1997). Antiquités de l'Espagne: dépôt au Musée des antiquités nationales de Saint-Germain-en-Laye / Musée du Louvre. Paris: Réunion des Musées Nationaux.

Rouillard, P. (2010). La Fonteta / Rábita (Guardamar del Segura, Alicante): Las excavaciones hispano-francesas 1996-2001. En Guardamar del Segura, arqueología y museo. Museos municipales en el MARQ (MARQ, diciembre 2010-febrero 2011) (pp. 80-89). Alicante: Museo Arqueológico de Alicante - Museo Arqueológico de Guardamar del Segura.

Rouillard, P., Gailledrat, E. y Sala, F. (Eds.). (2007). L'établissement protohistorique de La Fonteta (fin VIIIe-fin Ve siècle av. J.-C.). Fouilles de la Rábita de Guardamar II. Collection de la Casa de Velázquez, 96. Madrid: Casa de Velázquez.

Ruiz, A. y Molinos, M. (1992). Los iberos: análisis arqueológico de un proceso histórico. Barcelona: Crítica.

Ruiz de Arbulo, J. (1990). Rutas marítimas y colonizaciones en la Península Ibérica. Una aproximación náutica a algunos problemas. Itálica, 18, 79-115.

Ruiz Mata, D. y Pérez, C.J. (1995). El poblado fenicio del Castillo de Doña Blanca (El Puerto de Santa María, Cádiz). El Puerto de Santa María: Excmo. Ayuntamiento de El Puerto de Santa María.

Ruiz-Gálvez, M. (1986). Navegación y comercio entre el Atlántico y el Mediterráneo a fines de la Edad del Bronce. Trabajos de Prehistoria, 43, 9-42.
Ruiz-Gálvez, M. (1989). La orfebrería del Bronce Final. El poder y su ostentación. En El oro en la España prerromana (pp. 46-57). Revista de Arqueología, Extra. Madrid: Zugarto Ediciones.

Ruiz-Gálvez, M. (1992). La novia vendida: orfebrería, herencia y agricultura en la Protohistoria de la Península Ibérica. Spal, 1, 219-251. DOI: https://doi.org/10.12795/spal.1992. i1.11

Ruiz-Gálvez, M. (1993). El occidente de la Península Ibérica. Punto de encuentro entre el Mediterráneo y el Atlántico a fines de la Edad del Bronce. Complutum, 4, 41-68.

Ruiz-Gálvez, M. (1995). El significado de la Ría de Huelva en el contexto de las relaciones de intercambio y de las transformaciones producidas en la transición Bronce Final/Edad del Hierro. En M. Ruiz-Gálvez (Ed.). Ritos de paso y puntos de paso. La Ría de Huelva en el mundo del Bronce Final europeo (pp. 129-155). Complutum Extra, 5. Madrid: Universidad Complutense de Madrid.

Ruiz-Gálvez, M. (2005). Der fliegende Mittlemeermann. Piratas y héroes en los albores de la Edad del Hierro. En S. Celestino y J. Jiménez Ávila (Eds.). El Período Orientalizante. Actas del III Simposio Internacional de Arqueología de Mérida: Protohistoria del Mediterráneo Occidental (pp. 251-275). Anejos de Archivo Español de Arqueología, 35. Mérida: Consejo Superior de Investigaciones Científicas.

Sala, F. (1994). Las importaciones de los ss. VI-IV a. C. en Alicante y su repercusión en el mundo indígena. En P. Cabrera, R. Olmos y E. Sanmartí (Coords.). Iberos y Griegos: lecturas desde la diversidad (pp. 275-296). Huelva Arqueológica, XIII. Huelva: Diputación Provincial de Huelva.

Sala, F. (1996). Algunas reflexiones sobre la fase antigua de la Contestania Ibérica: de la tradición orientalizante al período clásico. Anales de Arqueología Cordobesa, 7, 9-31. DOI: https://doi.org/10.21071/aac.v0i.11332

Sala, F. (2001). El contexto material. En L. Abad y F. Sala (Eds.). Poblamiento ibérico en el Bajo Segura: El Oral (II) y La Escuera (pp. 143-150). Bibliotheca Archaeologica Hispana, 12. Madrid: Real Academia de la Historia.

Sala, F. (2006). Les fortificacions a la Contestània: entre la representació social i la defensa del territori. En A. Oliver (Coord.). Arquitectura defensiva. La protección de la población y del territorio en época ibérica (pp. 123-165). Castelló de la Plana: Sociedad Castellonense de Cultura.

Sala, F. (2007). Algunas reflexiones acerca de la escultura ibérica de la Contestania y su entorno. En L. Abad y J. A. Soler (Eds.). Arte Ibérico en la España Mediterránea. Actas del congreso (Alicante, 2005) (pp. 51-82). Alicante: Diputación Provincial de Alicante, Instituto Alicantino de Cultura Juan Gil-Albert.

Sala, F. y Abad, L. (1994). El Oral (San Fulgencio, Alicante): un poblado ibérico antiguo en el Sureste de la Península Ibérica. Madrider Mitteilungen, 35, 183-221.

Sala, F. y Abad, L. (2006). Arquitectura monumental y arquitectura doméstica en la Contestania. Lucentum, XXV, 23-46. DOI: https://doi.org/10.14198/LVCENTVM2006.25.03 
Sala, F. y Abad, L. (2014). El litoral de Alicante: un espacio de encuentros en el sureste de la península ibérica durante el I milenio a. C. En A. Lemaire (Ed.). Phéniciens d'Orient et d'Occident. Mélanges Josette Elayi, CIPOA vol. II (p. 601618). Paris: Editions A. Maisonneuve - Jean Maisonneuve.

Sanctis, G. de. (1984). Dalle monarchie ai governi di classe aristocratici. En L'origine dello stato nella Grecia antica (pp. 103-107). Roma: Editori Reuniti.

Sánchez, C. (2004). La cerámica ática del yacimiento ilicitano. En T. Tortosa (Ed.). El yacimiento de La Alcudia. Pasado y presente de un enclave ibérico (pp. 43-53). Anejos de Archivo Español de Arqueología, 30. Madrid: Consejo Superior de Investigaciones Científicas.

Sánchez Sánchez-Moreno, V. M., Galindo, L., Juzgado, M. y Dumas, M. (2012). El asentamiento fenicio de la Rebanadilla a finales del siglo IX a. C. En E. García Alfonso (Ed.). Diez años de Arqueología Fenicia en la provincia de Málaga (2001-2010). María del Mar Escalante Aguilar in memoriam (pp. 67-85). Sevilla: Junta de Andalucía, Consejería de Cultura y Deporte.

Sanmartí, E. (1976). Cerámicas de importación ática de El Puig (Benicarló, Castellón). Cuadernos de Prehistoria y Arqueología Castellonense, 3, 219-28.

Santos, J. (1992). Territorio económico y político del sur de la Contestania ibérica. Archivo Español de Arqueología, 65, 33-47. DOI: https://doi.org/10.3989/aespa.1992.v65.460

Santos, M. (2009a). Vaixella de bord i vasos per al comerç: la cerámica fina i comuna. En X. Nieto y M. Santos. El vaixell grec arcaic de Cala Sant Vicenç (pp. 81-124). Monografies del CASC, 7. Barcelona: Generalitat de Catalunya.

Santos, M. (2009b). Les àmfores gregues. En X. Nieto y M. Santos. El vaixell grec arcaic de Cala Sant Vicenç (pp. 125-152). Monografies del CASC, 7. Barcelona: Generalitat de Catalunya.

Santos, M. (2009c). El vaixell en el context del comerç grec a l'Oest del Mediterrani. En X. Nieto y M. Santos. El vaixell grec arcaic de Cala Sant Vicenç (pp. 301-309). Monografies del CASC, 7. Barcelona: Generalitat de Catalunya.

Schauenburg, K. (1981). Zu einer Situla in Provatbesitz. Mededelingen Nederlands Historisch Instituut Rome, 8, 83-89.

Schulten, A. (1955). Ora Maritima: (periplo massaliota del siglo VI a. de J.C.) junto con los demás testimonios anteriores al año 500 a. de J.C. Fontes Hispaniae Antiquae, I. Barcelona: Librería Universitaria de A. Bosch.

Schweizer, B. (1936). Der Paris des Polygnot. Hermes, 71(3), 288-294.

Senent, J. (1930). Excavaciones en la necrópolis de El Molar. Memoria de la Junta Superior de Excavaciones Arqueológicas, 107. Madrid: Tip. de la Revista de Archivos, Bibliotecas y Museos.

Shefton, B. B. (1982). Greeks and Greek Imports in the South of the Iberian Peninsula. En H.-G. Niemeyer (Ed.). Phönizier im Westen (pp. 337-370). Madrider Beiträge, 8. Mainz: Philipp von Zabern.
Shefton, B. B. (1995). Greeks Imports at the Extremities of the Mediterranean, West and East: Reflections on the Case of Iberia in the Fifth Century BC. En B. Cunliffe y S. Keay (Eds.). Social Complexity and the Development of Towns in Iberia. From the Copper Age to the Second Century AD (pp. 127-155). Proceedings of the British Academy, 86. Oxford: Oxford University Press.

Silgo, L. (2013). Estudio de toponimia ibérica. La toponimia de las fuentes clásicas, monedas e inscripciones. Valencia: Visión Libros.

Sillières, P. (1982). Une grande route romaine menant à Carthagène: la voie Saltigi-Carthago Nova. Madrider Mitteilungen, 23, 247-257.

Soriano Boj, S., Jover Maestre, F. J. y López Seguí, E. (2012). Sobre la fase Orientalizante en las tierras meridionales valencianas: el yacimiento de Casa de Secà (Elche, Alicante) y la dinámica del poblamiento en el Sinus Ilicitanus. Saguntum, 44, 77-97. Recuperado de: https://ojs.uv.es/index.php/saguntum/article/view/1772/1788

Soriano, R. (1985). Contribución al estudio del Bronce Tardío y Final en la Vega Baja del Segura. Saguntum, 19, 107-129.

Sourisseau, J.-C. (2011). La diffusion des vins grecs d'Occident du VIIIe au IVe s. av. J.-C., sources écrites et documents archéologiques. En La vigna di Dioniso. Vite, vino e culti in Magna Grecia, Atti del 49e Convegno di Studi sulla Magna Grecia (Taranto, 2009) (pp. 145-252). Taranto: Istituto per la Storia e l'Archeologia della Magna Grecia.

Sparkes, B. A. y Talcott, L. (1970). Black and plain pottery of the 6th., 5th. and 4th. centuries B.C. The Athenian Agora, XII. Princeton: American School of Classical Studies at Athens. DOI: https://doi.org/10.2307/3601977

Tendero, M. (2005). La cerámica del período Ibérico Antiguo en La Alcudia (Elche, Alicante). En L. Abad, F. Sala e I. Grau, I. (Eds.). La Contestania ibérica, treinta años después (pp. 305-316). Alicante: Universidad de Alicante.

Thouvenot, R. (1927). Catalogue des figurines et objets de bronze du Musée archéologique de Madrid I. Bronzes grecs et romains. Bordeaux - Paris: Feret \& Fils - E. de Boccard.

Todisco, L. (2007). Danze orientali tra Attica e Magna Grecia. En F. Giudice y R. Panvini (Eds.). Il greco e il barbaro e la ceramica attica. Immaginario del diverso, processi di scambio e autorappresentazione degli indigena (pp. 131150). Roma: L’Erma di Bretschneider.

Torelli, M. (1983). Polis e «Palazzo». Architettura, ideologia e artigianato greco tra VII e VI secolo a. C. En Architecture et societé de l'archaïsme grec à la fin de la République (Rome, 1980) (pp. 471-499). Publications de l'École Française de Rome, 66. Rome: École Française de Rome.

Torelli, M. (1993). Storia degli Etrusci. Roma: Laterza.

Torelli, M. (2011). Bellum in privatam curam (Liv. II,49,1). Eserciti gentilizi, sodalitates e isonomia aristocratica in Etruria e Lazio arcaici. En C. Masseria y D. Loscalzo (Eds.). Miti di guerra, riti di pace. La guerra e la pace: un confronto interdisciplinare. Atti del Convegno (Torgiano - Perugia 2009) (pp. 225-234). Bari: Edipuglia. 
Torelli, M. (2018). La «Tumba del Guerrero» del Museo de Málaga. Málaga: Real Academia de Bellas Artes de San Telmo.

Torres, M. (2002). Tartessos. Bibliotheca Archaeologica Hispana, 14. Madrid: Real Academia de la Historia.

Torres, M. (2018). Los Fenicios en la provincia de Huelva. En M. Botto (Ed.). De Huelva a Malaka. Los fenicios a la luz de los descubrimientos más recientes (pp. 37-67). Roma: CNR Edizioni.

Torres Salinas, M. (1995a). Segunda campaña de excavaciones arqueológicas en el castillo de Santa Bárbara de Cox (Alicante). Castells, 5, 37-42.

Torres Salinas, M. (1995b). Restos arqueológicos ibéricos del castillo de Santa Bárbara de Cox (Alicante). En Actas del XXIII Congreso Nacional de Arqueología (Elche, 1995), Vol. $I$ (pp. 515-524). Elche: Ajuntament d'Elx.

Trelis, J. (1995). Aportaciones al conocimiento de la metalurgia del Bronce Final en el sureste peninsular: el conjunto de moldes del Bosch (Crevillente-Alicante). En Actas del XXIII Congreso Nacional de Arqueología (Elche, 1995), Vol. I (pp. 185-190). Elche: Ajuntament d'Elx.

Trelis, J. y Molina, F. A. (2017). Control y defensa del territorio de la Penya Negra (Crevillent, Alicante): los fortines de 'les Barricaes'y 'el Cantal de la Campana'. En F. Prados y F. Sala (Eds.). El Oriente de Occidente. Fenicios y púnicos en el área ibérica. VIII Coloquio Internacional del CEFYP (Alicante - Guardamar del Segura, 7-9 de noviembre de 2013) (pp. 155-176). Alicante: Universidad de Alicante.

Tréziny, E. (1986). Les techniques grecques de fortification et leur diffusion à la périphérie du monde grec d'Occident. En P. Leriche y H. Tréziny (Eds.). La fortification dans l'histoire du monde grec. Actes du colloque de Valbonne 1982 (pp. 185-200). Paris: Centre National de la Recherche Scientifique.

Tréziny, H. (2010). Les fortifications grecques: l'apport de la Grèce d'Occident. Les Dossiers d'Archéologie, 342, 80-87.

Trías, G. (1967-1968). Cerámicas griegas de la Península Ibérica, I-II. Monografías sobre cerámicas hispánicas, 2. Valencia: The William Bryant Foundation.

Tsirkin, Y. B. (1983). The battle of Alalia. Oikumene, 4, 209221.

Untermann, J. (1985). Lenguas y unidades políticas del Suroeste hispánico en época prerromana. En De Tartessos a Cervantes. Forum Ibero-Americanum, 1. Köln: Böhlau.

Untermann, J. (1990). Monumenta Linguarum Hispanicarum. III Die iberischen Inschriften aus Spanien. Wiesbaden: Ludwig Reichert Verlag.

Uroz Rodríguez, H. y Uroz Sáez, J. (2010). Rito, religión y sociedad en la Guardamar ibérica. La necrópolis de Cabezo Lucero. En Guardamar del Segura, arqueología y museo. Museos municipales en el MARQ (MARQ, diciembre 2010-febrero 2011) (pp. 90-113). Alicante: Museo Arqueológico de Alicante - Museo Arqueológico de Guardamar del Segura.
Uroz Rodríguez, H., Lorrio Alvarado, A. J. y Uroz Sáez, J. (e.p.). La muralla y las primeras huellas de urbanismo de la fase ibérica antigua de La Alcudia (Elche, Alicante).

Van Compernolle, T. (2009). Les coupes ioniennes de l'épave: étude de provenance. En X. Nieto y M. Santos. El vaixell grec arcaic de Cala Sant Vicenç (p. 103). Monografies del CASC, 7. Barcelona: Generalitat de Catalunya.

Vassallo, S. (2010). Una offerta di schinieri di un mercenario iberico nella battaglia di Himera del 480 a. C. En Miscellanea di Studi in onore di Graziella Fiorentini (pp. 533-540). Sicilia Antiqua, 11. Pisa - Roma: Fabrizio Serra Editore

Velaza, J. (2011). Los sufijos en notación greco-ibérica. En XXVI Seminario de lenguas y epigrafias antiguas. (pp. 83-98). ELEA, 11. Valencia: Real Academia de Cultura Valenciana.

Verdú, E. (2009). La llamada koré de Alicante. En M. Olcina Doménech y J. Ramón Sánchez (Eds.). Huellas griegas en la Contestania Ibérica (catálogo de exposición) (p. 118). Alicante: Museo Arqueológico de Alicante.

Villanueva, M. C. (1987). Images de Dionysos et de son cortège dans la céramique grecque du IVe. s. en provenance de la Péninsule Ibérique. En Grecs et ibères au IVe siècle avant Jésus-Christ. Commerce et iconographie, table ronde (Bordeaux, 16-18 décembre 1986) (pp. 297-317). Revue d'études anciennes, 89, 3-4. Bordeaux: Centre Pierre Paris. DOI: https://doi.org/10.3406/rea.1987.4294

Vives-Ferrándiz, J. (2005). Negociando encuentros: situaciones coloniales e intercambios en la costa oriental de la Península Ibérica (ss. VIII-VI a. C.). Cuadernos de Arqueología Mediterránea, 12. Barcelona: Universitat Pompeu Fabra.

Vives-Ferrándiz, J. (2007). A propósito de un infundibulum etrusco hallado en aguas de la Bahía de Xàbia (Alacant). Madrider Mitteilungen, 48, 154-173.

Weber, Th. (1983). Bronzekannen. Studien zu ausgewähltenarchaischen und klassischen Oinochoenformen aus Metall, I Griechenland und Etrurien. Archäologische Studien, 5. Frankfurt am Main: P. Lang.

Werner, I. (2005). Dionisos in Etruria. The Ivy Leaf Group. Acta Instituti Romani Regni Sueciae, Series $4^{\circ}, 58$. Stockholm: Svenska Institutet i Rom.

Willi, A. (2008). Cows, houses, hooks: the Graeco-Semitic letter names as a chapter in the history of the alphabet. Classical Quarterly, 58(2), 401-423. DOI: https://doi.org/10.1017/ S0009838808000517

Winter, F. E. (1971). Greek fortifications. London: Routledge \& Kegan Paul.

Woodard, R. D. (1997). Greek Writing from Knossos to Homer. A linguistic Interpretation of the Origin of the Greek Alphabet and the Continuity of Ancient Greek Literacy. New York - Oxford: Oxford University Press.

Xella, P. (2015-2016). Il texto fenicio di Pyrgi. En V. Bellelli y P. Xella (Eds.). Le lamine di Pyrgi. Nuovi studi sulle iscrizioni in etrusco e in fenicio nel cinquantenario della scoperta (pp. 45-68). Studi Epigrafici e Linguistici sul Vicino Oriente antico, 32-33. Verona: Essedue edizioni. 